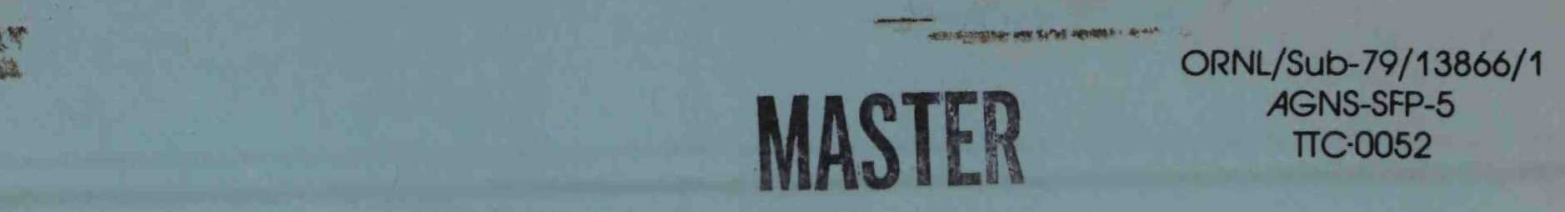

\title{
Fleet Servicing Facilities for Servicing, Maintaining and Testing Rail and Truck Radioactive Waste Transport Systems: \\ Functional Requirements Technical Design Concepts and Options \\ Cost Estimates and Comparisons
}

\author{
report prepared by \\ Allied-General Nuclear Services \\ P.O. Box 847 \\ Barnwell, SC 29812 \\ under subcontract \\ $85 \times 13866 \mathrm{~V}$ \\ for \\ Oak Ridge National Laboratory \\ Oak Ridge, Tennessee 37830
operated by
Union Carbide Corporation
Nuclear Division \\ for the \\ U.S. Department of Energy \\ Washington, D.C. 20545 \\ Under Contract No. W-7405-eng-26
}

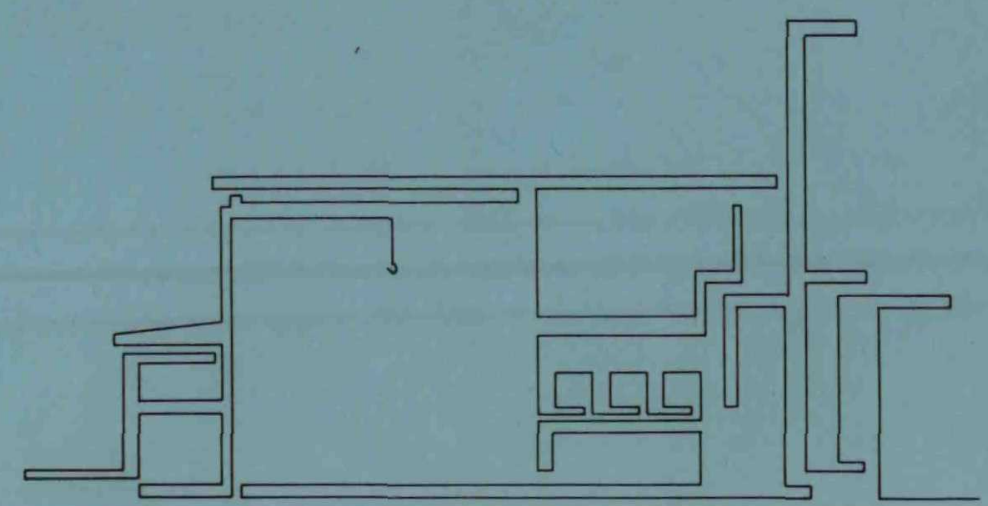


Printed in the United States of America. Available from

National Technical Information Service

U.S. Department of Commerce

5285 Port Royal Road, Springfield, Virginia 22161

NTIS price codes-Printed Copy:A0\& Microfiche A01

This report was prepared as an account of work sponsored by an agency of the United States Government. Neither theUnited States Government nor any agency thereof, nor any of their employees, makes any warranty, express or implied, or assumes any legal liability or responsibility for the accuracy, completeness, or usefulness of any information, apparatus, product, or process disclosed, or represents that its use would not infringe privately owned rights. Reference herein to any specific commercial product, process, or service by trade name, trademark, manufacturer, or otherwise, does not necessarily constitute or imply its endorsement, recommendation, or favoring by the United States Government or any agency thereof. The views and opinions of authors expressed herein do not necessarily state or reflect those of the United States Government or any agency thereof. 


\section{DISCLAIMER}

This report was prepared as an account of work sponsored by an agency of the United States Government. Neither the United States Government nor any agency Thereof, nor any of their employees, makes any warranty, express or implied, or assumes any legal liability or responsibility for the accuracy, completeness, or usefulness of any information, apparatus, product, or process disclosed, or represents that its use would not infringe privately owned rights. Reference herein to any specific commercial product, process, or service by trade name, trademark, manufacturer, or otherwise does not necessarily constitute or imply its endorsement, recommendation, or favoring by the United States Government or any agency thereof. The views and opinions of authors expressed herein do not necessarily state or reflect those of the United States Government or any agency thereof. 


\section{DISCLAIMER}

Portions of this document may be illegible in electronic image products. Images are produced from the best available original document. 
ORNL/Sub-79/13866/1

AGNS-SFP- 5

TTC-0052

\section{FLEET SERVICING FACILITIES FOR SERVICING, MAINTAINING, AND TESTING RAIL AND TRUCK \\ RADIOACTIVE WASTE TRANSPORT SYSTEMS: \\ Functional Requirements \\ Technical Design Concepts and Options \\ Cost Estimates and Comparisons}

\section{CONTRIBUTORS AND AUTHORS}

Oak Ridge National Laboratory:

Clyde D. Watson, Editor

Barry J. Hudson

Don A. Keith*

Max K. Preston, Jr.*

Oak Ridge National Laboratory** Post office Box $x$

Oak Ridge, Tennessee 37830

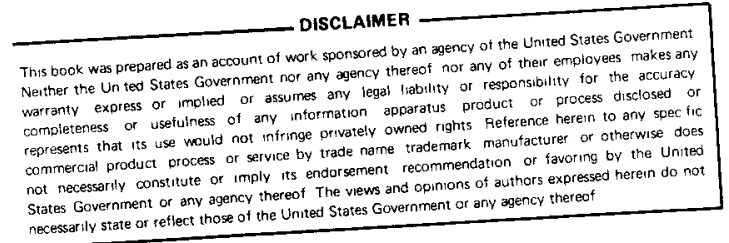

Allied-General Nuclear Services:

Paul N. McCreery, Editor

William Knox

Eugene M. Easterling

Arthur S. Lamprey

George Wiedemann

Allied-General Nuclear Services

Post Office Box 847

Barnwell, South Carolina 29812

Date Published - May 1980

Funding and basic guidance for this study and report were supplied through the Transportation Technology Center of DOE, Sandia Laboratories, Albuquerque, New Mexico.

*Union Carbide Nuclear Division

* Operated by Union Carbide Corporation for the United states Department of Energy. 


\section{ABSTRACT}

This is a resource document which examines feasibility design concepts and feasibility studies of a Fleet Servicing Facility (FSF). Such a facility is intended to be used for routine servicing, preventive maintenance, and for performing requalification license compliance tests and inspections, minor repairs, and decontamination of both the transportation casks and their associated rail cars or tractor-trailers. None of the United States' waste handling plants presently receiving radioactive wastes have an on-site FSF, nor is there an existing "third party" facility providing these services. This situation has caused the General Accounting Office* to express concern regarding the quality of waste transport system maintenance once the system is placed into service. Thus, a need is indicated for FSF's, or their equivalent, at various radioactive materials receiving sites.

In this report, three forms of FSF's solely for spent fuel transport systems were examined: independent, integrated, and colocated. The independent concept was already the subject of a detailed report** and is extensively referenced in this document so that capital cost comparisons of the three concepts could be made. These facilities probably could service high-level, intermediate-level, low-level, or other waste transportation systems with minor modification, but this study did not include any system other than spent fuel. Both the integrated and colocated concepts were assumed to be associated with some radioactive materials handling facility such as an AFR repository.

Sufficient work was accomplished to permit an economic comparison, based on capital cost, with the existing concept of the Independent reference facility. The Integrated FSF featured dry unloading, and the Colocated FSF featured wet unloading, because all existing facilities are wet. Cask turnaround time for the dry mode was estimated to be 8 hours less than for the wet mode. The design of the two concepts of this report was examined using a General Purpose Computer Simulation System (GPSS) and operating times based on actual cask handling experience. Both concepts were shown to be highly feasible and worthy of additional study, detailed design, and analysis.

Results of this study indicate that the Independent FSF is the most costly (approximately $\$ 26 \mathrm{M}$ ) and the Integrated FSF is the least costly (approximately $\$ 13 M$ ). The capital cost of the Colocated FSF will range between these two extremes, depending on the site selected. For the site chosen in this report, the Barnwell Nuclear Fuel Plant (BNFP) in Barnwell, 
South Carolina, the capital cost of an FSF is approximately $\$ 16 M$. The colocated FSF would be expected to more nearly approach the Integrated cost when site-specific design conditions are very favorable. To reap the benefits of an Integrated facility, plans must be made to include such work early in the parent facility (AFR, reprocessing plant, waste repository) design programs.

A continued in-depth study of a colocated FSF is recommended. To the degree that they can be considered as part of the DOE strategy, two additional candidate sites should be examined as potential parent facilities with which an FSF could be colocated, namely, the General Electric Morris, Illinois site and the Nuclear Fuel Services, Inc., West Valley, New York site. Other FSF feasibility concepts should also be developed and analyzed for high-, intermediate-, TRU, low-level waste transport, and AwayFrom-Reactor (AFR) spent fuel storage systems.

*General Accounting Office (GAO) report, Federal Actions Are Needed To Improve Safety and Secur ity of Nuclear Materials Transportation, EMD-79-18 (May 1979).

**P. N. McCreery, et al., The Conceptual Design of a spent Fuel Cask Fleet Servicing Facility, (AGNS-1040-1.5-48) (September 1978). 


\section{TABLE OF CONTENTS}

PAGE

ABSTRACT

GLOSSARY

DEFINITIONS

EXECUTIVE SUMMARY

1.0 INTRODUCTION . . . . . . . . . . . . . . 1

2.0 INTEGRATED FLEET SERVICING FACILITY CONCEPT . . . 5

2.1 Site Features . . . . . . . . . . . 5

2.2 Functional Description of Integrated Facility

Concept . . . . . . . . . . . 5

2.2.1 Summary Facility Description . . . 5

2.2.2 Summary Operating Procedure . . . . 7

3.0 COLOCATED FLEET SERVICING FACILITY CONCEPT • • . 17

3.1 Colocated FSF Site Selection . . . . . . 17

3.2 Functional Description of the Colocated

Facility . . . . . . . . . . . . 18

3.2.1 Summary Facility Description . . . . 18

3.2.2 Summary Operating Procedure . . . . 20

4.0 COMPUTER SIMULATION ANALYSIS OF THE INTEGRATED AND

COLOCATED FLEET SERVICING FACILITIES • • • • • . 27

4.1 Background . . . . . . . . . . . . . 27

4.2 Analysis of the Integrated FSF Concept • . . 27

4.2.1 Operational Traffic Flow Patterns . . 27

4.2.2 Events . . . . . . . . . . . . 29

4.2.3 Assumptions . . . . . . . . . . 29

4.2.4 Various Cases That Were Examined.. . 31

4.2.5 Discussion of the Various Cases . . . 32

4.2.6 Conclusions of Simulation Analysis . . 35

4.3 Analysis of the Colocated FSF Concept . . . 35

4.3.1 Operational Traffic Flow Patterns . . 35

4.3.2 Events . . . . . . . . . . . . 37

4.3.3 Assumptions •. . . . . . . . . . 37

4.3.4 Various Cases That Were Examined . . 37

4.3.5 Discussion of the Various Cases . . 39

4.3.6 Conclusions of Simulation Analysis . . 42 
TABLE OF CONTENTS (CONTINUED)

$\underline{\text { PAGE }}$

5.0 COST ANALYSIS OF THE INTEGRATED AND COLOCATED

FSF CONCEPTS . . . . . . . . . . . . . 61

5.1 Cost Estimate of the Integrated Concept and

Comparison to the Reference Independent

(FSF) Concept .. . . . . . . . . . 61

5.1 .1 Scope . . . . . . . . . . . 61

5.1 .2 Assumptions .............. 61

5.1 .3 Method of Estimating.........61

5.1 .4 Labor .................62

5.1 .5 Material ............. 62

5.1 .6 Sales Tax ...............62

5.1 .7 Indirect costs........... 62

5.1 .8 Escalation .............. 62

5.1 .9 Contingency . . . . . . . . . 62

5.1.10 Cost Exclusions . . . . . . . . 62

5.1 .11 Contracting Method . . . . . . . . 63

5.1 .12 Supporting Tables . . . . . . . . 63

5.1.13 Cost Comparison of the Integrated FSF

vs Independent FSF . . . . . . . . 63

5.2 Cost Estimate of the Colocated Design

Concept................ 63

5.2 .1 Scope . . . . . . . . . . . 63

5.2 .2 Assumptions . . . . . . . . . . 67

5.2.3 Method of Estimating ........ 67

5.2 .4 Labor ................ 67

5.2.5 Material............. 68

5.2 .6 Sales Tax . . . . . . . . . . 68

5.2.7 Indirect Costs . . . . . . . . 68

5.2 .8 Escalation . . . . . . . . . 68

5.2 .9 Contingency . . . . . . . . . . 68

5.2.10 Cost Exclusions . . . . . . . . . 68

5.2.11 Contracting Method . . . . . . . 69

5.2.12 Supporting Tables . . . . . . . . . 69

5.2.13 Cost Comparison of the Independent FSF, and Colocated FSF(S)....... 69

5.3 A Summary Cost Comparison of the Three Fleet Servicing Facility Concepts (Independent, Integrated, Colocated) . . . . . . . . 69

6.0 CONCLUSIONS AND RECOMMENDATIONS . . . . . . 73

7.0 ACKNOWLEDGMENT . . . . . . . . . . . . 75

8.0 REFERENCES . . . . . . . . . . . . . . 77 
TABLE OF CONTENTS (CONTINUED)

APPENDIX A - DESCRIPTION OF THE INTEGRATED FLEET SERVICING FACILITY AREAS

APPENDIX B -- GENERIC OPERATING PROCEDURE FOR THE INTEGRATED FLEET SERVICING FACILITY

APPENDIX C -- SUMMARY OF THE REFERENCED DOCUMENT

APPENDIX D -- COST ESTIMATE - INTEGRATED FLEET SERVICING FAC ILITY

APPENDIX E - COST ESTIMATE - COLOCATED FLEET SERVICING FACILITY

\section{LIST OF TABLES}

TABLE NO.

TITLE

PAGE

4-1 Operating Events, Integrated Concept . . . 30

4-2 A Summary of the Results Obtained from Computer Simulation Analysis of the Integrated Fleet Servicing Facility . . . 33

4-3 Operating Events, Colocated Concept . . . 38

4-4 A Summary of the Results Obtained from Computer Simulation Analysis of the Colocated Fleet Servicing Facility . . . . 40

5-1 Integrated FSF Design Concept Project Summary . . . . . . . . . . . . . 64

5-2 Labor Rates - Capital Line Item Construction Southeast USA . . . . . . . . . 65

5-3 Composite Crew Rates Southeast USA . . . . 66

5-4 Colocated FSF Design Concept Project Summary •. • • . . • . . • • • • 70

5-5 Independent/Integrated/Colocated FSF Design Concept Cost Comparison . . . . . 71 
TABLE OF CONTENTS (CONTINUED)

\section{LIST OF FIGURES}

FIGURE NO.

TITLE

PAGE

2-1 Spent Fuel Cask Fleet Servicing Facility

2-2 Spent Fuel Cask Fleet Servicing Facility

$2-3$ Conceptual Design-Sections .. . . . . . 11

$2-4$ HVAC Flow Diagram . . . • • • • • . • 13

$3-1$ Integrated Fleet Servicing Facility . . . 15

$3-2$

$3-3$ Colocated FSF AGNS - BNFP Barnwell, S. C. . 23 Colocated FSF AGNS - BNFP Barnwell, S. C. . 24

4-1 Colocated Fleet Servicing Facility . . . . 25

$4-2$ Integrated FSF Normal Traffic Flow . . . . 45

4-3 Integrated FSF Traffic Flow for Integrated FSF Traffic Flow for Contaminated Transport Systems . . . . . . 47 Requalification (or Repair) of

4-4 Integrated FSF General operational Flów ${ }^{\bullet} \quad 49$

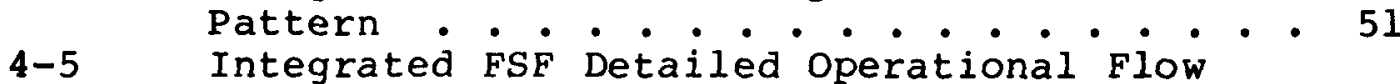

Paths ....... . . . . . . . . 52

4-6 Integrated FSF Cask On- and off-Loading . 53

4-7 Integrated FSF Rail Fuel Unloading . . . . . 53

4-8 Integrated FSF Truck Fuel Unloading . . . 53

4-9 Integrated FSF Rail T\&R ... . . . . . . . 54

4-10 Integrated FSF Truck T\&R............ 54

4-11 Integrated FSF Vehicle T\&I . . . . . . . . 54

4-12 Integrated FSF Rail Fuel Unloading . . . . 55

4-13 Integrated FSF Truck Fuel Unloading . . . 55

4-14 Integrated FSF Vehicle T\&I . . . . . . . 55

4-15 Integrated FSF Cask On- and Off-Loading . . 56

4-16 Integrated FSF Rail Fuel Unloading . . . . . 56

4-17 Integrated FSF Truck Fuel Unloading . . . . 57

4-18 Integrated FSF Vehicle T\&I . . . . . . . 57

4-19 Colocated FSF AGNS-BNFP Barnwell, S. C. . . 58

4-20 Colocated FSF Receiving and Washdown . . . 59

4-21 Colocated FSF Fuel Unloading Cup . . . . . 59

4-22 Colocated FSF Cask T\&R . . . . . . . . . . 59

4-23 Colocated FSF Fuel Unloading Cup . . . . . . 59 


\section{GLOSSARY}

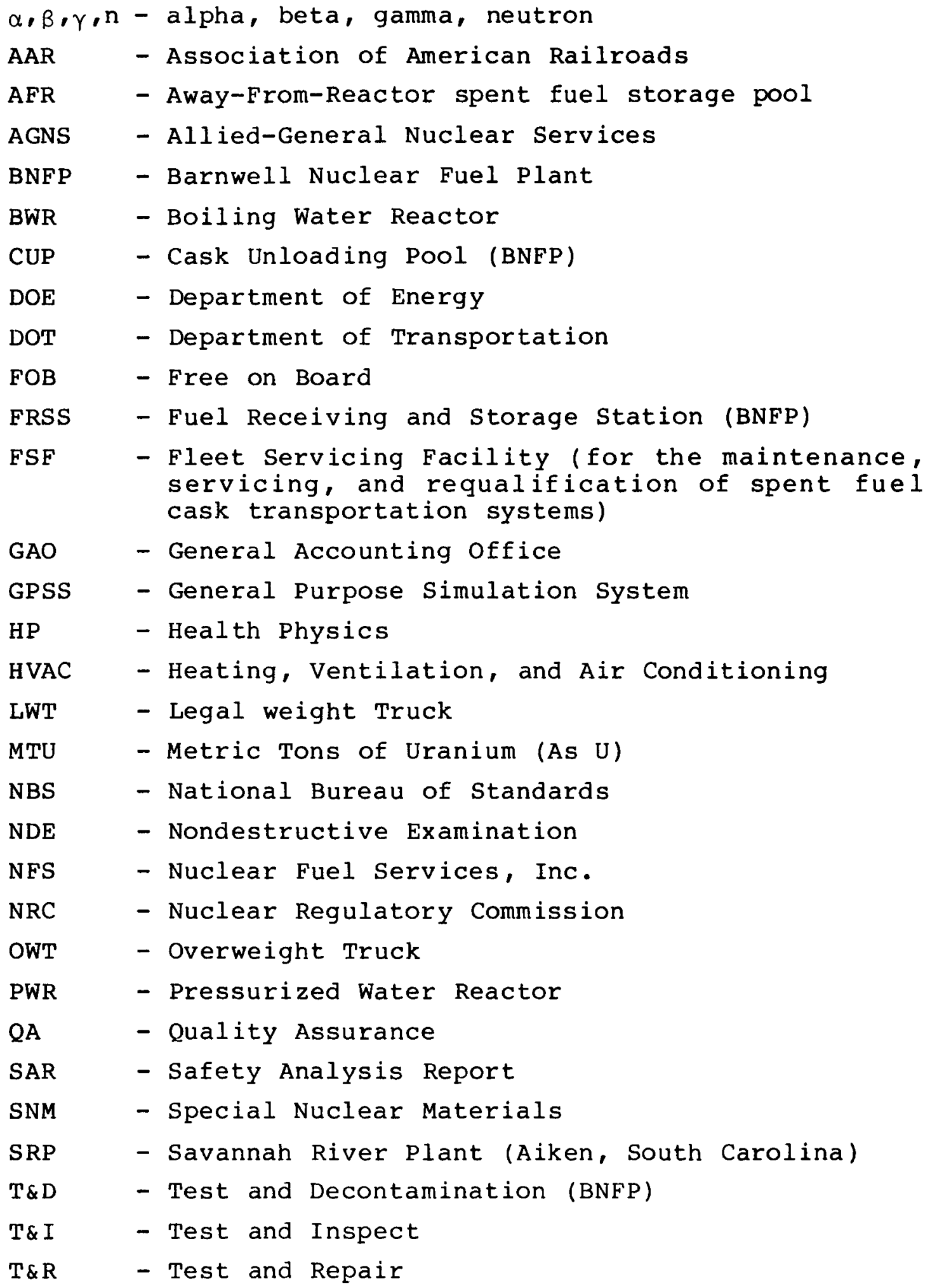


DEFINITIONS

- Cask System - All the components comprising a given cask including ancillary equipment for cooling, sampling, filling, draining, and monitoring.

- Colocated Fleet Servicing Facility - A unit located in the proximity of or attached to a supporting parent previously built facility.

- Crud - A deposit or encrustation, as used herein, a dislodgement or flaking of radioactive and nonradioactive material from Zircaloy or stainless steel cladding.

- Dinged - A damaged area.

- Dry Decontaminate - The removal of radioactive nuclides from a surface by wiping and/or abrading.

- Fleet Servicing Facility - A facility for inspecting, maintaining, and requalifying spent fuel transportation systems (rail, truck, etc.).

- Generic - Characteristic of a whole group or class; not relating specifically to any one entity.

- Hostile Intrusion - Unauthorized diversion or sabotage of the carrier system.

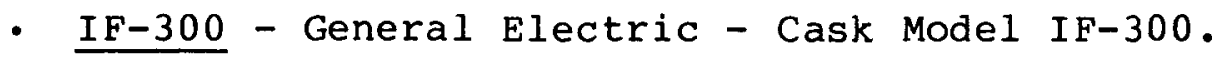

- Independent Fleet Servicing Facility - A self-sufficient unit capable of operation without support from a parent facility.

- Integrated Fleet Servicing Facility - A unit incorporated into and fully integrated with a supporting parent facility.

- Loading Site - Any facility in which spent fuel is loaded into a transportation cask.

- NAC-1 (NFS-4) - Nuclear Assurance Corporation-cask Model 1 (Nuclear Fuel Services-Cask Model 4 ).

- $\underline{N L I-1 / 2}$ - NL Industries - Cask Model 1/2.

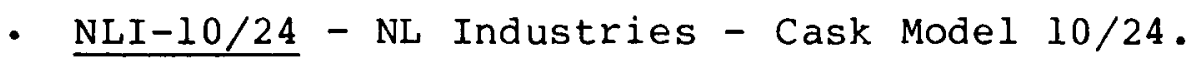


DEFINITIONS (CONTINUED)

- Personnel Barrier (P. B.) - A lightweight thermal and radiation safety shield placed around but not in contact with the surface of a shipping cask to prevent human contact. It may also serve as a protective shield to discourage tampering with the cask and its auxiliary equipment.

- Rad Waste - Liquid radioactive waste system.

- Requalification - A quality assurance procedure to inspect transportation systems to assure and document their roadworthiness and continued compliance with their NRC certification.

- Scheduler - One who schedules each transport system through the parent facility and the FSF.

- Shuttle Wagon - A mobile power unit used for on-site movement of rail cars.

- Site Specific - Pertaining to the physical configuration and qualities of an existing AFR, waste repository, or reprocessing plant to which the design of a fleet servicing facility must be made to fit or conform.

- Slots - Space that can be occupied by a cask and/or vehicle as used in the GPSS computer simulation program.

- $\underline{T N-8 / 9}$ - Transnuclear - Cask Model 8 or Model 9 .

- Transportation Systems

- Rail - A special rail car to which is attached a heavily shielded spent fuel shipping cask containing up to 12 PWR or 32 BWR spent fuel assemblies.

- Truck - A truck tractor semitrailer unit in which the trailer is customized for attaching and carrying a heavily shielded spent fuel cask containing up to 3 PWR or 7 BWR spent fuel assemblies.

- Unloading Site - Any facility in which spent fuel is removed from a transportation cask.

- Yard Tractor - A truck which is confined to site operation and is used to move commercial trailers in the absence of a commercial carrier's motive unit. 


\section{EXECUTIVE SUMMARY}

This is a resource document which examines feasibility design concepts and feasibility studies of a Fleet Servicing Facility (FSF). Such a facility is intended to be used for routine servicing, preventive maintenance, and for performing requalification license compliance tests and inspections, minor repairs, and decontamination of both the transportation casks, and their associated rail cars or tractor-trailers. None of the United States' waste handling plants presently receiving radioactive wastes have an on-site FSF, nor is there an existing "third party" facility providing these services. This situation has caused the General Accounting Office [General Accounting office (GAO) report, "Federal Actions are Needed to Improve Safety and Security of Nuclear Materials Transportation," EMD-79-18 (May 1979)] to express concern regarding the quality of waste transport system maintenance once the system is placed into service. Thus, a need is indicated for FSF's or their equivalent, at various radioactive materials receiving sites. The variety of both the transport systems in service and the waste categories which have been, or will be, handled (spent fuel, high-, intermediate-, and low-level wastes, cladding hulis, and TRU) is broader in scope than was addressed in this report. The specific needs associated only with spent fuel transportation systems are developed in this study. In the evaluation of the facility requirements for these needs, this report compares the respective capital costs and operating characteristics of three concepts of a spent Fuel Cask transportation system Fleet servicing Facility (FSF). The three concepts are:

- Integrated FSF - which is a functional operating area included in the original design and contruction of a parent facility, such as an AFR, reprocessing plant, waste repository, etc., and is totally supplied by the parent's services, manpower resources, and other capabilities.

- Colocated FSF - which is built in the proximity of an existing parent unit and shares services, manpower resources, and capabilities to the extent the parent can provide. In some cases, the colocated FSF may be attached directly to the selected parent facility.

- Independent FSF - which does not depend on the near proximity of a parent reprocessing plant, AFR, etc., for any type of support, whatsoever. 
A previous study, summarized in Appendix C, [P. N. McCreery, et al, "The Conceptual Design of a Spent Fuel Cask Fleet Servicing Facility" (AGNS-1040-1.5-48) (September 1978)] examined the characteristics of an Independent FSF and this concept became the basis with which the Integrated and Colocated concepts were compared. Each facility was designed to receive $2000 \mathrm{MTU}$ (as heavy metal) of spent fuel per year, 758 of which was delivered by rail and $25 \%$ of which was delivered by truck. The design concept and cost study of each facility was completed in order to:

(1) Determine relative feasibility and capital cost of the three basic concepts and design options; provide a basis for selecting a concept for further on-going detailed design work; provide a basis for selecting a parent facility concept upon which to produce a more detailed, realistic construction and operational cost analysis; and, support development of future DOE implementation strategy.

(2) The Integrated and Colocated concepts were analyzed by computer simulation (General Purpose simulation system International Business Machines, New York, New York) to determine the adequacy of the two design concepts as compared to the Independent base case. No serious deficiencies were found in either design with regard to operational provisions and target throughput rates. The main difference, as determined by GPSS using real measured operational time, was between dry unloading (Integrated) and wet unloading (Colocated); wet unloading reflects the mode used in all existing facilities. $A$ decrease of 8 hours in cask turnaround time for the dry mode was indicated. A more in-depth study on the wet versus the dry unloading mode question appears warranted.

of the possible parent plants considered in selecting a host facility next to which a Colocated FSF could be placed, the Allied-General Nuclear Services (AGNS) plant at Barnwell was chosen. The type and location of the parent facility may have a significant influence on the cost of the colocated FSF. For example, a colocated facility concept of the Morris, Illinois plant would be a major step in completing a comparison of potential and existing facilities in the United states.

The results of the previous base study indicate that, in 1979 dollars, the cost of an Independent FSF would be approximately $\$ 26 \mathrm{M}$, and an Integrated FSF would add approximately $\$ 13 \mathrm{M}$ to the cost of building a parent facility. The cost of a colocated FSF, while dependent upon the actual site and parent facility, is estimated to cost approximately $\$ 16 \mathrm{M}$ for the case considered here (BNFP). 
An FSF is quite sensitive to the economics of scale. If regional AFR's or reprocessing sites, or waste repositories, should come into being, then an economic and logistic comparison of several smaller, strategically located, FSF's versus a single, high-capacity facility would be indicated. This evaluation, however, is beyond the scope of this report, and must be dealt with in development of future implementation strategy. Some salient conclusions and recommendations of this study are:

(1) The Independent and the Integrated FSF concepts are useful in establishing the anticipated maximum-tominimum cost range ( $\$ 26 \mathrm{M}$ and $\$ 13 \mathrm{M}$, respectively); however, the Colocated concept (at about $\$ 16 \mathrm{M}$ ) is the most practical in the near term since this concept applies to facilities already built. These three facilities probably could handle high-level waste transport system, but this study did not include any other waste (high-level, intermediate-level, low-level, TRU, and spent fuel hulls) transport systems.

(2) An FSF will provide, among other things, maintenance and requalification tests of transportation systems by an organization independent of owners or users (which essentially involve QA functions with appropriate verifications). This is consistent with NRC QA policy, as indicated in Federal Regulations 10 CRF 50 , Appendix $B$.

(3) The FSF will provide transport vehicles with inspections and services in a facility capable of handing contaminated equipment. This is not currently practical in existing facilities.

(4) Such inspections are expected to be more frequent and more thorough than those given under present practices. The potential for accidents resulting from vehicles being in poor roadworthy condition will be diminished.

(5) As fleet sizes grow and components are increasingly interchanged, a central control system at each FSF may provide compliance assurance more economically than can a number of small, decentralized, purpose facilities. Cask requalification applies to each significant component of a cask system, not just a single cask body.

(6) The FSF concept provides a positive response to the criticism of GAO regarding cask maintenance, and it is recommended that studies continue on the FSF with greater emphasis placed on the more feasible concepts and near-term needs. 
(7) The in-depth study and analysis of an FSF should provide for transport systems for waste forms other than those for spent fuel.

(8) A Department of Energy/Office of Nuclear Waste Isolation management implementation strategy should be developed through a system analysis effort. This should include DOE programmatic needs, future facility plans and schedules, and, also facility funding and ownership considerations. 


\subsection{INTRODUCTION}

This is a resource document which contains basic feasibility design concepts of facilities for servicing rail and truck waste transport systems. None of the United States' facilities presently receiving radioactive wastes have on-site Fleet Servicing Facilities (FSF) for maintaining, inspecting, servicing, decontaminating, and requalifying the waste transportation systeins comprised of the transportation casks with their associated rail cars or tractor-trailers. The design and construction of these systems are subject to strigent design, manufacturing, quality assurance, and control procedures. Similar procedures govern their use and their servicing and maintenance programs. However, the design, fabrication, service, and maintenance of vehicles, in general, are not commensurate with the level of sophistication applied in design and manufacture of the packages they carry. It is not practical to return the packages, such as spent fuel casks, to the manufacturer for service and maintenance because the manufacturing areas are not intended to handle contaminated equipment, nor are they equipped to process the radioactive wastes generated in cask decontamination, nor located properly for minimizing out-ofservice time. Facilities available at existing sites which normally handle transportation casks are frequently not designed for such work, and the personnel available for assignment to the testing and maintenance jobs perform these operations as a secondary function and cannot be expected to develop the degree of expertise that would be found at an FSF. Although the work is generally carried out under the supervision of a representative of the cask owner, the facilities and personnel currently used for this specific purpose cannot duplicate those that would be found in an installation dedicated solely to this function. In this report, such an installation is referred to as a spent fuel Cask fleet servicing Facility, or FSF. While this report is concerned primarily with spent fuel systems, the same concepts are expected to apply to the servicing and maintenance needs of other types of radioactive materials shipping systems. The extent of the application of a spent fuel FSF, especially in the areas of LLW and TRU waste, should be the subject of future work.

Another facet of this subject involves cask certification. NRC reviews the design, manufacturing, and operating proposals for a new cask system, and approval of that system is given in the form of a certificate of Compliance (COC). Although these certificates usually are valid for a period of five years, they become void, automatically, the moment any condition of the system certification is not in full compliance. Compliance testing may be required each time 
the cask is used or, on various parts, quarterly, semiannually, annually, or over longer intervals. Such tests may include nondestructive examinations, pressure testing, strength (load) tests, helium leak testing, examination for radiation streaming, thermal measurements, and others which may be system specific. Each cask model is subject to its specific testing modes and cycles as described by the Quality Assurance Program specified in its Safety Analysis Report for Packaging (SARP) and reported in the Certificate of Compliance. In addition, each component of a cask system must be shown to be in compliance; if not, the entire system is out of compliance.

The NRC does not "certify" the vehicles used in hauling the casks. However, the design, manufacture, and maintenance of vehicles is governed by DOT regulations and carried out by operators or their agents. A thorough inspection, along with preventive and corrective maintenance, prior to each round trip could reduce even further the infrequent, but all too visible, incidents related to vehicle malfunction, which must be avoided in transporting radioactive materials.

Still another vital area in which an installation dedicated to transportation system maintenance and servicing could make a significant contribution is in the effort toward achieving "as low as reasonably achievable" (ALARA) radiation exposure to workers and of the public in general. An FSF would be the logical place in which cask internals could be removed, cleaned, stored, replaced, or exchanged in a facility specifically designed for that purpose and at a location away from the general work area and with appropriate remote handling devices.

The functional requirements for all waste forms and the related economics of an FSF warrant a broader investigation than was included within the scope of this report; however, some points in this regard were developed in general terms. For example, revenue paid to cask owners by the shippers of radioactive material ceases when the cask is "out-ofservice" for maintenance or repairs. If the maintenance is performed at a third site lother than the loading or unloading sites), then the out-of-service time is extended by the travel time. Since the waste unloading site will be common to several shippers, it follows that an FSF at that site is the most logical location, in terms of achieving maximum utilization of equipment. This, in turn, would require balancing increased cask revenues and lowered fleet requirements against FSF charges which would enhance return on investment. Indeed, cask owners should be willing to share this saving with the FSF operators, as well as to pay for high-quality maintenance of their systems (subject to the cask owners' audits and approvals). Although it seems 
apparent that unit costs will tend to be inversely proportional to the fleet size, this warrants additional investigation in light of the upcoming decisions as to the number and locations of future unloading sites (Away-From-Reactors, or AFR's, waste packaging facilities, repositories, storage/ disposal sites, etc.)

In this study, private sector ownership of the transportation systems and government ownership of the FsF was assumed.

It is intended that an FSF would perform routine servicing, maintenance, repair, and inspection of the vehicles, along with the more demanding requalification operations and tests for the shipping casks.

Presently, three basic forms of FSF's are envisioned as: Independent, Integrated, and Colocated.

The first is totally independent of any parent operation (any type of cask unloading facility), the second is completely integrated with a parent facility (simultaneous design and construction is mandated), and the third would be colocated with an existing facility, drawing upon as many services as the parent facility could contribute. Assuming a need for a servicing facility capable of handing spent fuel fleets within the next 10 years, the Colocated concept is the most likely to be developed because there are such facilities that presently exist. The Independent facility has the highest capital costs, while the Integrated facility is the most efficient and has the lowest capital costs. A generic analysis of both the Integrated and Independent FSF's is useful in that it defines the parametric extremes in both costs and operational efficiencies for the long term. The Independent facility was treated previously $(2)$ and became the basis for economic comparison. This present work deals mainly with the Integrated and colocated concepts. Both design concepts were evaluated by computer simulation using the General Purpose simulation system. (3)

The purpose of this report is to provide guidance for the continued orderly development of the FSF concept and to ensure that such a facility is capable of maintaining spent fuel cask systems to the high degree of reliability and roadworthiness required, minimizing cost and out-of-service time. The need is twofold: first, every effort to maximize cask utilization should be made, thereby keeping their out-of-service time to a minimum by servicing them with experienced crews at a location common to their use. The second need is emphasized in a recent General Accounting office (GAO) report (4) which states, in part, that safe shipping containers are "the first line of defense in 
protecting the public from radioactive shipments." It further states that current inspection practices do not adequately assure that containers meet Federal safety specifications, and it expresses great concern that the Nuclear Regulatory Commission (NRC) and the Department of Transportation (DOT) rely on container users and manufacturers to meet safety specifications without adequate independent inspections (as would be done in an FSF). Centralization of all safety inspections in a well-equipped and staffed FSF, with a total Quality Assurance (QA) program, can meet the above needs. This study is directed toward that end.

It should be noted that, in this report, dry unloading was the mode assumed for the Integrated FSF and wet unloading was site-specific for the Colocated FSF because the BNFP was originally designed and constructed for this mode. In addition, the parameters of the base case(2) (the Independent FSF) are described in Appendix $C$. The costs in the original document have been escalated in accordance with the information given in Appendix $C$. 


\subsection{INTEGRATED FLEET SERVICING FACILITY CONCEPT}

\subsection{Site Features}

By definition, an Integrated FSF would not materialize unless and until a new fuel receiving facility came into being. For the purpose of this study, certain assumptions were made regarding this parent facility. This is necessary for the computation of cask turnaround time and for the computer simulation studies in which queuing and sensitivity analyses are treated.

The parent facility is assumed to receive spent fuel cask at rates comparable to those of the Independent Facility with which comparisons are to be made. Dry unloading was selected to minimize that portion of time that the cask spends in the unloading operation. This, in turn, amplifies any bottlenecks in the system introduced by the servicing operations. The cask servicing features of the Integrated and Independent Facilities are nearly identical.

2.2 Functional Description of the Integrated Facility Concept

The Integrated Facility will take advantage of not only the physical plant provisions of the parent fuel site, but also will benefit in sharing manpower and software systems. Management of the servicing facility is very quality-assurance oriented. From a functional viewpoint, this consists of a continuing audit of test requirements and testing schedules, followed by getting the backup data to certify that each test and inspection was done properly. This approach provides assurance that the results are within the acceptance criteria, and that no cask will be on the road with an expired interval of validity for any given test, and that each of the variety of transportation systems is properly monitored.

Commercial carriers will move the transportation systems only when outside the entrance portal of the FSF. All on-site movement will be done by facility-owned yard tractors and shuttle wagons.

2.2.1 Summary Facility Description (See Appendix A for a more detailed description)

In addition to the washdown, off-loading, and vehicle maintenance areas (refer to Figures 2-1, 2-2, and 2-3), the fleet servicing facility includes a multiple purpose "Cask and Insert Cleaning Area." Its primary function is to facilitate changing, cleaning, and storage of the many 
varieties of cask inserts (baskets, spacer plugs, and drain lines). Its secondary function includes the periodic removal of crud that has accumulated in the cavity bottom, a decontamination station for excessively contaminated incoming casks and a working station for damaged casks. It is expected that the FSF will be capable of repairing damaged casks. However, casks damaged so severely that they cannot be opened in a normal way will be considered on a case-bycase basis. The contents of the casks; spent fuel, highlevel wastes, etc., will be a major consideration as to how it is opened and the kind of area needed to perform the opening or repair operations. The E-MAD* Facility in Nevada might serve as a central repair station. A facility with water-filled pits might also be used, if justified.

Because of the quantity of highly radioactive materials expected to be removed from casks and inserts, a "Cask and Insert Waste Service Area" is provided for the initial separation and processing of the material. The filtrate from this area is pumped to the radioactive waste handling system of the parent facility.

Stalls for the testing of casks and for repair work are located opposite the cask unloading pits. These stalls are equipped with the utilities needed for pressure testing and leak testing. They provide an elaborately scaffolded work area for changing cask parts and can double as decontamination stalls.

Since some components may have to be returned to their manufacturer for repair, equipment is provided to decontaminate these items. Included would be ultrasonic and electrolytic decontamination capabilities. An adjacent storage area is provided for items with detectable quantities of surface contamination, but with lower limits which would preclude their use on a cask system.

The "Vehicle Test and Inspection Area" includes the space and spare parts necessary to maintain rail and highway vehicles. A separate room is provided to charge and store the storage batteries used in conjunction with some of the cooling systems. A maintenance area is provided for bench work on parts, diesel engines, etc.

The Health Physics laboratory provides rapid sample evaluation capabilities so as to expedite the release or reinspection of cask systems. *Jackass Flats, Nevada, Engine-Maintenance and Disassembly
Facility. 
A separate office is provided for a representative of each cask owner where he may keep his records on audits of spare parts procurement and usage, cask certifications, etc.

\section{A vault is provided for storing cask records.}

Next to the off-loading area in the high bay, sufficient space and a separate crane are provided to handle and store the numerous lifting yokes, shock absorbing structures (or impact limiters), and large spare parts used with the variety of casks that a system such as this would be expected to handle.

The maintenance and refueling installation for truck tractors is provided in a separate facility located within the secured area. This facility could be government-owned and leased to a commercial carrier or any other of a variety of combinations. The cost of this facility is not included in the bottom line of the estimated cost of the integrated FSF. However, information obtained from a commercial carrier indicated the capital cost of such a facility would be approximately $\$ 200 \mathrm{~K}$ with a yearly operating cost covering a five-person working force plus utilities, etc.

\section{$\underline{2.2 .2 \text { Summary Operating Procedure }}$}

As a cask system progresses through the Integrated Facility, it is first checked for radiological cleanliness. Next, road dirt is removed and an inspection is made for structural damage. The cask is off-loaded and moved to the fuel unloading station. While the fuel is being dry unloaded, the vehicle is moved into the vehicle inspection bay where it receives a thorough check for roadworthiness. Parts are repaired or replaced as necessary during maintenance and servicing. Nondestructive evaluation (NDE) and repainting are done in this bay. The vehicle and the unloaded cask meet once again in the cask off-loading bay, the assembled system receives a final check, and then it is released to pick up another load of spent fuel. A generic operating procedure is presented in Appendix $B$. 
BLANK PAGE

$-8-$ 


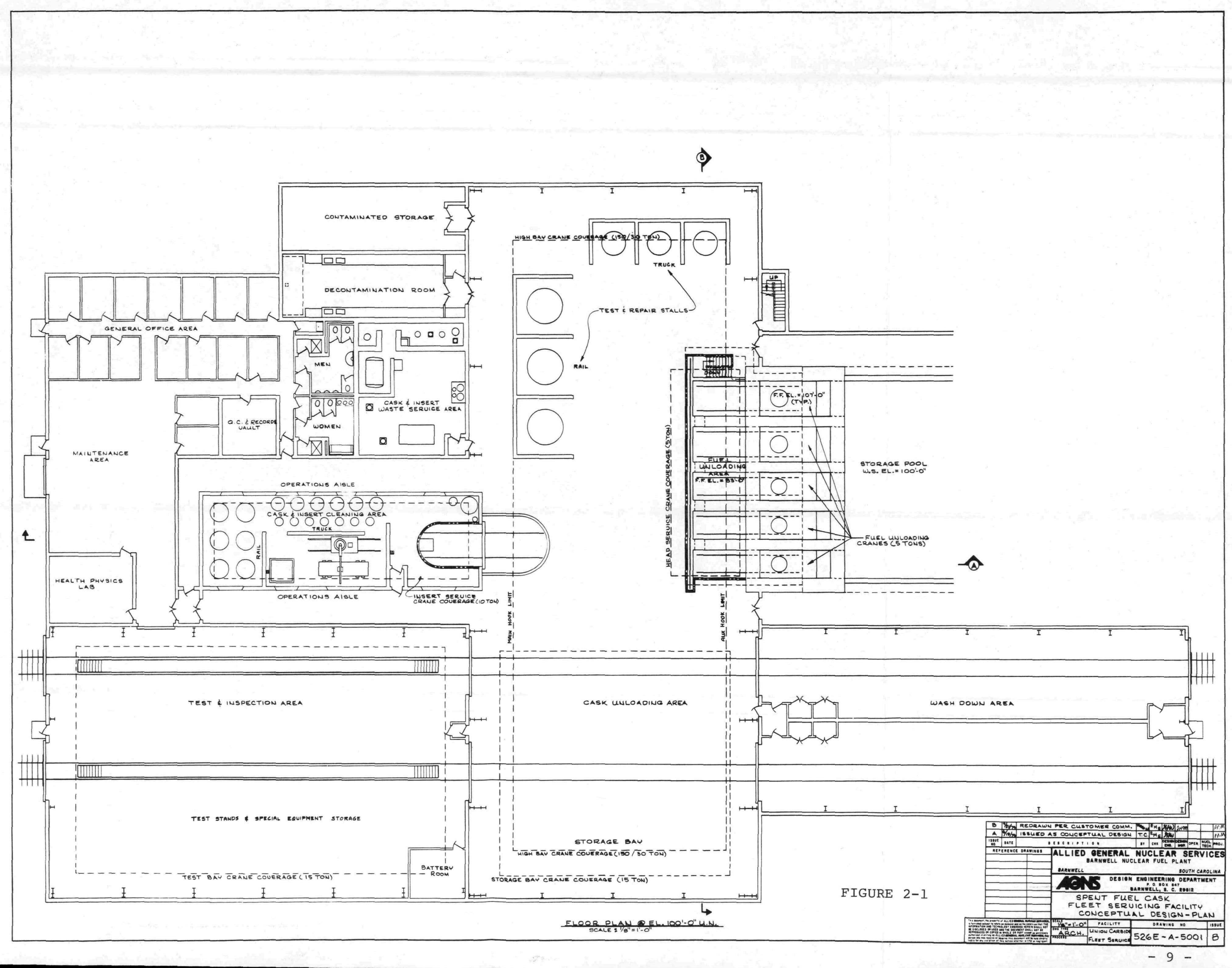


$$
\text { . }
$$ 

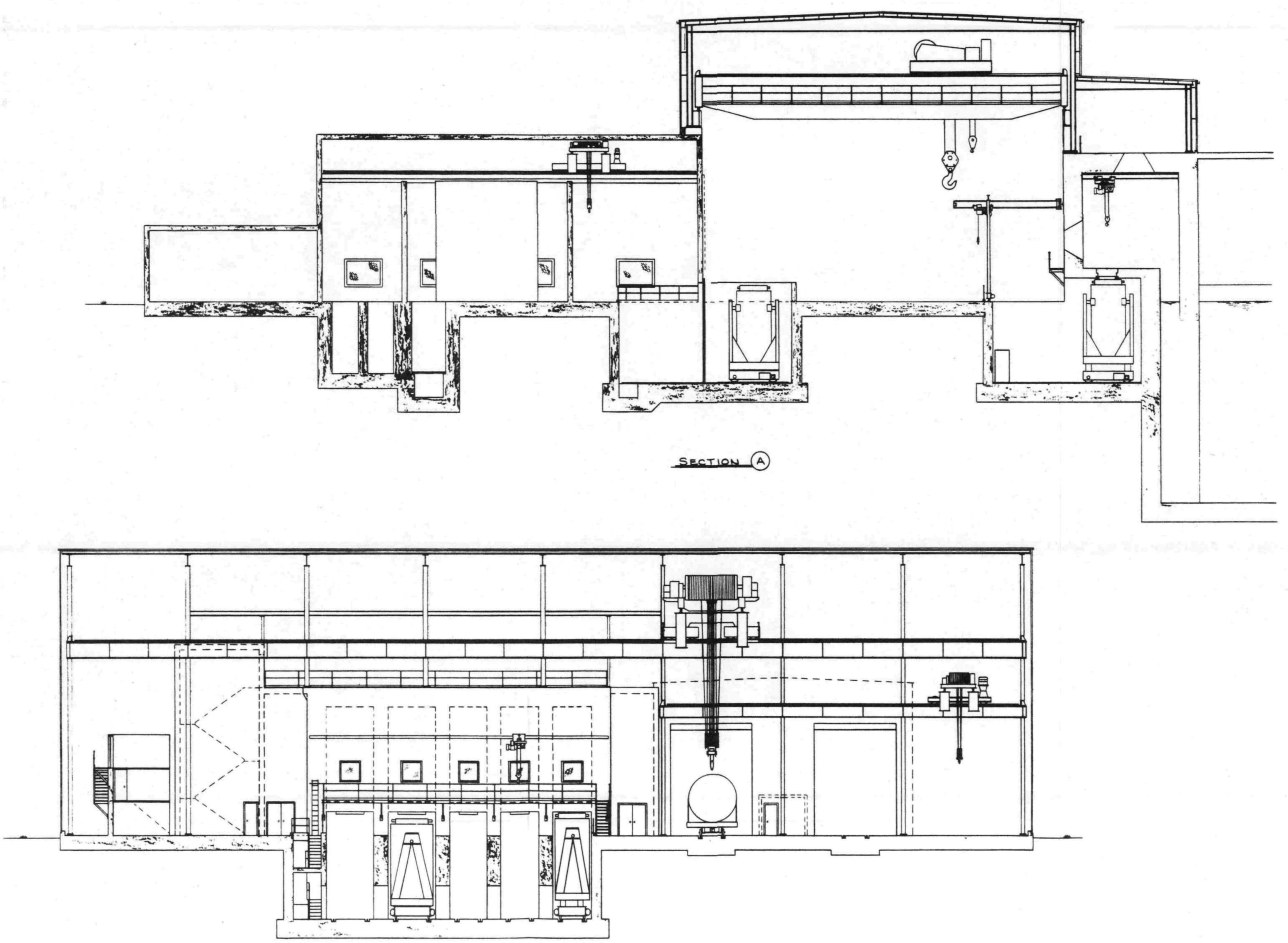

FIGURE 2-2

SEction (B) 
$$
\text { . }
$$ 


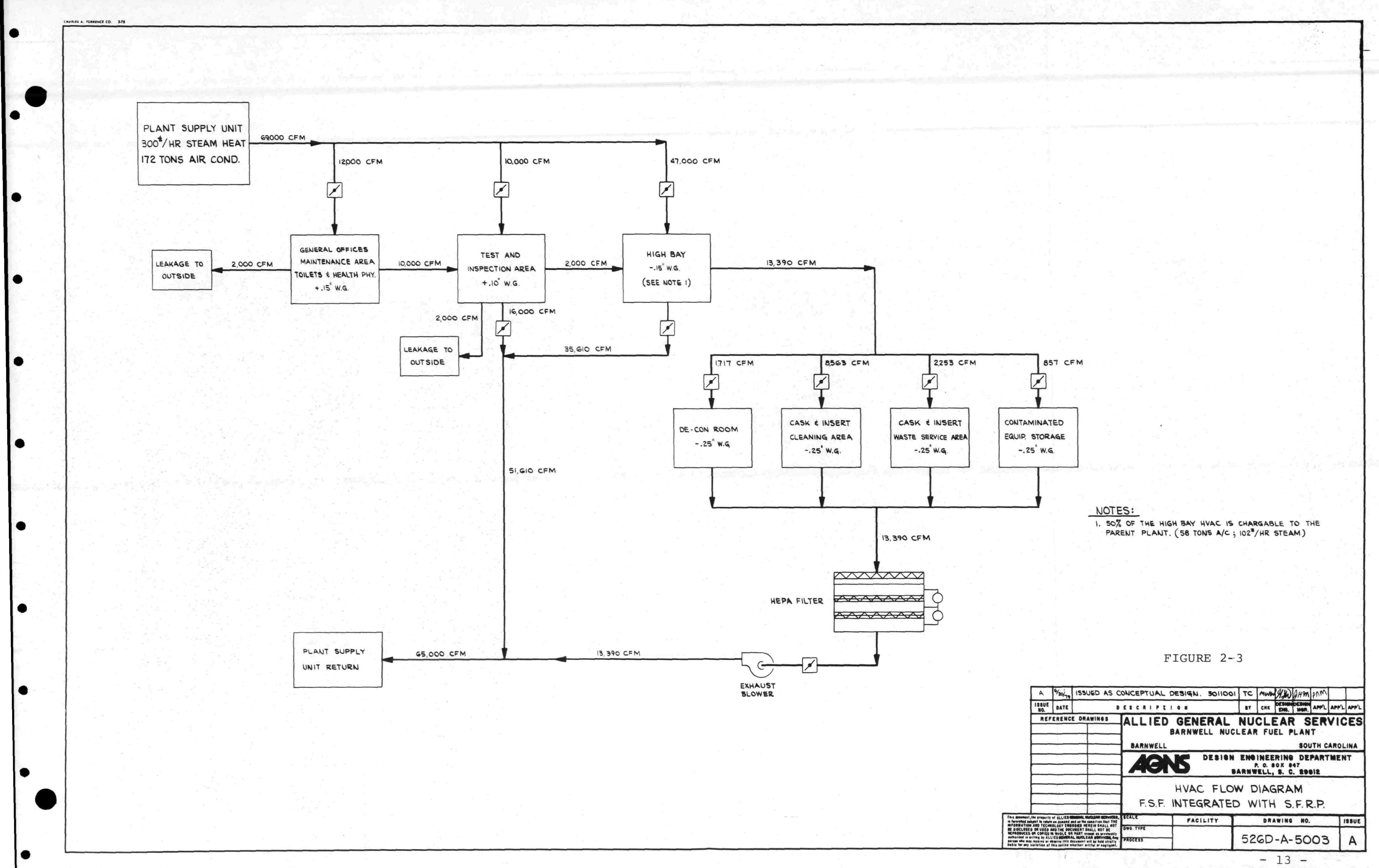


$$
\text { . }
$$ 


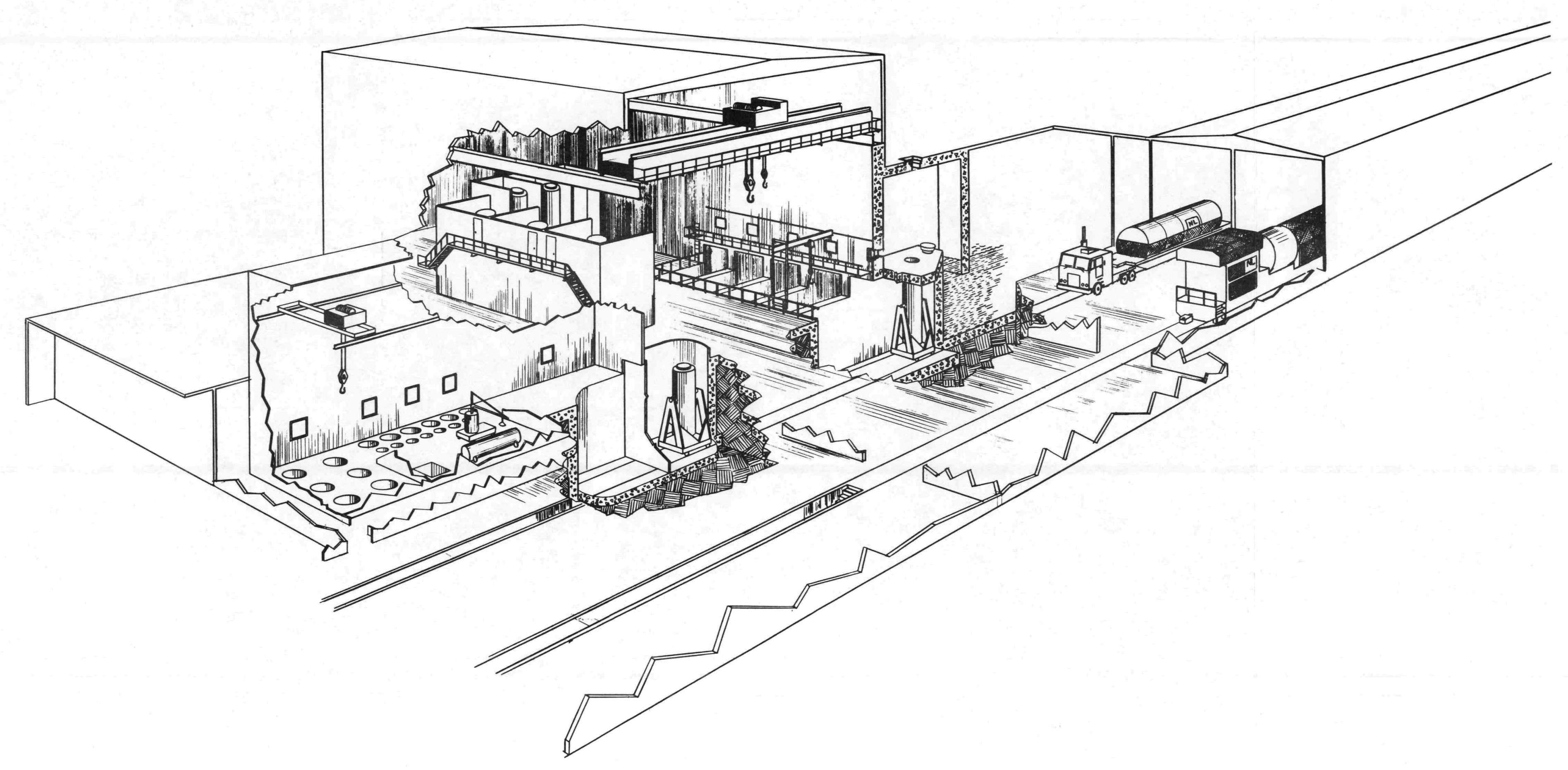

INTEGRATED FLEET SERVICING FACILITY FIGURE 2-4 
$$
\text { . }
$$ 


\subsection{COLOCATED FLEET SERVICING FACILITY CONCEPT}

\subsection{Colocated FSF site Selection}

In the introduction to this report, the statement is made that of the three potential modes of an FSF (Independent, Integrated, and Colocated), only the Colocated is considered to be a practical alternative for the relatively near future. Further, for a meaningful design to be pursued, the site of the facility must be quite specific, since it is to be an add-on to an existing facility.

In the selection of a specific site, some questions to be considered are:

- To what extent can the FSF make use of existing hardware and services?

- Can the FSF function efficiently without disrupting the efficiency of the fuel unloading facility; or better yet, can it improve the latter's efficiency?

- Is there ample available space at the existing site for the addition of an FSF?

- Does the existing site handle a sufficient quantity of spent fuel (i.e., cask receiving rate) to justify economically an FSF, inasmuch as an FSF is probably very sensitive to the economics of scale?

- Is the anticipated useful life span of the parent facility of sufficient duration to enable a reasonable returnon-investment of the FSF? Ideally, the parent facility would have the potential of almost unlimited expansion, or have the potential for consuming or transshipping fuel at some time after its receipt, at a rate equal to receipt.

- Should the FSF be expected to service casks other than those being unloaded in the parent facility? If so, at what rate and $\mathrm{mix}$ ?

To obtain commercial opinions on a selection for a Colocated FSE parent facility site, four sources were contacted and personally visited; Exxon, Bellevue, Washington; General Electric Operations, Morris, Illinois; Nuclear Fuel services, Inc., West Valley, New York; and Allied-General Nuclear Services, Barnwell, South Carolina. As a means of orientation, presentations of the Integrated FSF concept were made followed by discussions on possible Colocated FSF 
design features. Some conclusions became obvious as the visits were completed.

- The primary uncertainty in selecting any site is the present and future political philosophy on fuel storage and spent fuel reprocessing in the United States. (4)

- The future of the construction of the Exxon reprocessing plant continues to be uncertain and may be delayed for years.

- Nuclear Fuel Services, Inc., appears (politically and commercially) to be closed indefinitely and completely out of consideration.

- The General Electric Morris, Illinois, facility is very impressive and exceedingly well operated, however, its present receiving capability is well below the 2000 MTU/ year rate postulated in this report but is worthy of a future study.

- The AGNS/BNFP is built but is not yet licensed for spent fuel storage. Recently, however, AGNS was budgeted by DOE to prepare the necessary procedural and regulatory paperwork, etc., such that the Fuel Receiving and Storage Station (FRSS) could be licensed for operation by 1985 . The FRSS receiving rate capability is of the same order of magnitude as the reference document (2) capacity, thus, AGNS was selected as the site for the colocated FSF concept and comparative cost estimate.

\subsection{Functional Description of the Colocated Facility}

\subsubsection{Summary Facility Description}

For this report, an effort was made to arrange the components needed for an FSF into some workable array as close to the AGNS Fuel Receiving and storage Station (FRSS) as practical, and to establish compatibility of the two operations. The conceptual arrangement seems to approach very nearly the optimum (Integrated, see Appendix A) concepts (see Figures 3.1 and 3.2 ).

\section{For example:}

- Existing stairwell areas shown in Figure 3-l can be modified as cask sit-down areas for the "Test and Repair Stalls" and for the cask "Internals Cleaning Area."

- The existing cask crane can handle all cask movements needed. 
- Existing bays for off-loading and reloading casks will continue to be used as such. Crane time associated with these bays will be reduced substantially because impact limiters and personnel barriers will be handled in the outer (new) bays.

- Areas of potentially high radiation levels are arranged in a compact array with those in need of the greatest shielding at the center.

- Extensive storage area is made available to the FRSS as well as the FSF.

The Colocated FSF is envisioned as a southward extension of the FRSS. The core structure which houses the high radiation areas is about 80 feet by 85 feet and this is the only added area requiring substantial foundations. The remainder of the 150-foot by 200-foot structure, except for the 15-ton crane-way supports, will require no more than conventional loadings for light industrial operations. One side of the 80-foot by 85-foot core structure will be about 23 feet greater in overhead elevation than the other, so the roof of the lower side will provide room for inactive storage which was not available in the previous concepts. The 15-ton crane serves both incoming and outgoing bays as well as the storage and shop area between the bays. The Health Physics counting room is close to the receiving and departure areas, but well away from the high radiation areas of the complex.

It is expected that the FSF will be capable of repairing damaged casks. However, casks damaged so severely that they cannot be opened in a normal way will be considered on a case-by-case basis. The contents of the casks; spent fuel, high level wastes, etc., will be a major consideration as to how it is opened and the kind of area needed to perform the opening or repair operations. The E-MAD Facility in Jackass Flats, Nevada, might serve as a central repair station. A facility with water-filled pits might also be used, if justified.

The overall facility makeup is nearly identical to that of the Integrated FSF. The arrangement of the various components is changed to the extent necessary to mate with the FRSS. The salient difference is that the colocated concept does not have the flow-through traffic pattern; i.e., once a cask is off-loaded or on-loaded, the vehicle must move back out along the same route that it entered. This might be awkward for semi-trailers because of the relatively long distance to back up. In this regard, it would be well to develop a set of flanged wheels, similar to those used on the shuttle wagon, which could be attached easily to the 
rear of a trailer to use the rails as a guide when moving the trailer in reverse.

The cask on/off-loading bays (two) have the same capacity in this concept as in the others, but instead of both being able to serve for either on-loading or off-loading, each bay is assigned only one function. This has the effect of slowing down the throughput rate. On the other hand, these bays are not tied up during the handling of impact limiters and personnel barriers and this improves throughput. These relative attributes are discussed in more detail in section 4.0 .

Four test and repair stalls are provided rather than six, since computer simulations of the earlier concepts indicated a surplus in this area. A fifth position is provided as surge capacity. Since the main crane has access only to the sit-down pit (former stairwell), some means must be provided to move the casks from the pit to the work stations. It is proposed to use air pallets for this. Air pallets are extremely maneuverable, will require only 50 psig for a 100-ton cask, and would be far less expensive than installing tracks, turntables, and wheeled dollies. .

The roof over the areas for test and repair, cleaning equipment service, decontamination and contaminated storage will provide excellent sheltered storage for infrequently used equipment from both the FSF and the FRSS. It is accessible from the FRSS at the same floor level as at pool-side and is accessible from the FSF work area by elevator and stairs and, perhaps, a jib crane. A section could be extended to allow service by the 15-ton crane.

The office area, Health Physics office, wash rooms, records vault, data processing room, etc., occupy about the same floor area as in the previous studies but in two elevations rather than one. A scheduler working on the second floor of this complex would have an excellent field of view for status-checking vehicles throughout the FSF.

\subsubsection{Summary Operating Procedure}

(1) Cask systems are stopped at the security access portal* where they are surveyed for both security and preliminary Health Physics requirements.

*Not shown on drawings in this report. 
(2) Vehicles will be parked inside the security access portal by the commercial carriers. All subsequent movement within the secured area will be by plant motive power.

(3) Vehicles without excessive contamination will be routed to the outside washdown area and cleaned of road dirt. Those with excessive contamination will be taken inside where the vehicle will be decontaminated until acceptable for outside washing, and the cask will be decontaminated in the cask and insert cleaning area.

(4) Washed vehicles will be brought into the east, or receiving and washdown, * bay. They will receive spot cleaning as required and be given an inspection for travel damage.

(5) Removable personnel barriers and impact limiters will be taken off and moved to a location in the shop and storage bay.

(6) As soon as the cask off-loading bay is clear, the loaded cask will be moved into the unloading position. The cask will be available for immediate lift-off almost as soon as the vehicle is positioned.

(7) Cask handling from the vehicle, into the Test and Decontamination (T\&D) Pit of the FRSS, into and out of the Cask Unloading Pools (CUP), through decontamination and back onto the car in the cask loading bay will be identical to existing BNFP handling procedures.

(8) While the cask is in the T\&D/CuP complex, the vehicle will be moved to the west bay for inspection, servicing, and repair.

(9) If periodic checking is due for cask qualification or

if cask repair is needed, the 135-ton crane (existing

in the FRSS) will place the cask into the test and repair well, onto an air pallet which will transport it to a repair stall.

*This term is retained for easier reference to the other two FSF concepts. In this concept, it might be better described as a "spot cleaning" bay. 
(10) If cask cleaning or internals changeout is needed, the 135-ton crane will place the cask onto a dolly in the cask and insert-cleaning area well. This dolly is used to move the cask into the controlled-atmosphere area for processing.

(11) When both cask and vehicle have been processed, the vehicle will move into the cask loading bay to receive the cask.

(12) The cask and vehicle will return to the Maintenance and Inspection Bay to have impact limiters reattached, personnel barriers set into place, and Health Physics checks completed.

(13) The cask system will be returned to the parking area to await dispatching for its next load.

(14) The "decontamination room" (Area 3, Figure 3-1) nearest the center of the drawing is used to clean small items.

Appendix B provides a detailed operating procedure for the Integrated Facility. The same general operating procedure also applies to the Colocated Facility. 
1 Cleaning Area Service Equipment

2 Decontaminated Parts Storage

3 Decontamination Room

4 Test and Repair Stalls
5 Casks on Air Pallets

6 Cask and Insert Cleaning Area

Existing Building

(Head End AGNS-BNFP)

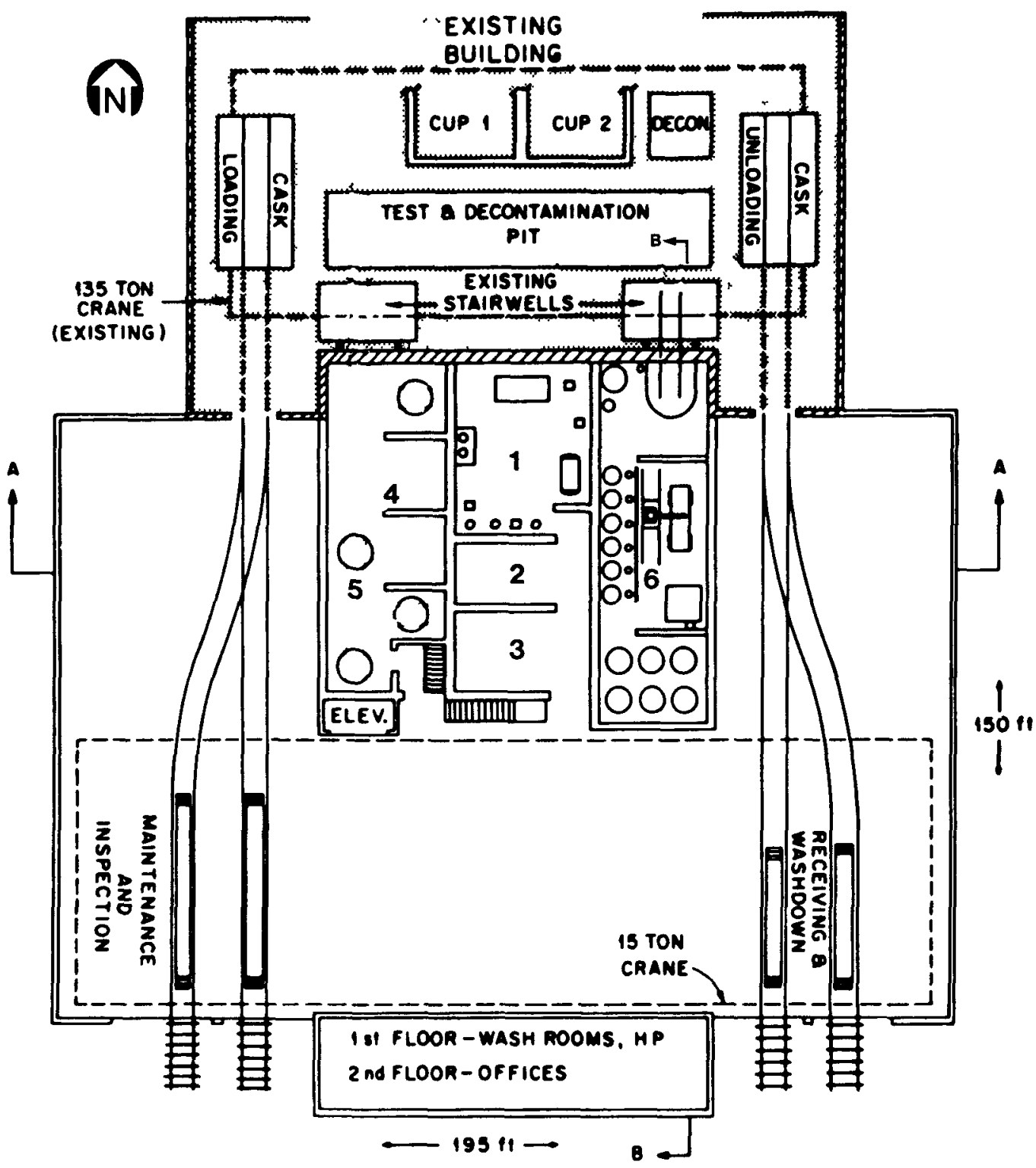

COLOCATED FSF AGNS-BNFP BARNWELL, S. C.

FIGURE $3-1$ 

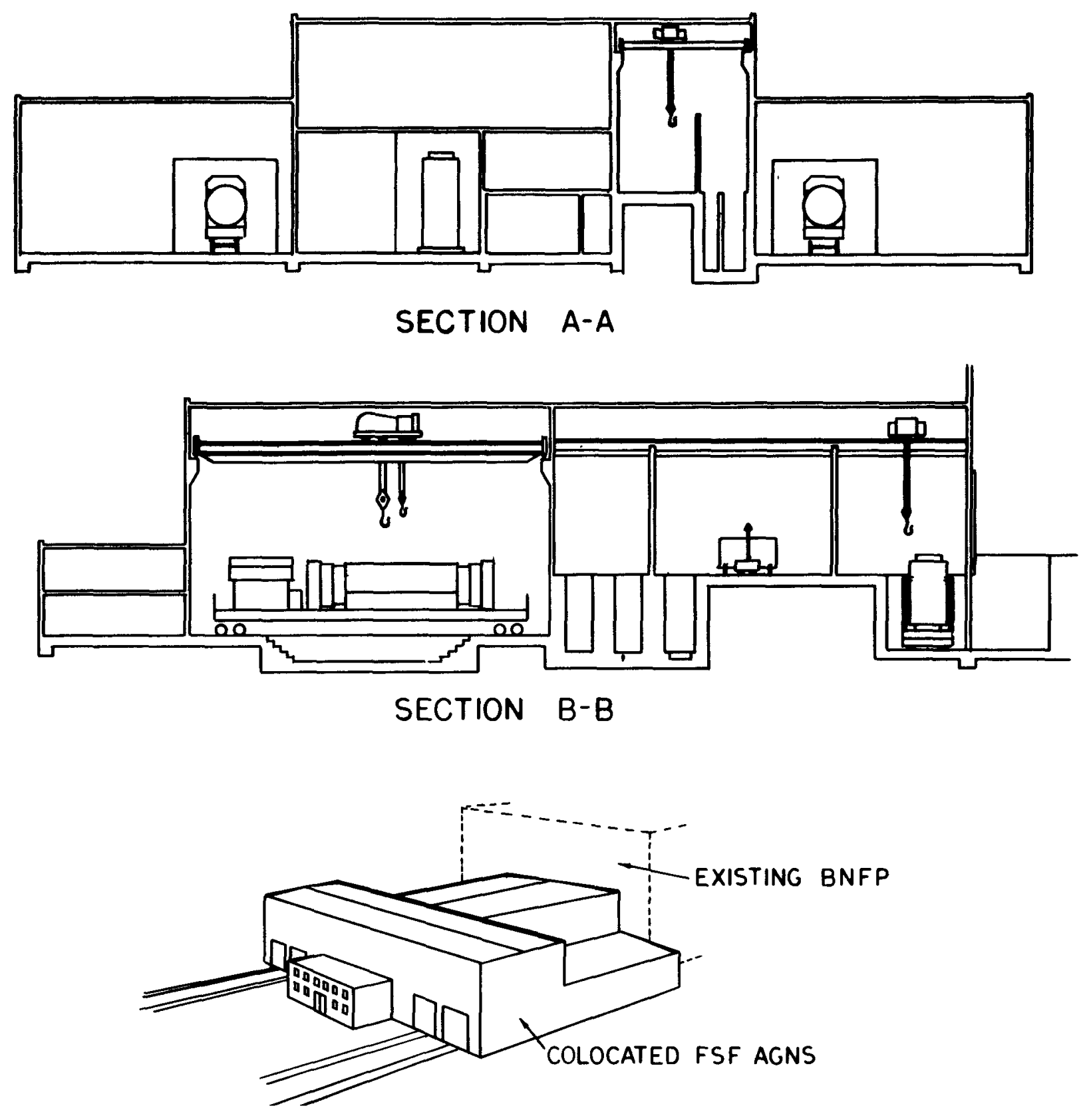

COLOCATED FSF AGNS-BNFP BARNWELL, S. C.

FIGURE 3-2 


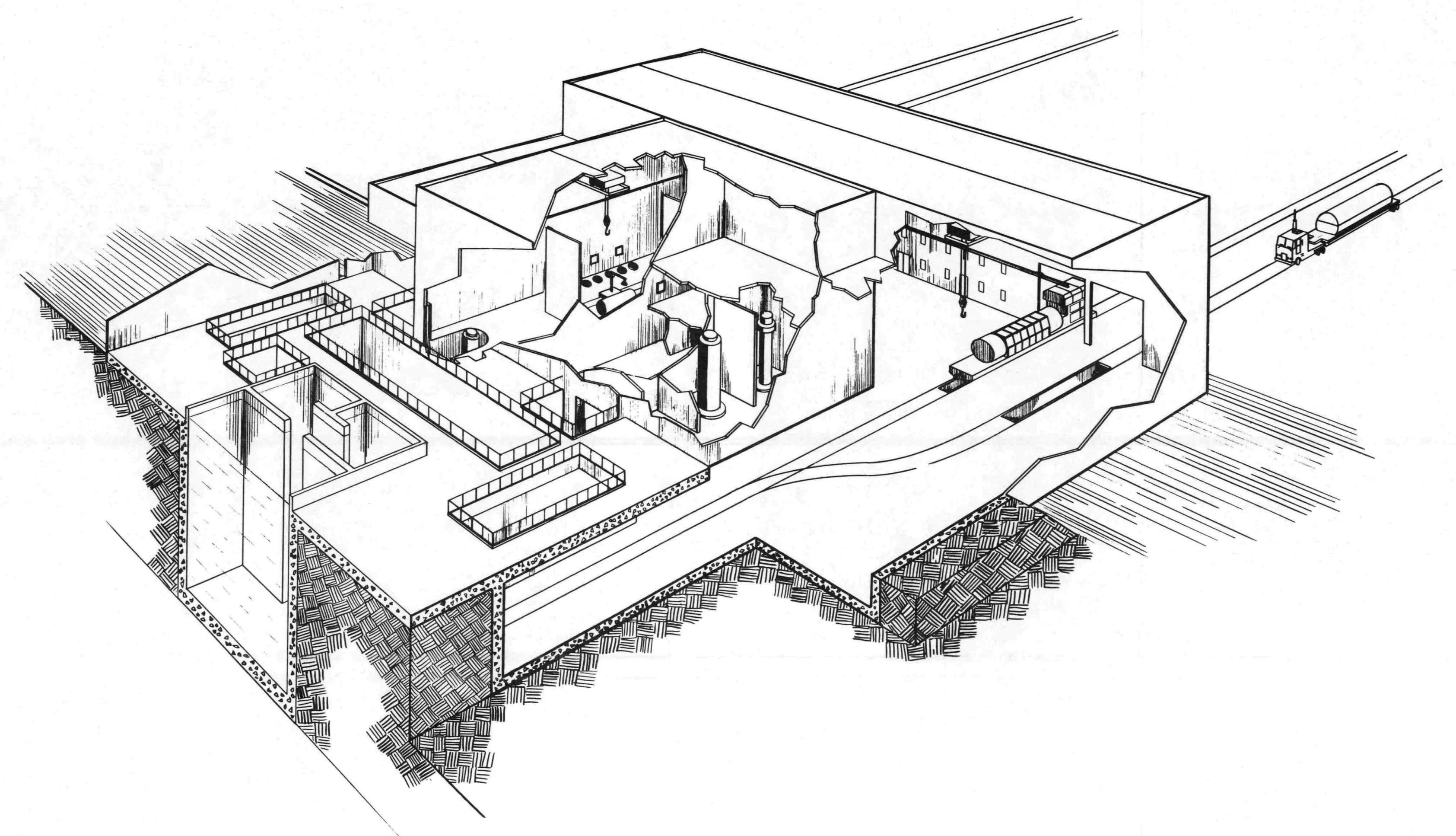

COLOCATED FLEET SERVICING FACILITY FIGURE $3-3$ 
-

- 


\subsection{COMPUTER SIMULATION ANALYSIS OF THE INTEGRATED AND COLOCATED FLEET SERVICING FACILITIES}

\section{$4.1 \quad$ Background}

The use of computer modeling to evaluate the performance of yet untested physical operating systems has proven to be very effective in recent years. To be modeled, a system needs only to be broken down into a series of "discrete tasks" or events as they are called. By assigning time parameters to each separate event, establishing interaction among events, and linking the events back together, the model of the entire operating system can be established.

By allowing the computer model to examine the system behavior over a simulated time of many years, it is possible to study the impact of variances and interactions. Additionally, once a computer model has been established, it is quite easy to change parameters such as arrival rates, facility handling capacities, crane speeds, and cask mixtures. Once a parameter has been changed, the model can be rerun and the probable impact of this change is immediately visible.

The computer simulation language chosen for this model was the IBM Program Product, General Purpose Simulation system (GPSS). (3) It is designed to aid in modeling discrete event systems having shared facilities of limited capacities.

\subsection{Analysis of the Integrated FSF Concept}

\subsubsection{Operational Traffic Flow Patterns}

There will be three basic traffic patterns for the spent fuel casks and their associated vehicles in the Integrated FSF concept. These traffic patterns are designated as normal, contaminated, and requalification. Some appreciation of these flows is necessary to follow through the computer analysis of the system, in which any given cask may follow any possible flow path through random selection. See Figure 4-5.

\section{Normal Traffic Flow}

Any transportation system not requiring special internal routing for cask insert changeout, requalification or decontamination will go through the normal traffic pattern as shown in Figure 4-1. Note that once the cask is off-loaded, then the fuel unloading proceeds simultaneously with vehicle inspection and maintenance. Both operations must be completed before subsequent operations can begin. 
The normal sequence is:

Location

Outside
Event

Receiving inspection, paperwork; cask and vehicle smears

Washdown

Removal of personnel barriers and impact limiters (as required by cask type). Removal of cask from vehicle

Fuel unloading (takes place simultaneously with next operation)

Vehicle inspection and maintenance (and repair)

Cask loading onto vehicle

Outgoing inspection.

Traffic Flow for Contaminated Transport System

If the incoming system is found to be contaminated to a degree not acceptable for normal handling (e.g., above DOT Limits), the components of the system will follow the pathway shown in Figure 4-2. Cask decontamination ordinarily will take place in the cask and insert cleaning area, but it might also be done in one of the test stalls, depending on the nature of the contamination. Note that once the deficiency is corrected, the cask (or vehicle) enters the queue of its next "normal" flow position. One should also be aware that some of the smaller items can be removed from a cask or vehicle and these can be decontaminated while the remainder of the system is progressing through normal channels.

Traffic Flow for Requalification (or Repair) of Transport Systems

If requalification testing is scheduled on any component of the cask, this will be done after the fuel is removed from the cask (potential exceptions are the TN casks which may require (by SAR) spent fuel to be in the cask cavity as a heat and radiation source during thermal and radiation streaming tests, respectively). At times, it may be prudent to remove crud from the inside of the cask before certain tests are done but for purposes of this evaluation, we shall assume that casks move directly from the unloading pits to the test and repair stalls. Once the tests are satisfactorily completed, the cask returns to the on-loading position 
and continues routinely through the remainder of the system (see Figure 4-3). Cask to be repaired will follow essentially this routing, with variations dictated by circumstances.

\subsubsection{Events}

For the purpose of this study, the operating system was broken down into the separate events described in Table 4-1. Also given is their place of occurrence, and their durations for the model base case. Please refer to Figures 4-4 and 4-5 for the location of the various work areas and flow of events.

\subsubsection{Assumptions}

(1) Five percent of the casks received have exterior contamination requiring special attention.

(2) A fleet of 30 rail casks with a capacity of $4.5 \mathrm{MTU}$ each, and 15 truck casks with a capacity of $0.45 \mathrm{MTU}$ per cask is assumed (see Reference 1 ).

(3) Seventy-five percent of the fuel (by weight) arrives by rail and the balance by truck.

(4) Every cask enters test and repair twice each year.

(5) On the average, a rail cask will arrive every 24 hours and a truck cask will arrive every 8 hours. Individual rail cask arrivals may vary \pm 24 hours and truck cask arrivals may vary \pm 8 hours.

(6) If a cask is found to be contaminated, and the cleaning area is occupied, it is not moved until the cleaning area is vacated.

(7) The facility is operated 24 hours/day, every day with a 40-minute break every 8 hours (shift change) and a 30minute break is scheduled 4 hours after the start of the shift (lunch). No new activity is begun on a cask during one of these scheduled breaks, but any activity already in progress when the break began is assumed by GPSS to continue without interruption. These times of unavailability simulate an $85 \%$ duty factor (15\% slack time) for the employees.

(8) All process times follow a truncated normal distribution providing a maximum time of 1.5 times the expected, and a minimum of 0.8 times the expected. 


\section{TABLE 4-1}

\section{OPERATING EVENTS, INTEGRATED CONCEPT}

\begin{tabular}{|c|c|c|}
\hline Event & Location ** & $\begin{array}{c}\text { Average } \\
\text { Time in Minutes } \\
\text { (Rail/Truck) } \\
\end{array}$ \\
\hline Receiving & 1 & $125 / 100$ \\
\hline $\begin{array}{l}\text { Outside Decontamination } \\
\text { (if necessary) }\end{array}$ & 5 & $120 / 100$ \\
\hline Washdown & 2 & $35 / 25$ \\
\hline Cask off-Loading* & 3 & $95 / 25$ \\
\hline $\begin{array}{l}\text { Prep. Fuel Removal, } \\
\text { Decontamination }\end{array}$ & 4 & $565 / 310$ \\
\hline Cask On-Loading* & 3 & $120 / 40$ \\
\hline $\begin{array}{l}\text { Vehicle Test and Inspection } \\
(\mathrm{T \& I})\end{array}$ & 6 & $300 / 180$ \\
\hline $\begin{array}{l}\text { Basket Change and Internal* } \\
\text { Decontamination }\end{array}$ & 5 & $240 / 240$ \\
\hline $\begin{array}{l}\text { Cask Test and Repair*** } \\
(T \& R)\end{array}$ & 7 & $2050 / 1300$ \\
\hline Final Survey & 8 & $75 / 65$ \\
\hline
\end{tabular}

* Times do not include the crane movement times which are assumed to be $30 / 20$ for movement of a cask from one location to another.

${ }^{\star}$ Refer to Figures 4-1, 4-2, and 4-3.

***Twice each year regardless of number of trips. 


\subsubsection{Various Cases That Were Examined}

The objective of making many different computer runs was to study the impact on cask throughput time when parameters in the system are changed, as well as the frequency that the work areas are full or nearly full. The average occupancy of these work areas may also serve as an indicator for system performance. Keeping in mind, for example, that although the average occupancy of a 3-bay area might be $1-1 / 2$, it might never be full. On the other hand, it might be full more than 408 of the time and empty the rest of the time. This is why average occupancy factors alone are not conclusive data. The analyses of the results will indicate average occupancy, actual occupancy, and time spent in queues preceding each work station. The examination of queues will also serve to point out bottlenecks in the system, since a queue will always develop in front of a bottleneck.

Five runs were made, each simulating two years of facility operation. The first run, or base case, was based on the assumptions noted in section 4.2.3. In subsequent runs, one parameter was varied in order to study its effect on the system. The five cases are described below:

- Case 1 - Base Case

To be used as the primary case (2000 MTU/year throughput) to which the other cases are compared. See Table 4-1.

- Case 2-1008 Duty Factor

In this case, all facilities and personnel are always available, permitting the study of the impact of attaining 1008 productivity.

- Case 3 - Slower Vehicle T\&I

Vehicle $T \& I$ times were increased by a factor of two over the base case to determine system sensitivity to $T \& I$ times.

- Case 4 - 3000 MTU/Year Receiving Rate

Throughput rate was increased by 50 \% to evaluate the impact on operating capacity.

- Case 5 - 10\% Contaminated Casks

The number of excessively contaminated casks arriving at the facility was increased to 108 to evaluate this parameter on plant operation. 
Data from the 5 cases are presented in Table 4-2 and the results summarized below.

\section{2 .5 Discussion of the Various Cases}

\section{Case 1}

Case 1 is a reference point for the other four cases. This case simulates the facility under assumed circumstances, many of which are only roughly defined. Since some assumptions are not totally fixed, they have been varied in later runs to examine the sensitivity to those changes. In all the runs, the washdown area was utilized less than $10 \%$ of the time and is, therefore, insensitive to all changes in Cases 2 through 5 .

Facilities that are not duplicated (e.g., the heavy crane and the cleaning/decontamination area) are of particular interest. When occupied, they can block the flow of casks through the system, thus becoming likely bottlenecks. In all cases, however, the average queue in front of these facilities was negligible. The cask throughput times for both rail and truck serve as indicators to system performance. These times are defined as the interval between cask arrival and cask departure. For the base case, these times are 1811 minutes for a rail cask and 835 minutes for a truck cask. The crane utilization is $18 \%$ and the cleaning area is occupied 148 of the time. Also, note that the cask loading area is sometimes full, even though its average occupancy as shown in Table 4-2 is only about 50\%. Also, the vehicle T\&I area sometimes services four vehicles simultaneously while its average is less than one.

To gain further insight into system performance, the data produced by the computer simulation were summarized in Figures 4-6 through 4-11. Figure 4-6 shows that the cask loading area is empty $60 \%$ of the time and full less than 10\%. Also, note the cask repair bays are occupied infrequently (see Figures 4-9 and 4-10) as is the vehicle T\&I area (see Figure 4-11). Although there are times that the vehicle T\&I areas are full, the third and fourth slots are occupied less than 2 of the time.

Case 2

Making all personnel and facilities $100 \%$ available had little impact on the system. The reduction of throughput times was less than $4 \%$, indicating that the $15 \%$ slack time allowed for in the basic assumption would probably have been idle time anyway on the average. Aside from this and the lower utilization of the crane, there would be no obvious 
TABLE $4-2$

A SUMMARY OF THE RESULTS OBTAINED FROM COMPUTER SIMULATION ANALYSIS OF THE INTEGRATED FLEET SERVICING FACILITY

The Average Number of Casks in an Area.

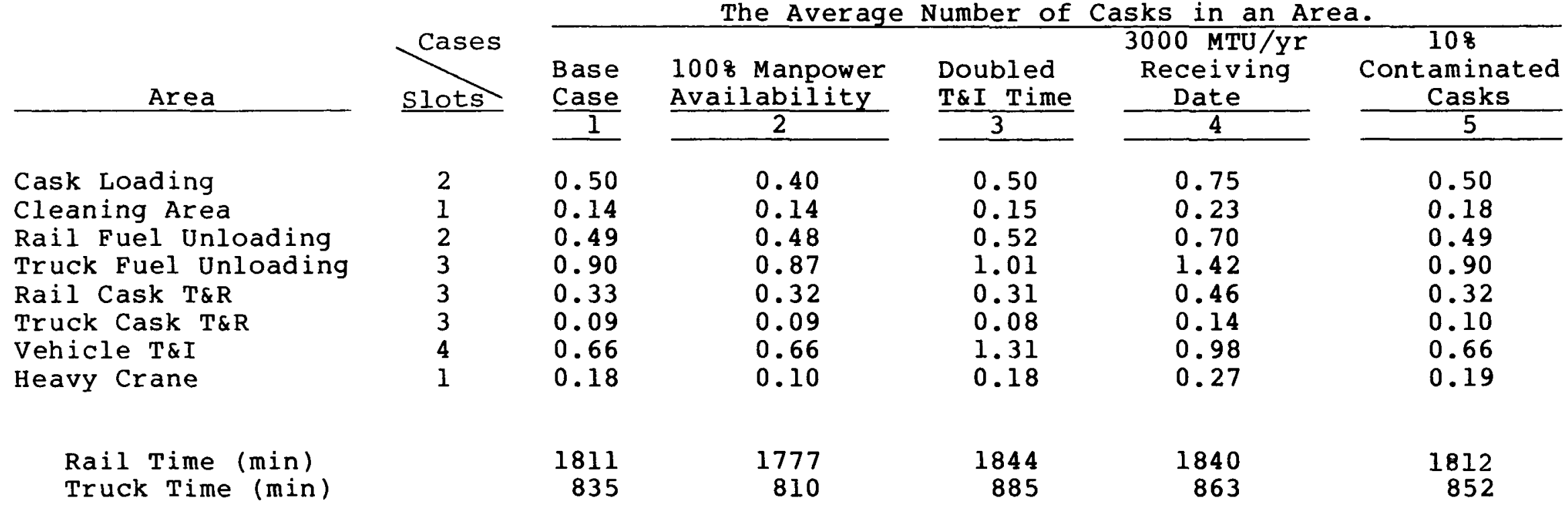

Please refer to histograms (Figures 4-6 through 4-18) for further details. 
advantage to attaining more than 858 availability out of the system components.

Case 3

When the vehicle T\&I times were doubled, the throughput time was increased by only about 28 for rail casks, while truck cask time increased by 68 .

The most obvious change in the system is the occupancy of the vehicle T\&I area. A comparison of Figures 4-11 to 4-14 shows that, although the average number in $T \& I$ has doubled, it is full very infrequently. The third slot, however, is occupied a significant amount of the time as indicated in Figure 4-14.

The casks remain in the fuel unloading areas while awaiting the vehicle to leave the T\&I area, thus causing a shift in the distribution of casks in the fuel unloading areas. Note that this effect is less pronounced in the case of rail casks (compare Figure 4-7 and Figure 4-12) than with truck casks (compare Figure 4-8 and Figure 4-13).

The average wait by a cask for its vehicle was 50 minutes, and almost 558 of the casks waited, as compared to an average wait of less than one minute for only 18 of the casks in the base case. This waiting time is the main contributor for the increased throughput times.

Case 4

This run, which simulates arrivals of $3000 \mathrm{MTU} / \mathrm{year}$, caused the use of the 150-ton crane to rise to 278 and caused a shift in the distributions. Compare Figures 4-6 to 4-15; $4-7$ to $4-16,4-8$ to 4-17, and 4-11 to 4-18. Note that a 508 increase in arrivals translated directly to a 508 increase in average occupancy of most facilities, but the throughput times increased by much less than that. No bottlenecks appeared and the system, as modeled, performed very effectively.

\section{Case 5}

Since a contaminated cask uses the heavy crane more and also requires occupancy of the cleaning area, it might be expected that the number of contaminated casks would cause an increase in the utilization of these facilities. Surprisingly, however, there is virtually no impact on throughput times due to doubling the number of contaminated casks. There was no impact on crane utilization and although there was a 308 increase in the utilization of the cleaning area, it is still empty 828 of the time (see Table 4-2). It 
appears that there would be no problem in handing an increased number of contaminated casks unless the cleaning area becomes crowded due to an increase in basket change requirements or if decontamination times are really greater than currently estimated.

\subsubsection{Conclusions of Simulation Analysis}

of all the parameters analyzed, it appears that vehicle T\&I times had the greatest direct impact on cask throughput times. Case 3, summarized in Table 4-2, shows that an increase of the vehicle T\&I times by a factor of $2 \mathrm{might}$ cause an increase in throughput time. The total time required for vehicle $T \& I$ is an important value to be determined accurately in actual practice, particularly, if it exceeds the time that a cask spends in the fuel unloading cycle. The casks that are awaiting vehicles for on-loading are usually in the fuel unloading area, occupying needed space critical to the flow of the system.

The overall system performance was very good and insensitive to most perturbations. It seems that the design criteria for a $2000 \mathrm{MTU} / \mathrm{year}$ facility is extremely conservative, since at $3000 \mathrm{MTU} / \mathrm{year}$ the throughput times were almost the same. Note that the third rail and truck cask T\&R pit was almost never used, and the second was only rarely used. If the assumed model is accurate, there should be absolutely no impact in the removal of the third slots for both cask types. The fuel unloading areas were full infrequently; and consideration might be given to reducing the total number of these, keeping in mind, however, that a more in-depth reliability study of these facilities would be well advised before such action.

\subsection{Analysis of the Colocated FSF Concept}

\subsubsection{Operational Traffic Flow Patterns}

As in the Integrated concept (Section 4.2.1), the Colocated Facility provides three basic traffic patterns for the spent fuel casks and their associated vehicles. A description of each traffic flow pattern follows.

\section{Normal Traffic Flow}

Any transportation system not requiring special internal routing for cask insert changeout, requalification, or decontamination will go through the normal traffic pattern. Referring to Figure 4-19, the sequence is: 
Washdown pad -- cask and vehicle smears (prior to washdown

(3) Removal of impact limiters and personnel barriers (as required by cask type)

(4) Cask off-loading (see below for cask operations during Steps 5 and 6 )

(5) Paint removal, sandblasting (as required), vehicle survey

(6) Vehicle maintenance

(7) Cask on-loading

(8) Attachment of impact limiters, personnel barrier (as required)

(9) Outgoing inspection -- final survey, paperwork check.

While the vehicle moves from Position 4 to 7 via the FSF ( 4 to 5 to 6 to 7 ), the cask moves from 4 to 7 via the FRSS ( 4 to $A$ to $B$ to $C$ to $D$ to 7 ), as follows.

Location Event

Cask off-loading

(A) Off-loaded cask surge area

(B) Cooldown (if required), flushing, and filling

(C) Fuel unloading

(D) Reassembly and decontamination

(7) Cask on-loading

Traffic Flow for Contaminated Transport System and Internals Changeout

If the incoming system is found to be contaminated to a degree not acceptable for normal handling, its routing will differ from the normal routing in only two ways. The system will bypass the outside washdown area and go directly to the unloading bay. The cask will then go from location 4 (Figure 4-19) to location $E$, cask decontamination, then back 
to the normal sequence at location $A$. The vehicle is cleaned prior to moving to the Maintenance and Inspection Bay, location 6 , but its routing is not affected at other than the pause at location 3 .

Casks for which internals are to be changed will follow the same routing and will be sent to location $E$ after being unloaded.

Traffic Flow for Requalification (or Repair) of Transport Systems

If requalification testing is scheduled for any component(s) of the cask, this will be done after the spent fuel is removed from the cask (see Section 4.2 .1 for possible exceptions). This routing involves a simple detour to location $F$ (Figure 4-19) after being decontaminated at location $D$, and prior to cask on-loading. Casks to be repaired will follow essentially the same routing, but the routing will be subject to variation according to circumstances.

\subsubsection{Events}

The events used in the analysis of this system are presented in Table 4-3.

\subsubsection{Assumptions}

The assumptions used in the analysis of the colocated Facility are the same as listed in section 4.2 .3 for the Integrated Facility.

\subsubsection{Various Cases That Were Examined}

The simulation approach for the Colocated Facility is the same as for the Integrated Facility. Since the flow of casks is very similar for both designs, the original model was modified to simulate the Colocated approach. The event times were changed to reflect the wet cask unloading process, and storage slots were reduced or increased to correspond with the Colocated design. Please refer to Table 4-3 and Figure 4-19 for event times and locations.

Five computer runs were made. As before, each run was designed to study the impact of varying a single parameter over the two-year study period. The cases and their objectives are listed below:

Case 1-Base Case

To be used as reference case $(2000 \mathrm{MTU} / \mathrm{year}$ as uranium metal). 


\section{OPERATING EVENTS, COLOCATED CONCEPT}

\begin{tabular}{|c|c|c|}
\hline Event & Location* & $\begin{array}{c}\text { Average } \\
\text { Time in Minutes } \\
\text { (Rail/Truck) } \\
\end{array}$ \\
\hline Receiving & 1 & $125 / 100$ \\
\hline Extraordinary Decon & 3 & $120 / 120$ \\
\hline Washdown & 2 & $35 / 25$ \\
\hline $\begin{array}{l}\text { Remove Impact Limiters and } \\
\text { Personnel Barriers }\end{array}$ & 3 & $60 / 40$ \\
\hline Cask off-Loading & 4 & $45 / 30$ \\
\hline$T \& D$ and $C U P$ & $A-B-C-D$ & $1125 / 470$ \\
\hline Cask On-Loading & 7 & $45 / 30$ \\
\hline $\begin{array}{l}\text { Reassemble Impact Limiters } \\
\text { and Personnel Barriers }\end{array}$ & 8 & $75 / 45$ \\
\hline Vehicle T\&I & 6 & $300 / 130$ \\
\hline Basket Change & $\mathrm{E}$ & $240 / 240$ \\
\hline Cask T\& $R^{* *}$ & $\mathrm{~F}$ & $2050 / 1300$ \\
\hline Final Survey & 9 & $75 / 65$ \\
\hline
\end{tabular}

\footnotetext{
${ }^{*}$ Location identification as marked on Figure 4-19. **Cask tested twice a year, regardless of number of trips.
} 
Case 2 - Two Light Duty Cranes

Study the benefit that might be obtained from having a 15-ton light duty crane at both the receiving and departing ends of the facility.

Case 3 - 108 Contaminated Casks

To study the impact of increased use of process areas caused by contaminated casks.

Case 4 - No Cask Maintenance, Repair, or Internal Changeout

Roughly simulates the existing facility and can be used as a reference case to measure the effect of the Colocated FSF on the parent plant operations.

Case 5 - Larger Facility

The CUP and cask maintenance capacities were increased to study the impact effect.

4.3.5 Discussion of the Various Cases

The five basic cases are discussed individually in this section and a summary is presented in Table 4-4.

Case 1 - Base Case

This case serves as a reference point for comparison to the other four cases. The casks flowed smoothly through the system with average times of 2440 minutes for a rail cask and 1442 minutes for a truck cask. Table 4-4 and Figures 4-20 through 4-22 provide data concerning this run. Note in Table 4-4 that the cask unloading pool (CUP) had an average of 1.3 casks while Figure 4-2l shows that it was filled to capacity $45 \%$ of the time. This situation indicates that the CUP could be a bottleneck, but the average wait for entering this location was only one half of an hour. The run also showed that $35 \%$ of the casks were waiting before entering the area.

The T\&D pit was occupied by an average of 1.8 casks and was filled to capacity over $20 \%$ of the time. The Vehicle Maintenance and Inspection area, which also serves as the point for replacement of the personnel barrier and impact limiters, contained an average of over one cask equal to 558 occupancy. This area always had a very small queue, and the equipment that waited were vehicles needing maintenance. However, the vehicle maintenance waiting times anticipated for this design were short enough so that the vehicle was always ready and waiting for cask arrival. Another computer 


\section{TABLE $\quad 4-4$}

A SUMMARY OF THE RESULTS OBTAINED FROM COMPUTER

SIMULATION ANALYSIS OF THE COLOCATED FLEET SERVICING FACILITY

The Average Number of Casks in an Area

\begin{tabular}{|c|c|c|c|c|c|c|}
\hline \multirow{2}{*}{ Area } & \multirow{2}{*}{$\underbrace{\text { Cases }}_{\text {lots }}$} & \multicolumn{5}{|c|}{ The Average Number of Casks in an Area } \\
\hline & & $\begin{array}{l}\text { Base } \\
\frac{\text { Case }}{1} \\
\end{array}$ & $\begin{array}{l}2 \text { Light } \\
\frac{\text { Cranes }}{2} \\
\end{array}$ & $\begin{array}{c}10 \% \\
\frac{\text { Contamination }}{3}\end{array}$ & $\begin{array}{c}\text { No Cask } \\
\text { Maintenance } \\
4\end{array}$ & $\begin{array}{c}\begin{array}{c}\text { Larger } \\
\text { Facility }\end{array} \\
5\end{array}$ \\
\hline $\begin{array}{l}\text { Receiving \& Wash } \\
\text { Cask Unloading } \\
\text { Cask Cleaning } \\
\text { T\&D Pit } \\
\text { CUP } \\
\text { Cask Loading } \\
\text { Cask T\&R } \\
\text { Maint. and Insp. } \\
\text { Heavy Crane } \\
\text { Light Crane }\end{array}$ & $\begin{array}{l}2 \\
1 \\
1 \\
4 \\
2 \\
1 \\
4 \\
2 \\
- \\
-\end{array}$ & $\begin{array}{l}0.19 \\
0.06 \\
0.12 \\
1.80 \\
1.31 \\
0.17 \\
0.43 \\
1.07 \\
0.29 \\
0.30\end{array}$ & $\begin{array}{l}0.15 \\
0.06 \\
0.12 \\
1.80 \\
1.31 \\
0.14 \\
0.43 \\
1.06 \\
0.29 \\
--\end{array}$ & $\begin{array}{l}0.19 \\
0.08 \\
0.16 \\
1.77 \\
1.31 \\
0.18 \\
0.43 \\
1.07 \\
0.29 \\
0.30\end{array}$ & $\begin{array}{l}0.18 \\
0.06 \\
0.04 \\
1.82 \\
1.31 \\
0.17 \\
-. \\
1.08 \\
0.28 \\
0.30\end{array}$ & $\begin{array}{l}0.17 \\
0.04 \\
0.11 \star \\
1.69 \\
1.28 \star \\
0.17 \\
0.43 \\
1.07 \\
0.29 \\
0.30\end{array}$ \\
\hline $\begin{array}{ll}\text { Turnaround } & \text { Rail (min) } \\
\text { Truck (min) }\end{array}$ & & $\begin{array}{l}2440 \\
1442\end{array}$ & $\begin{array}{l}2370 \\
1415\end{array}$ & $\begin{array}{l}2435 \\
1450\end{array}$ & $\begin{array}{l}1920 \\
1400\end{array}$ & $\begin{array}{l}2417 \\
1393\end{array}$ \\
\hline
\end{tabular}

*Special case; the capacity increased for this run. 
run indicated that even if these waiting times were $50 \%$ longer, there would be no real impact on turnaround.

The utilization times of the 15-ton light crane and the 135-ton heavy crane were $33 \%$ and 298, respectively, indicating no potential bottlenecks. The queue for the 135-ton heavy crane averaged 0.6 cask waiting less than 10 minutes. This situation, by no means, indicates a need for a second heavy crane. The cask cleaning and basket change area was used only $12 \%$ of the time.

The histograms in Figures 4-20 and 4-22 revealed more about system performance; for example, the Receiving and Washdown area (Figure 4-20) was full only 28 of the time, while the cask T\&R area (see Figure 4-22) contained more than two casks only 108 of the time, and was never filled.

Case 2

There seems to be little effect on operations by having two light-duty cranes available for impact limiters and personnel barrier removal and replacement. The computer run shows that if there were two cranes in use, they would be used at the same time only 38 of the time. However, two cranes do reduce waiting times and allow the cask to enter and depart at a greater rate, thus, slightly decreasing utilization and turnaround time. The decrease in utilization here indicates that some of the use in the base case is due to slots being utilized as cask surge storage areas, rather than exclusively for production.

\section{Case 3}

In this case, the number of contaminated casks received was increased to $10 \%$. It would be expected that doubling the number of contaminated casks received would cause an increase in the turnaround time. This run revealed, however, that was not the case as the turnaround time was not affected. In the base case, the cask cleaning area was occupied only 128 of the time and rose to 168 here. Each cask was serviced immediately, however, thus having no impact on the performance of the system. It is also evident that increased decontamination time for these casks would not significantly affect turnaround time.

Case 4

This particular run ignores all areas and events that would take place in a Colocated FSF attached to the BNFP. That is, there is no FSF cask or vehicle maintenance, and the sole objective is to unload spent fuel, decontaminate the cask, and return it to its scheduled destination. By 
comparing this run to the base case, the impact of cask maintenance on total turnaround time becomes evident; for example, the turnaround times for this case are 1920 minutes for rail, and 1400 minutes for truck, compared to 2440 minutes and 1442 minutes in the base case. The rail time is more drastically reduced, owing to the longer maintenance time on a rail cask than on a truck cask.

It is interesting to note that the average turnaround time for casks in the base case is only 540 minutes longer for rail, and 42 minutes longer for truck, considerably shorter times than would be required to process them in an Independent FSF. The times of 1920 minutes and 1400 minutes also represent the turnaround time expected in the base case for a typical cask requiring no maintenance.

\section{Case 5}

Since the two CUP(s) seemed to be the most highly utilized in the base case, its capacity was increased to three for this run. Additionally, since many casks had to wait for entry to the Cask Maintenance area, its capacity was increased to two. These changes dropped the average turnaround times by about 30 minutes. The impact was less than expected, but further study revealed that the third slot in CUP was used only 78 of the time (see Figure 4-23) and the second slot in the Cask Maintenance area was used less than 18 of the time. Since the extra facilities added were seldom used, their added benefit becomes quite marginal.

\subsubsection{Conclusions of Simulation Analysis}

On a comparative basis, the colocated FSF concept with wet unloading is not capable of producing turnaround times as fast as the Integrated FSF Facility with dry unloading. Almost all of the extra time involved is due to the unloading method rather than FSF concept, per se. The fuel unloading method alone accounts for an eight-hour increase in the minimum throughput time for a cask.

Since the occupancy of any of the facilities barely exceeds $60 \%$, there is no strong evidence that increasing the size of the CUP(s) or the T\&D pit would in turn decrease throughput times. Recall from the base case that the average wait for these facilities was less than one-half hour, with less than $40 \%$ of the casks waiting.

At 2000 MTU, the system does not seem to be approaching saturation or to begin to suffer from congestion. A run was made with cask arrivals simulating $1100 \mathrm{MTU} / \mathrm{year}$ and the turnaround times were only slightly lower, indicating that 
there are no excessive waiting times due to crowding in the base case.

There are a few operational considerations that were revealed by the study. One situation that could cause problems is that both casks in the CUP may be ready to enter the cask cleaning area when it is occupied. Should this happen, space must be available to temporarily set a cask while the transfers are made. It is likely, but there is no guarantee that there would be a free area in the T\&D pit. If this situation does occur, the net turnaround time is increased because of the extra crane movement that is required.

The GPSS analysis also shows that some of the casks that arrived at the colocated FSF with excess outside contamination were delayed entry because of the cleaning area being occupied. This delay added, on the average, an additional 35 minutes to a contaminated cask's turnaround time. 


\section{BLANK PAGE}

$-44-$ 


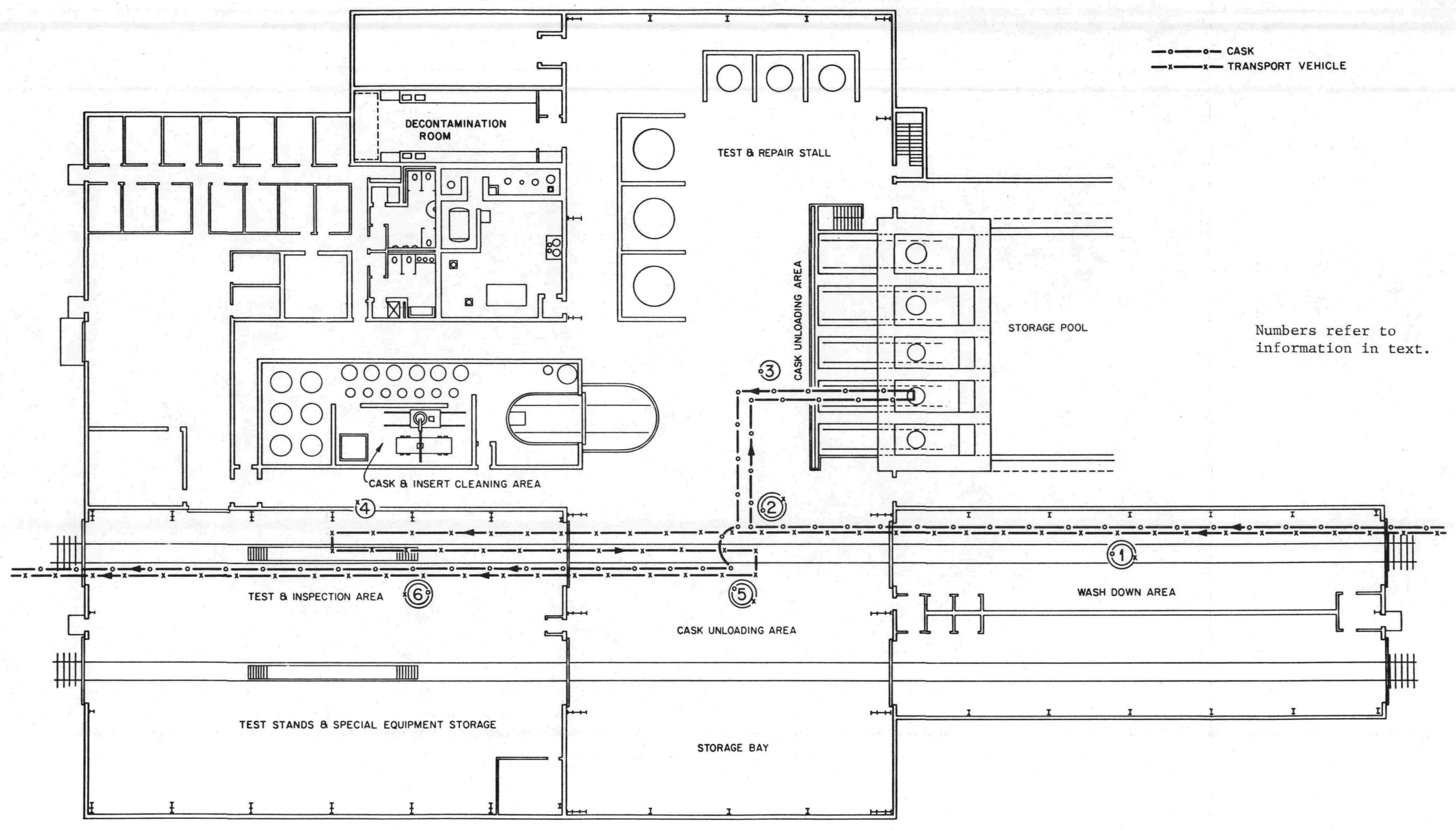

NORMAL TRAFFIC FLOW

INTEGRATED FSF NORMAL TRAFFIC FLOW

FIGURE 4-1 
-

- 


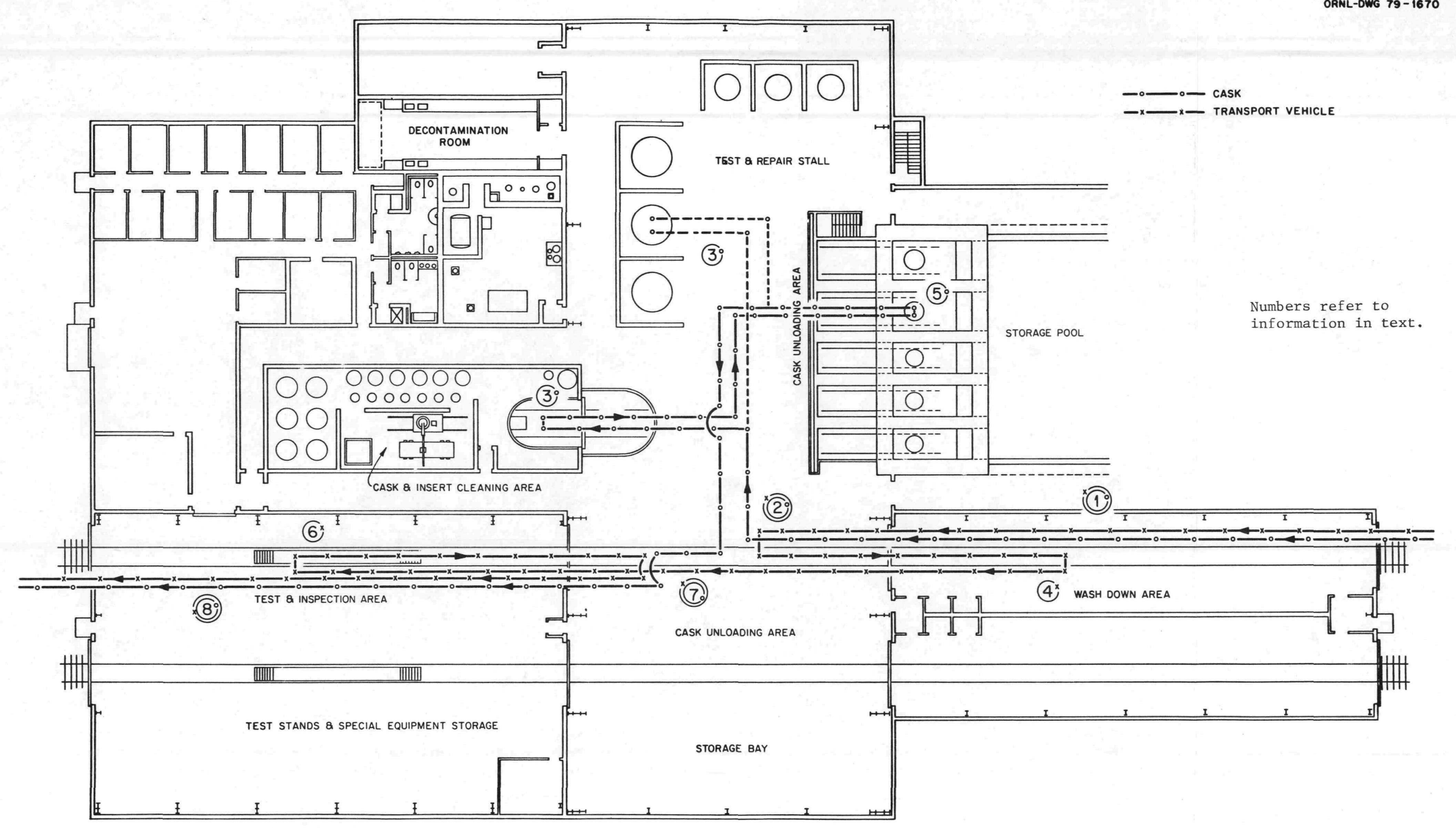

CONTAMINATED EQUIPMENT TRAFFIC FLOW 
$$
\text { . }
$$ 


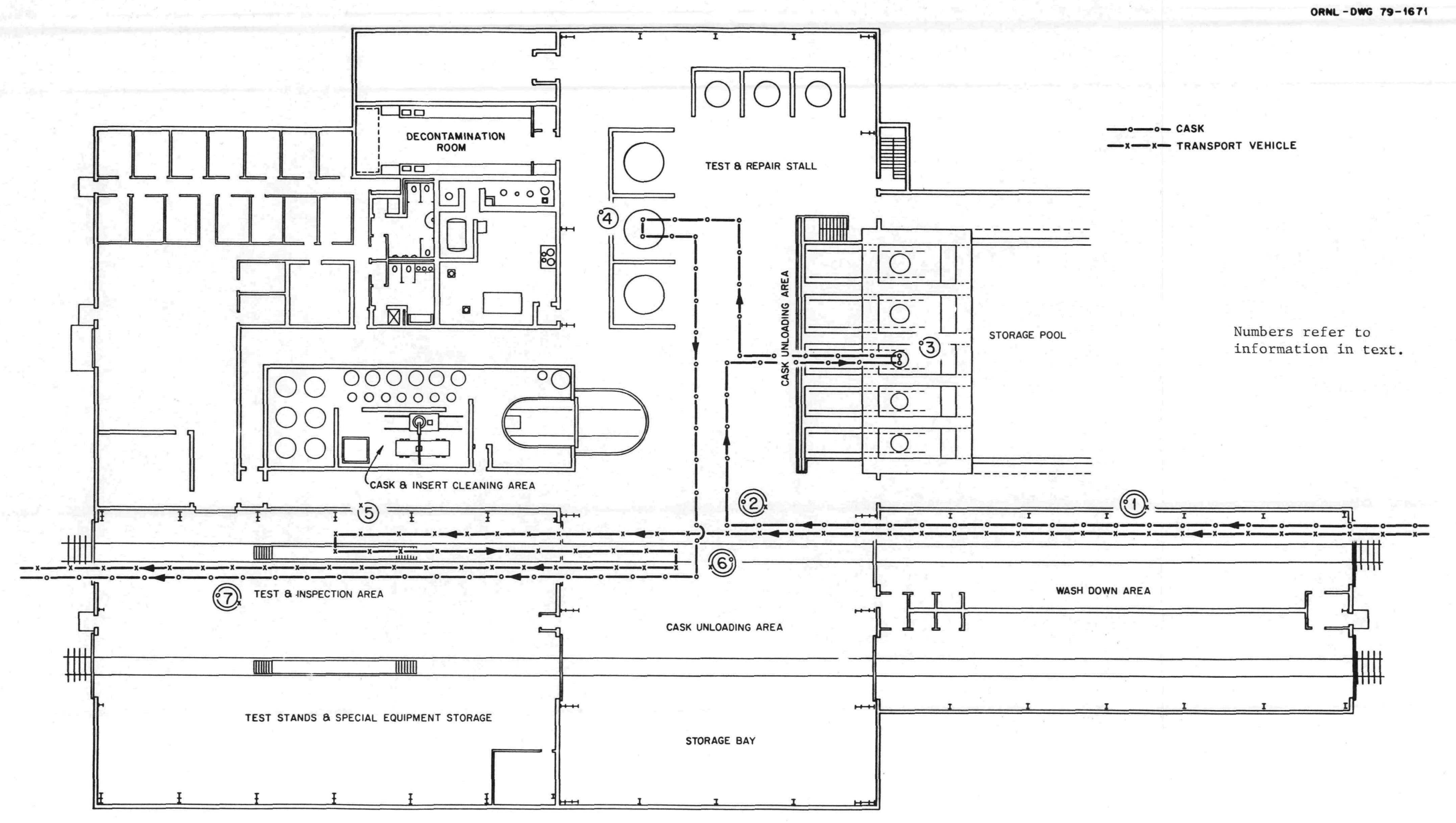

QUALIFICATION OF EQUIPMENT TRAFFIC FLOW

INTEGRATED FSF TRAFFIC FLOW FOR REOUALIFICATION (OR REPAIR) $\begin{array}{r}\text { FOR RE TRANSPORT SYSTEM } \\ \hline\end{array}$ 
-

- 
SEQUENTIAL PATHS

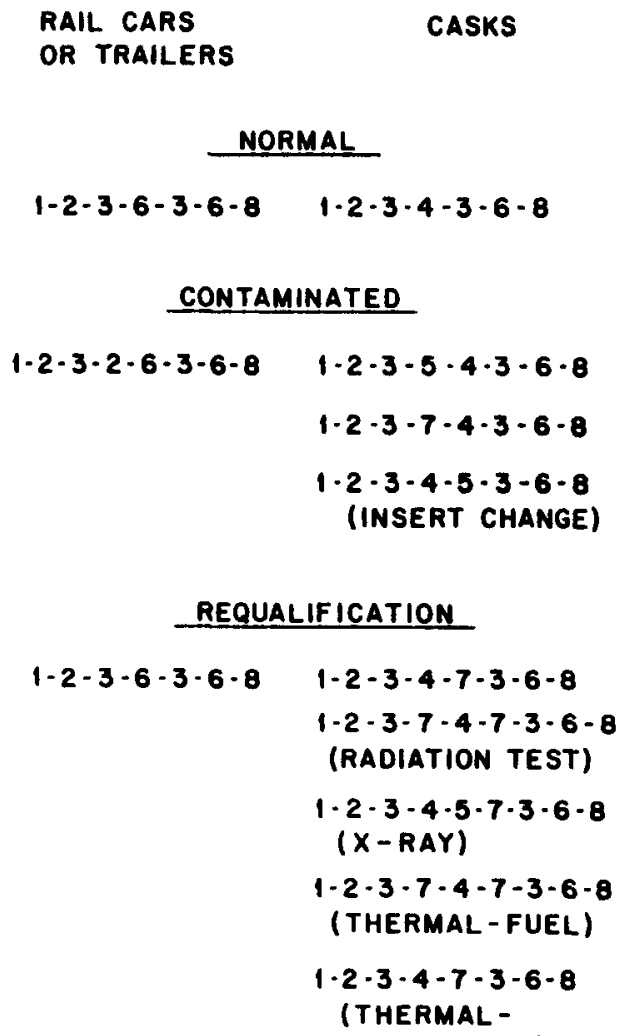

REQUALIFICATION

$1-2 \cdot 3-6 \cdot 3-6-8 \quad 1-2-3-4 \cdot 7-3-6-8$ $1-2 \cdot 3 \cdot 7 \cdot 4 \cdot 7 \cdot 3 \cdot 6-8$ (RADIATION TEST)

$1 \cdot 2 \cdot 3 \cdot 4 \cdot 5 \cdot 7 \cdot 3 \cdot 6 \cdot 8$ (X-RAY)

$1-2 \cdot 3 \cdot 7 \cdot 4 \cdot 7 \cdot 3 \cdot 6 \cdot 8$ (THERMAL - FUEL)

$1 \cdot 2 \cdot 3 \cdot 4 \cdot 7 \cdot 3 \cdot 6 \cdot 8$ (THERMAL HEATERS)

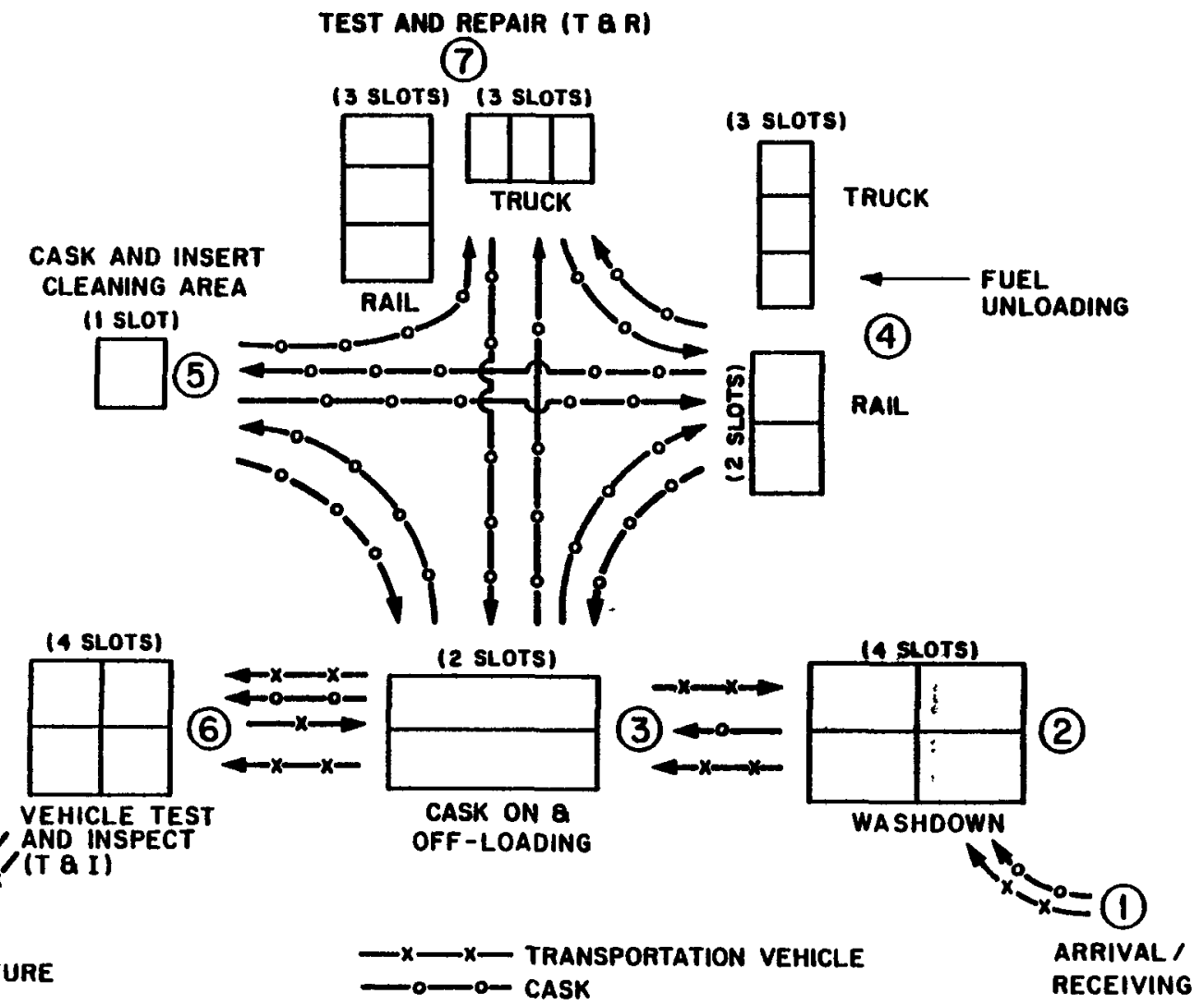

INTEGRATED FSF DETAILED OPERATIONAL FLOW PATHS

FIGURE 4-5 


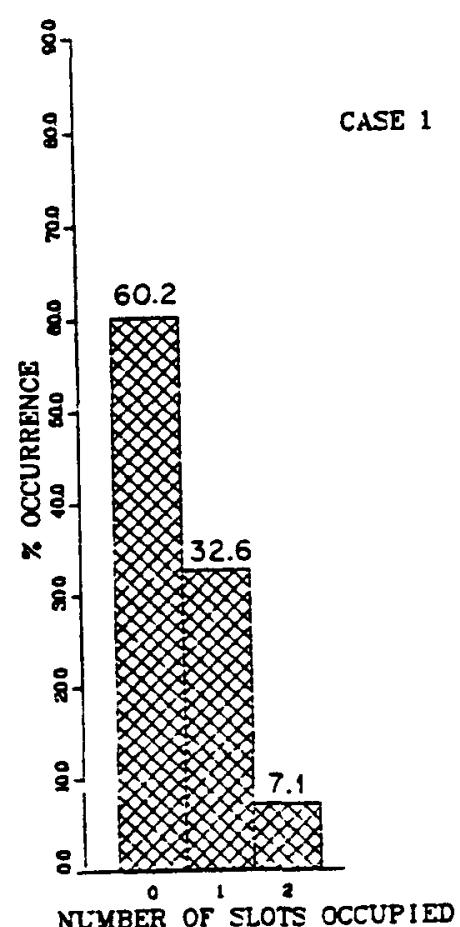

CASK ON- AND OFF-LOADING

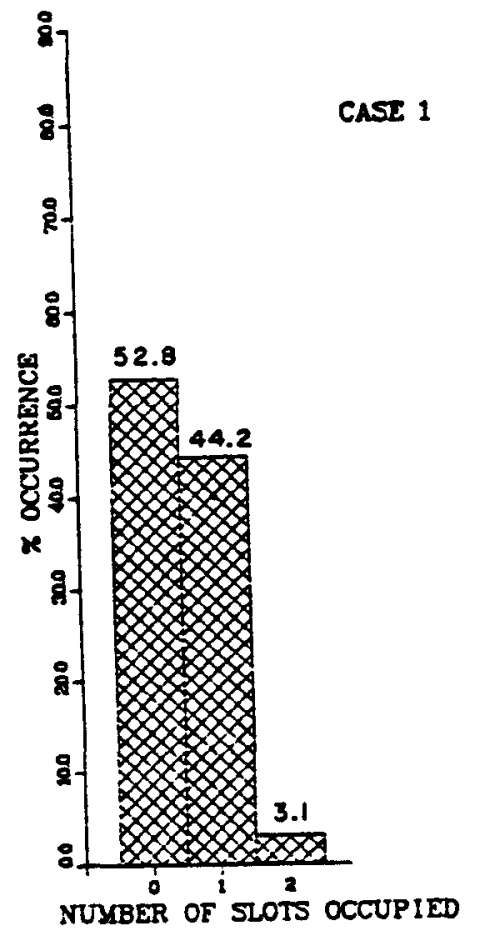

RAIL FUEL UNLOADING

FIGURE $4-7$

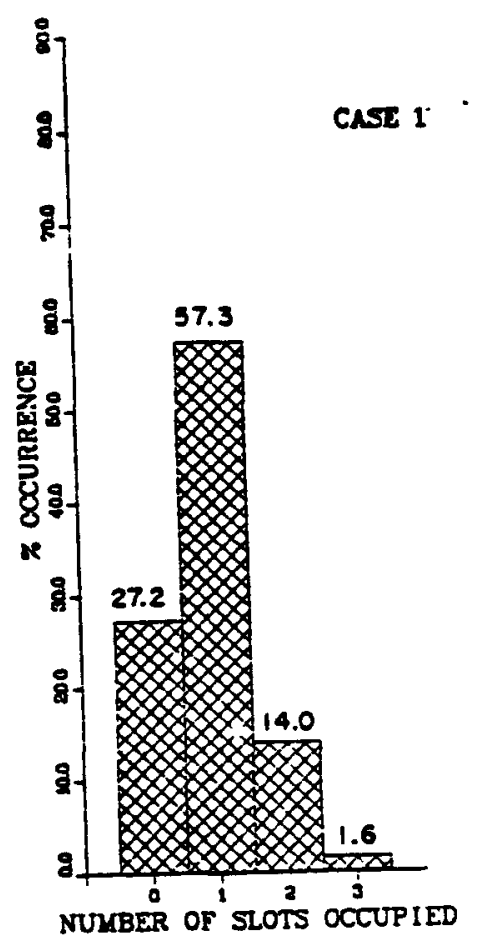

TRUCK FUEL UNLOADING

FIGURE $\quad 4-8$ 


\section{INTEGRATED FSF}

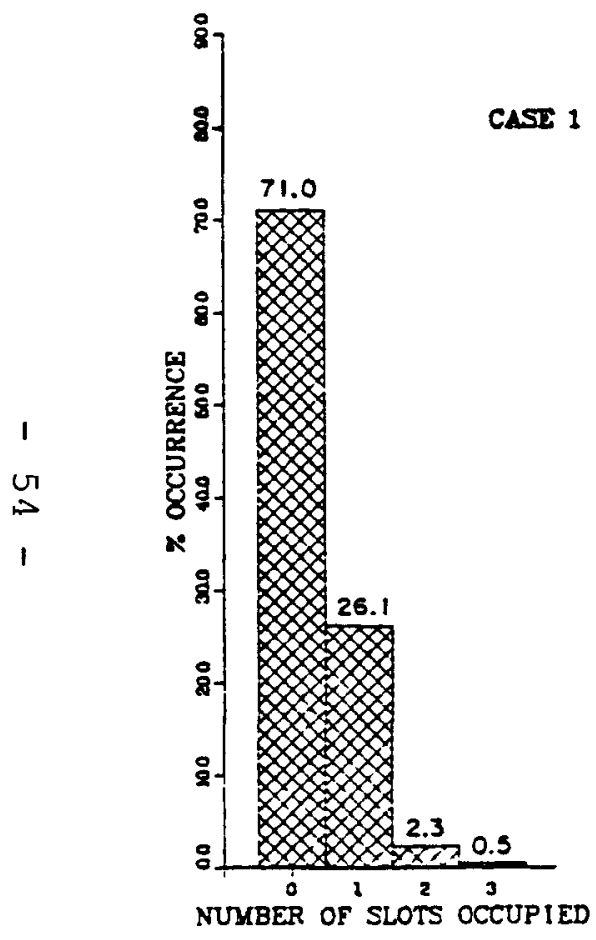

RAIL T\&R

F IGURE 4-9

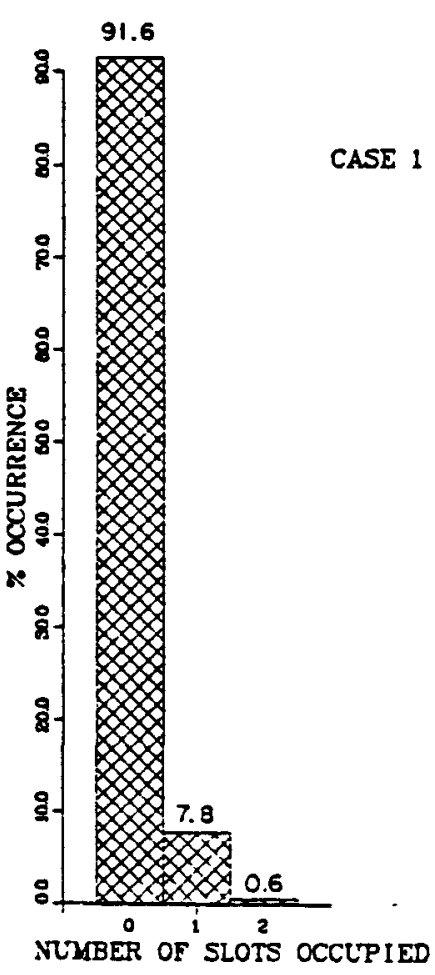

TRUCK T\&R

FIGURE $4-10$

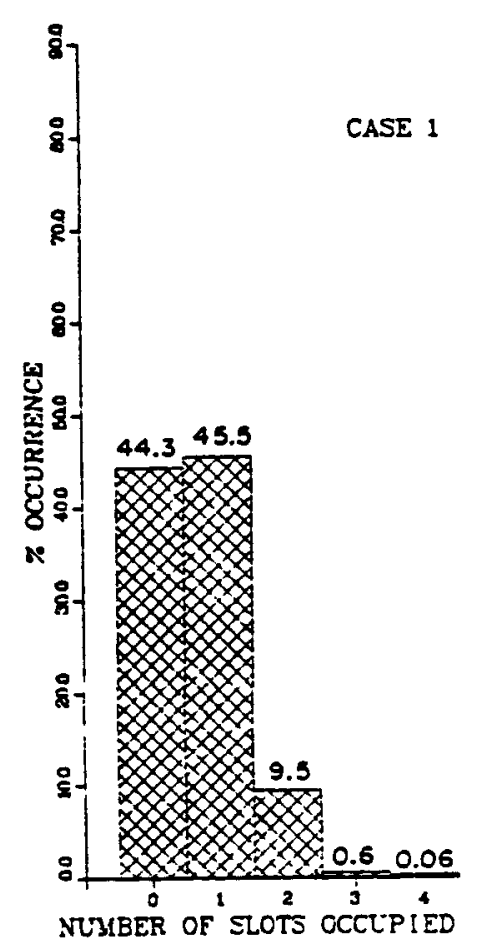

VEHICLE T\&I

FIGURE $4-11$ 


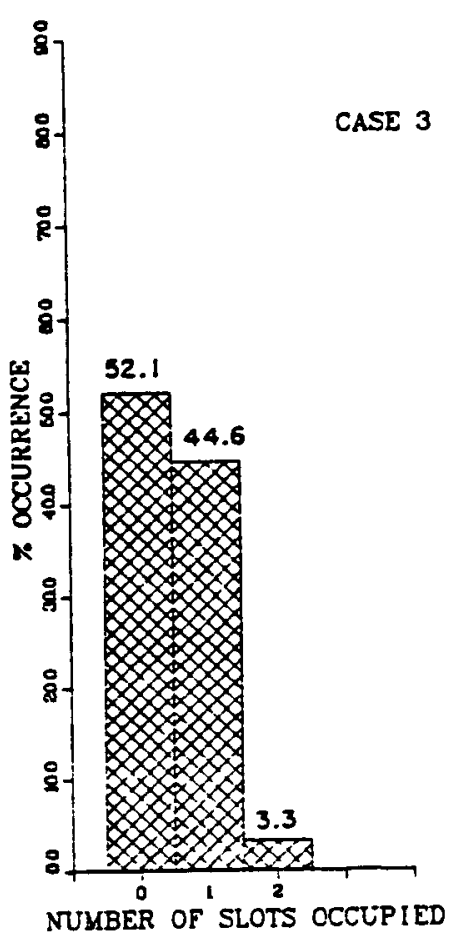

RAIL FUEL UNLOADING

F IGURE $\quad 4-12$

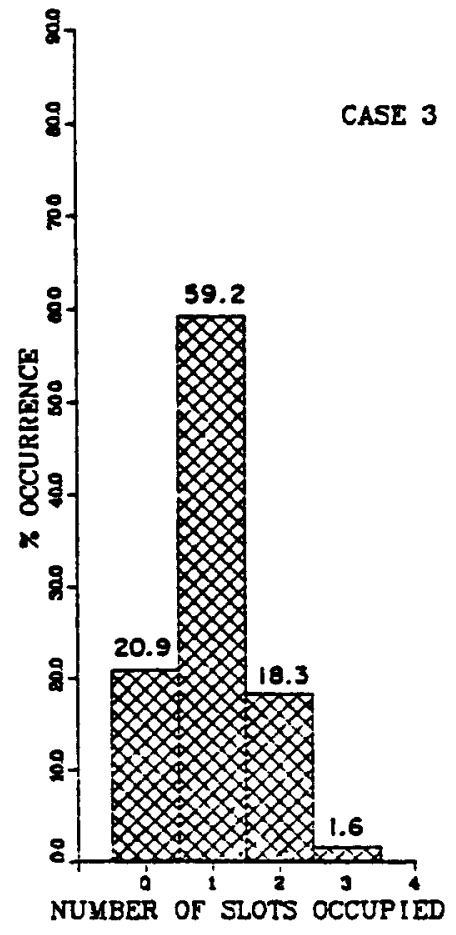

TRUCK FUEL UNLOADING

FIGURE 4-13

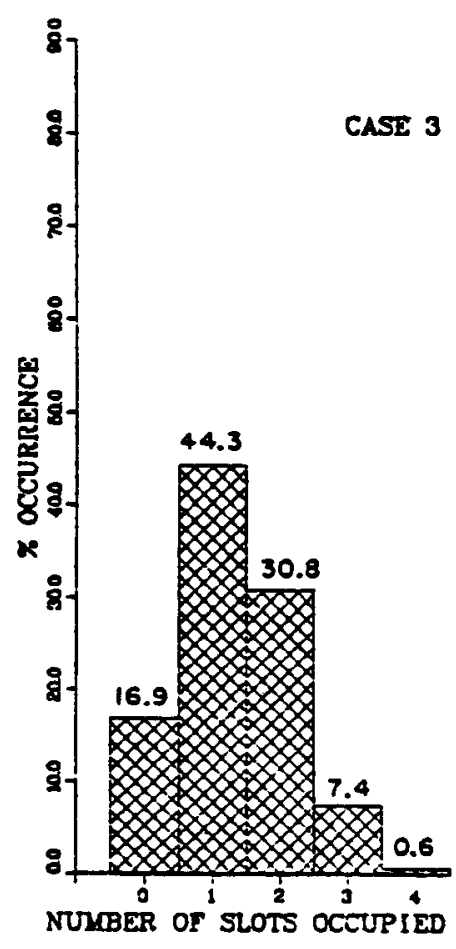

VEHICLE T\&I

FIGURE 4-14 


\section{INTEGRATED FSF}

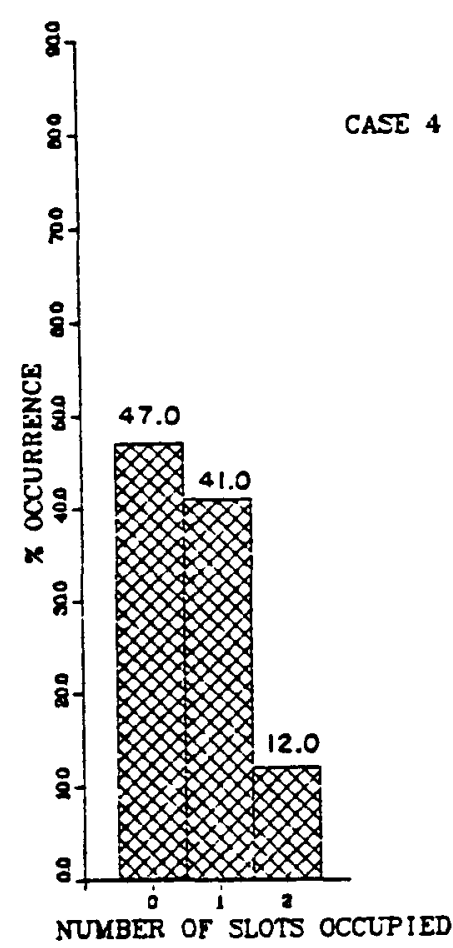

CASK ON - AND OFF-LOADING

F IGURE 4-15

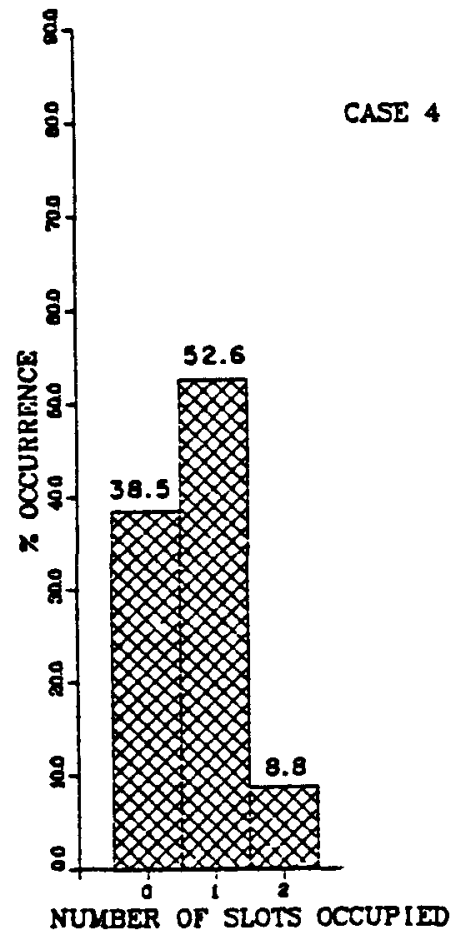

RAIL FUEL UNLOADING

FIGURE 4-16 


\section{INTEGRATED FSF}
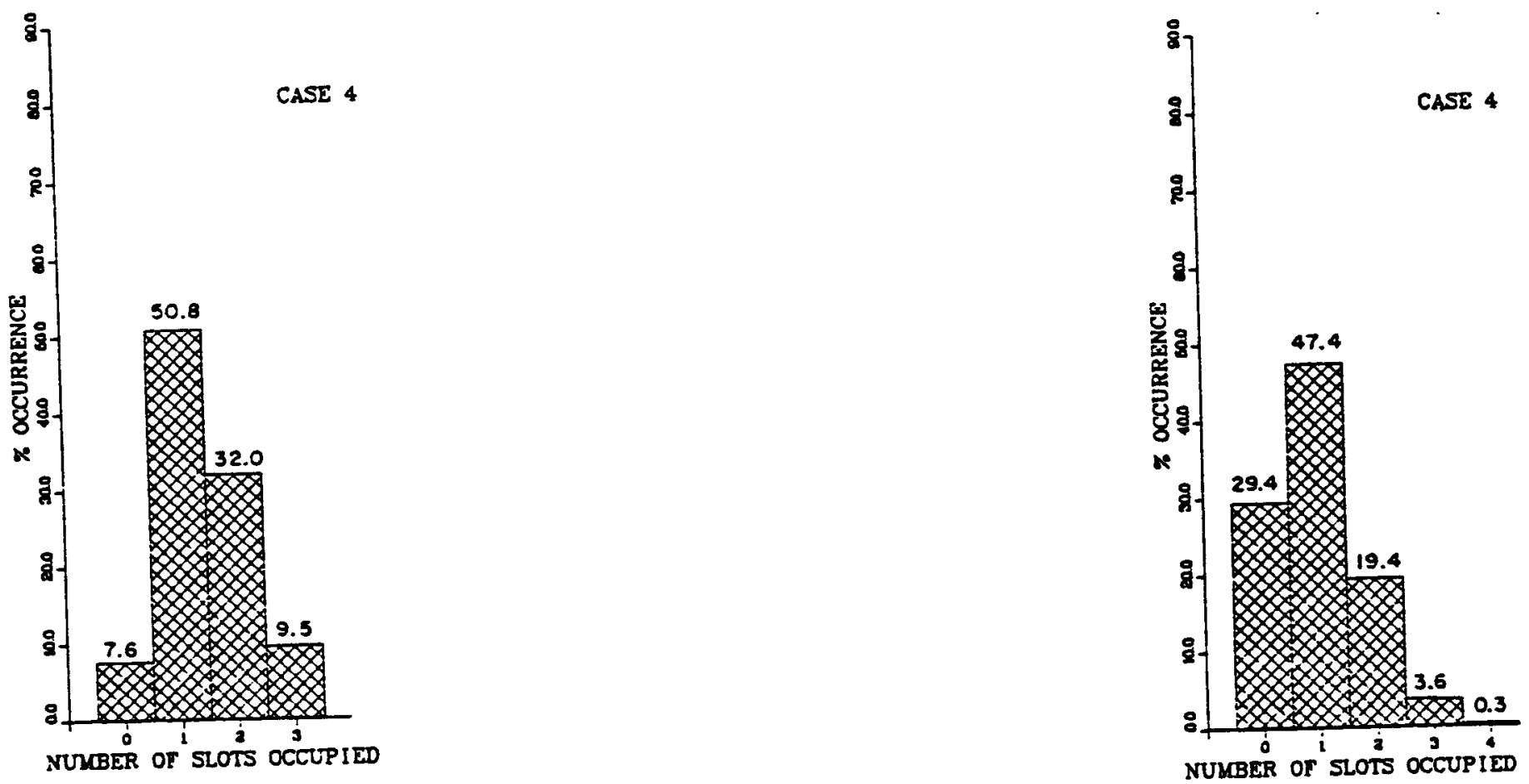

TRUCK FUEL UNLOADING

VEHICLE T\&I

FIGURE 4-17

F IGURE 4-18 


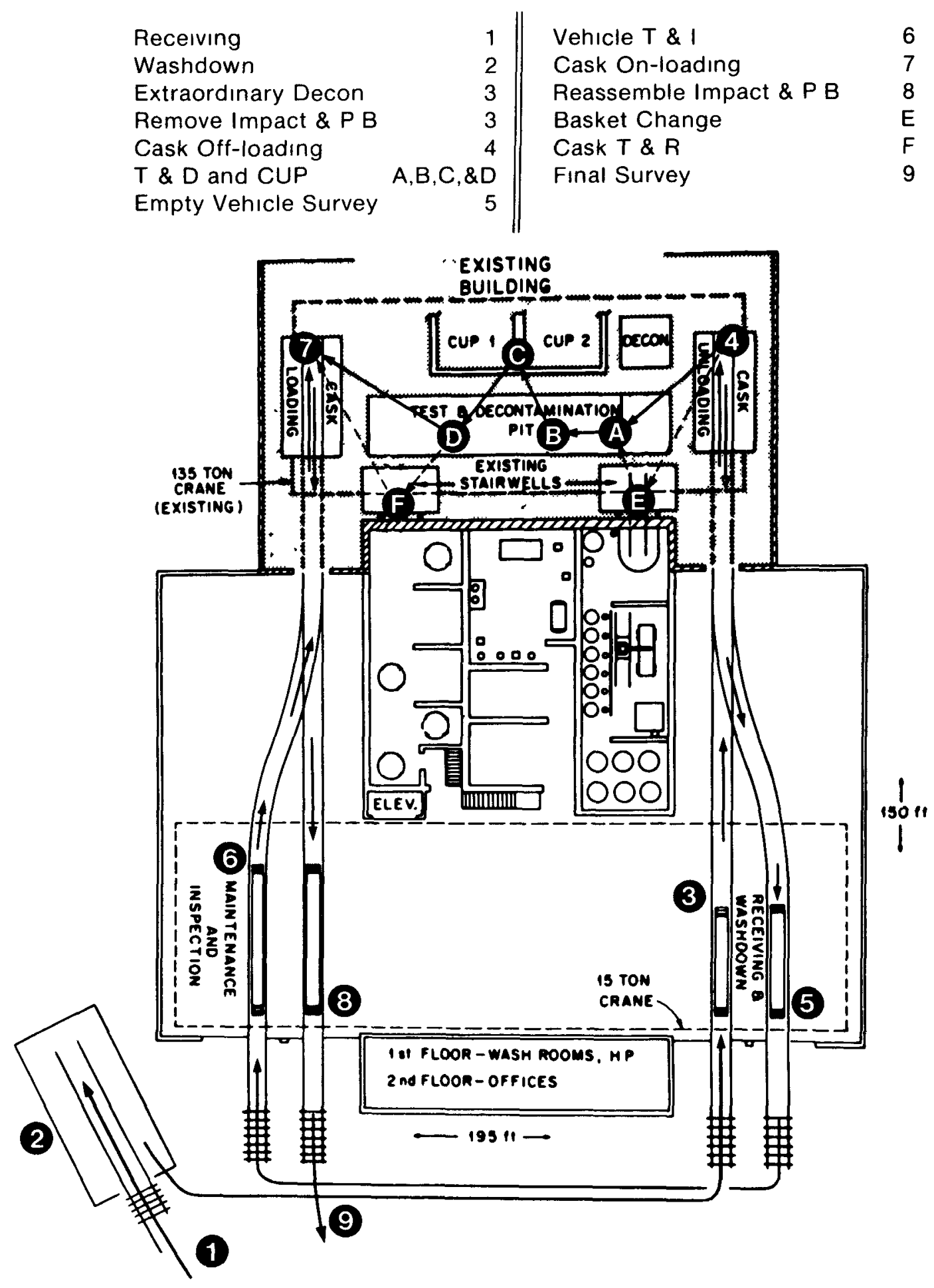

COLOCATED FSF AGNS-BNFP BARNWELL, S. C.

FIGURE $4-19$ 


\section{COLOCATED FSF}

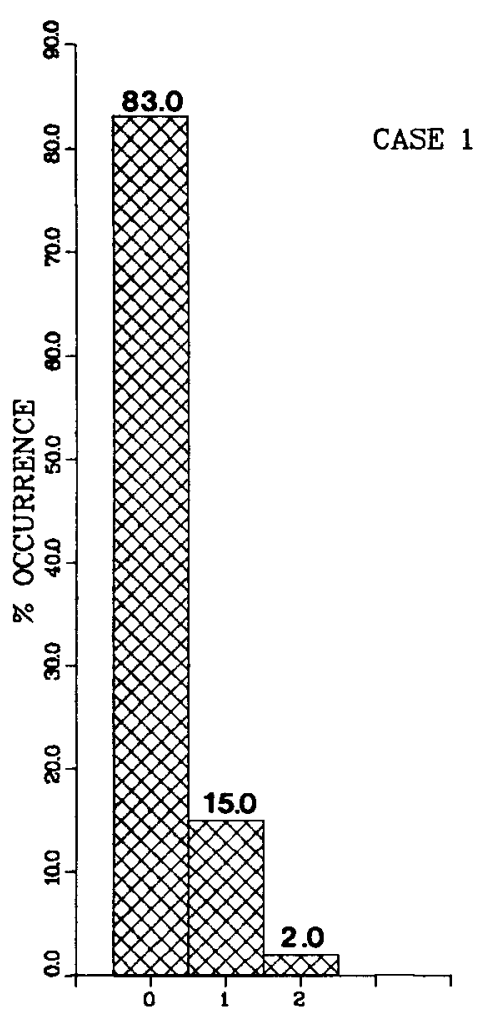

NUMBER OF SLOTS OCCUPIED

RECEIVING AND WASHDOWN

FIGURE 4-20

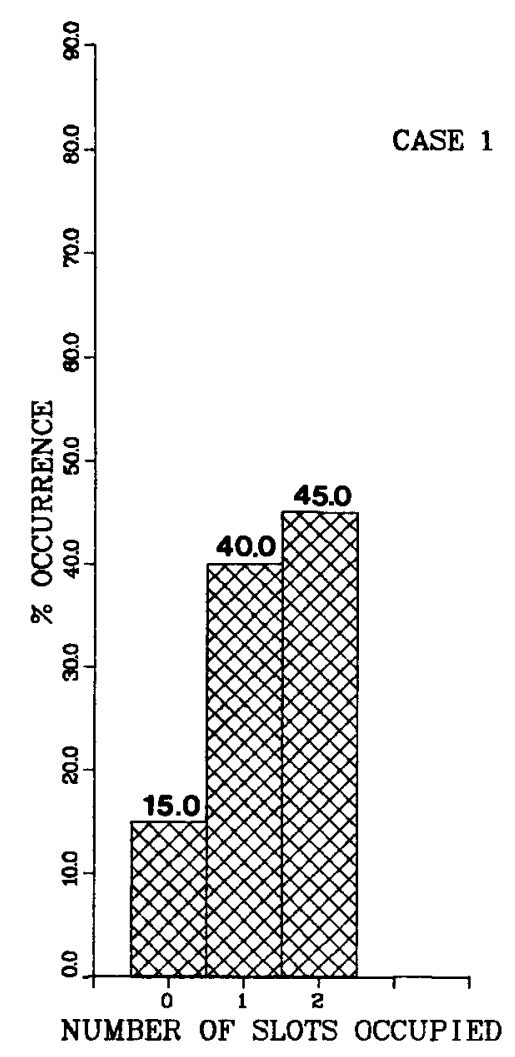

FUEL UNLOADING CUP

FIGURE 4-21

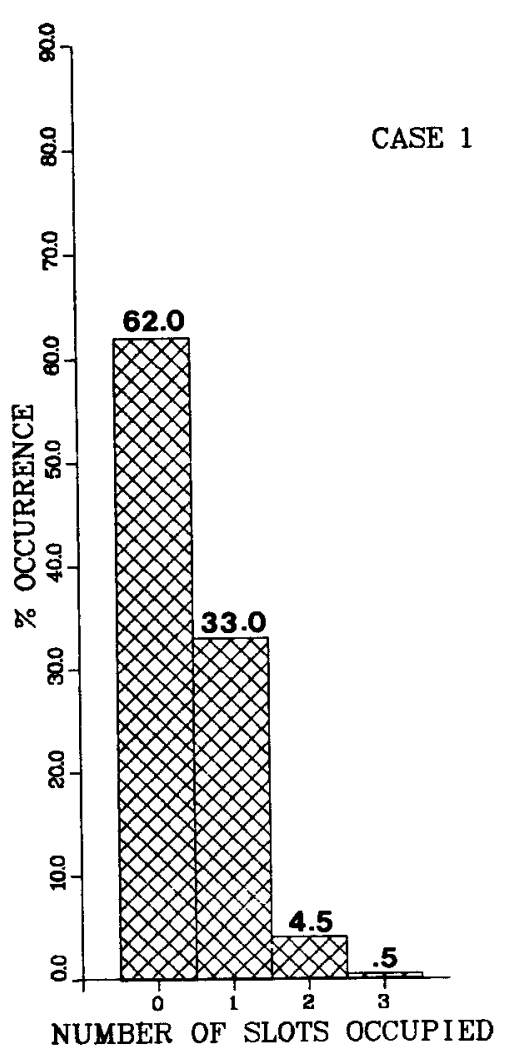

CASK T\&R

FIGURE $4-22$

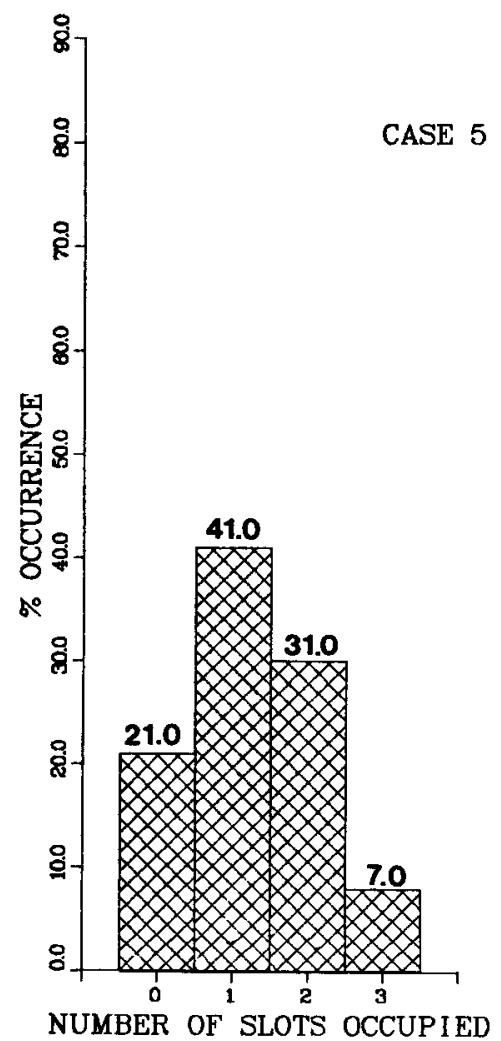

FUEL UNLOADING CUP

FIGURE 4-23 
BLANK PAGE

$-60-$ 


\subsection{COST ANALYSIS OF THE INTEGRATED \\ AND COLOCATED FSF CONCEPTS}

5.1 Cost Estimate of the Integrated Concept and Comparison to the Reference Independent (FSF) Concept

\section{1 .1 Scope}

This estimate covers the project costs for the construction of an Integrated Fleet Servicing Facility for receiving, inspecting, and servicing spent fuel casks and vehicles. This includes all facilities and equipment necessary for preventative/corrective maintenance and license compliance inspection services on casks, rail cars, and tractor trailer systems.

Facilities and services that are normally found at fuel receiving stations are not included in this estimate, because of the integrated nature of the concept.

\subsubsection{Assumptions}

In addition to the assumptions listed below, further information is provided in the Independent FSF study (2) and the Facility Description, Section 2, of this report.

- Facility is to be integrated with a fuels reprocessing plant.

- The companion facility will be designed for dry unloading and has a rated capacity of $2000 \mathrm{MTU} / \mathrm{year}$.

- No special provision is made for receiving extensively damaged casks but, once received, will be examined and a future course of action made on a case-by-case basis.

- Facility will handle existing U. S. certified casks and all casks presently undergoing certification.

- Facility will be Government owned; casks and carriers privately owned.

\subsubsection{Method of Estimating}

The estimate is based on drawings and specifications, conceptual design descriptions, and other back-up information provided by Design Engineers.

Material take-offs were made wherever sufficient detail was shown on the drawings. For certain work such as painting 
and finish items, allowances were included based on historical data.

\section{$5.1 .4 \quad$ Labor}

Labor rates were based on a typical southeast location. Detail and support for these rates are included in Tables 5-2 and 5-3. Construction of the Facilities has been assumed to be on a standard 40-hour work week and no allowance has been made for overtime or additional shifts.

\subsubsection{Material}

The cost of all material and equipment is FOB job-site, to be erected by an on-site Contractor. Pricing for construction materials and equipment was based on historical information from similar southeast construction sites.

$\underline{5.1 .6 \text { Sales Tax }}$

Sales tax, at 58 on materials, has been included in indirect costs.

\section{1 .7 Indirect Costs}

Indirect costs, including field distributables and payroll, burdens and mark-up (Fees), are shown on a separate summary. See Appendix D.

\subsubsection{Escalation}

All prices are based on third quarter FY 1979. Costs have not been escalated beyond that point.

\subsubsection{Contingency}

A contingency of approximately $30 \%$ was applied to the project, as presently defined. It is not intended to cover changes in scope, changes in Federal or state regulations, changes in location or changes in schedule.

\subsubsection{Cost Exclusions}

(1) Permits and Licenses

(2) Costs of any additional land

(3) Spare parts (except for installed equipment as listed and recommended by the manufacturer)

(4) Construction models of Facilities or equipment 
(5) Research and development except where considered a part of a purchase order to a Vendor.

(6) Government's administrative costs.

(7) Tornado resistant construction.

(8) Safeguard requirements in addition to those provided by the parent facility (FRSS).

\subsubsection{Contracting Method}

The method of contracting assumed is that the project will be let to a Cost Plus Fixed Fee Contractor with certain portions of the work subcontracted.

\section{1 .12 supporting Tables}

Table 5-1 is a summary of the project by budget category. Table 5-2 is a listing of craft wage rates used in this estimate.

Table 5-3 is a listing of composite crews used in this estimate.

Appendix $D$ is a detailed cost estimate.

\subsubsection{Cost Comparison of the Integrated FSF vs Independent} FSF

Table 5-5, page 71, presents a comparison of total project cost of the Integrated Design vs the Independent Design Spent Fuel Cask FSF. The probable cost of an Integrated FSF is about $\$ 13$ million, which is roughly half the cost of the reference Independent FSF.

\subsection{Cost Estimate of the Colocated Design Concept}

\section{2 .1 Scope}

This estimate covers the project costs for the construction of a colocated Fleet servicing Facility for receiving, inspecting, and servicing spent fuel casks and vehicles. This includes all facilities and equipment necessary for preventative/corrective maintenance and license compliance inspection services on casks, rail cars, and tractor trailer systems.

Facilities and services that are normally required and supplied at spent fuel receiving stations are not included 


\section{INTEGRATED FSF DESIGN CONCEPT PROJECT SUMMARY}

TOTAL \$ IN THOUSANDS

THIRD QUARTER FY 1979

Engineering Design

Land and Land Rights

Construction

Improvements to Land

New Building Costs

Bldg. Modifications

Special Facilities

Outside Utilities

Standard Equipment

SUBTOTAL

Contingency at $30 \%$ Approximate

TOTAL PROJECT IN THIRD QUARTER

FY 1979 IN THOUSANDS
1,580

$-0-$

8,120

90

4,190

$-0-$

3,710

20

110
9,700

$\underline{2,900}$

$\$ 12,600$ 
TABLE 5-2

LABOR RATES

CAPITAL LINE ITEM CONSTRUCTION SOUTHEAST USA

Craft

Insulator/Asbestos Worker
Boiler Maker
Brick Mason
Carpenter
Cement Finisher
Electrician
Electrician Helper
Iron Worker
Iron Worker Welder
Laborer
Millwright
Operating Engineer, Heavy Equipment
Operating Engineer, Medium Equipment
Operating Engineer, Light Equipment
Painter
Pipefitter
Pipefitter Helper
Sheetmetal Worker
Teamster
Roofer
Sprinkler Fitter

\begin{tabular}{|c|c|c|}
\hline $\mathrm{TH}$ & $\begin{array}{l}\text { PFF * RA } \\
\text { QUARTE }\end{array}$ & EY 1979 \\
\hline $\begin{array}{l}\text { Base } \\
\text { \$/hour }\end{array}$ & $\begin{array}{l}\text { Fringes } \\
\text { \$/hour }\end{array}$ & $\begin{array}{c}\text { Adjusted } \\
\text { Rate } \$ / \text { hour } \\
\end{array}$ \\
\hline 11.00 & 2.10 & 13.10 \\
\hline 11.25 & 2.20 & 13.75 \\
\hline 10.05 & .40 & 10.45 \\
\hline 6.30 & .40 & 6.70 \\
\hline 8.30 & .60 & 9.90 \\
\hline 10.60 & 1.65 & 12.25 \\
\hline 7.75 & 1.10 & 8.85 \\
\hline 10.30 & 1.35 & 11.65 \\
\hline 10.50 & 1.35 & 11.85 \\
\hline 6.05 & .50 & 6.55 \\
\hline 10.60 & .60 & 11.20 \\
\hline 10.20 & 1.10 & 11.30 \\
\hline 8.80 & 1.10 & 9.90 \\
\hline 8.20 & 1.10 & 9.30 \\
\hline 8.95 & .60 & 9.55 \\
\hline 11.75 & 1.10 & 12.85 \\
\hline 7.75 & 1.10 & 8.85 \\
\hline 10.35 & .50 & 10.85 \\
\hline 6.80 & & 7. \\
\hline 8.05 & .50 & 8.55 \\
\hline 11 & 1. & 13 \\
\hline
\end{tabular}

*CPFF - Cost Plus Fixed Fee. 


\section{TABLE 5-3}

\section{COMPOSITE CREW RATES SOUTHEAST USA}

Activity

Earthwork (Hand and Machine)

Concrete

Structural Steel

Electrical

Equipment Erection

Piping

Instrumentation

Demolition

Painting and Insulation

HVAC and Sheet Metal
Crew Rate

10.74

8.77

11.77

11.50

10.34

12.00

12.14

7.78

11.53

10.85 
in this estimate, because of the colocated/attached nature of the concept.

\section{2 .2 Assumptions}

In addition to the: assumptions listed below, further information is provided in the Independent FSF study (2) and the Facility Description, Section 2, of this report.

- Facility is to be colocated with the BNFP, FRS, Barnwell, South Carolina.

- The companion facility, BNFP, is designed for wet unloading with an assumed receiving capacity of $2000 \mathrm{MTU} /$ Year. *

- No special provisions are made for receiving extensively damaged casks but, once received, will be examined and the future course of action made on a case-by-case basis.

- Facility will handle U. S. certified casks as well as those currently in the certification process.

- Facility will be Government owned; casks and carriers privately owned.

\subsubsection{Method of Estimating}

The estimate is based on sketches and specifications, conceptual design descriptions, and other back-up information provided by Design Engineers.

Material take-offs were made wherever sufficient detail was shown on the drawings. For certain work such as painting and finish items, allowances were included based on historical data.

\section{2 .4 Labor}

Labor rates were based on a typical southeast location. Detail and support for these rates are included in Tables 5-2 and 5-3. Construction of the Facilities has been assumed to be on a standard 40-hour work week and no allowance has been made for overtime or additional shifts. Modifications to existing facilities (BNFP, FRSS) are to be accomplished while off-stream.

\footnotetext{
* This is in excess of the designed receiving rate of $1500 \mathrm{MTU} /$ year; however, $2000 \mathrm{MTU} /$ year is used to maintain a common capacity factor among the three FSF modes.
} 


\subsubsection{Material}

The cost of all material and equipment is FOB job-site, to be erected by an on-site Contractor. Pricing for construction materials and equipment was based on historical information from similar southeast construction sites.

\subsubsection{Sales Tax}

Sales tax, at $5 \%$ on materials, has been included in indirect costs.

\subsubsection{Indirect Costs}

Indirect costs, including field distributables and payroll, burdens and mark-up (Fees), are approximately 458 and 38 , the same as used for the Integrated Facility.

\subsubsection{Escalation}

All prices are based on third quarter FY 1979. Costs have not been escalated beyond that point.

\subsubsection{Contingency}

A contingency of approximately $30 \%$ was applied to the project as presently defined. It is not intended to cover changes in scope, changes in Federal or state regulations, changes in location or changes in schedule.

\subsubsection{Cost Exclusions}

(1) Permits and Licenses

(2) Costs of any additional land

(3) Spare parts (except for installed equipment as listed and recommended by the manufacturer)

(4) Construction models of Facilities or equipment

(5) Research and development except where considered a part of a purchase order to a Vendor

(6) Government's administrative costs

(7) Tornado resistant construction

(8) Utility tie-ins to be done by the Operating Contractor

(9) Safeguard requirements in addition to those provided by the parent facility (FRSS). 


\subsubsection{Contracting Method}

The method of contracting assumed is that the project will be let to a cost Plus Fixed Fee Contractor with certain portions of the work subcontracted.

\subsubsection{Supporting Tables}

Table 5-2 is a 1 isting of craft wage rates used in this estimate.

Table 5-3 is a listing of composite crews used in this estimate.

Table 5-4 is a summary of the project by budget category.

Appendix $\mathrm{E}$ is a detailed cost estimate.

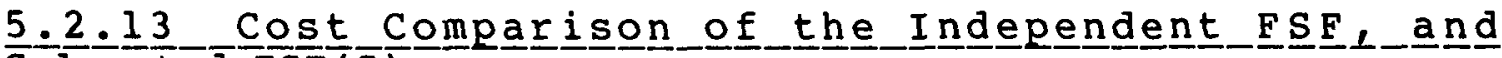
Colocated FSF (S)

Table 5-5 presents a comparison of total project cost of the Integrated, Independent, and Colocated spent Fuel cask FSF(S). The probable cost of the colocated FSF is about $\$ 16$ million, which is roughly two-thirds the cost of the reference Independent FSF.

5.3 A Summary Cost Comparison of the Three Fleet Servicing Facility Concepts (Independent, Integrated, Colocated)

The total project costs for the Independent FSF previously estimated in mid-year 1978 dollars was adjusted upward to third quarter 1979 dollars to allow a cost comparison in the same third quarter 1979 dollars of the Integrated and Colocated FSF(S). The self-sufficient Independent FSF was estimated at $\$ 26 \mathrm{M}$, Integrated at approximately $\$ 13 \mathrm{M}$ and the Colocated (attached to the BNFP, Barnwell, South Carolina) at approximately $\$ 16 \mathrm{M}$ which is summarized in Table 5-4. In using Table 5-5, the reader should be aware that the total capital costs of the Independent, Integrated, and Colocated FSF are comparable; however, there are significant differences in the individual portions that make up the total costs. For this reason, a direct comparison on an item-by-item basis should not be attempted; i.e., land and land rights cost is zero for the colocated Facility at BNFP, but it is a significant but unknown amount for the Independent Facility.

An example of a true cost difference is the main bay box crane in the Independent Facility at $\$ 770,000$ (direct) and 
COLOCATED FSF DESIGN CONCEPT PROJECT SUMMARY

TOTAL \$ IN THOUSANDS

THIRD QUARTER - FY 1979

Engineering Design

Land \& Land Rights

Construction

Improvements to Land

510

2,000

$-0-$

New Building Costs

Building Modifications

4,850

Special Facilities

Outside Utilities

140

3,850

440

standard Equipment

110

SUBTOTAL

11,900

Contingency at 308 Approximate

3,600

TOTAL PROJECT IN THIRD QUARTER FY 1979 IN THOUSANDS

$\$ 15,500$ 
TABLE 5-5

INDEPENDENT/INTEGRATED/COLOCATED FSF DESIGN CONCEPT COST COMPARISON

Engineering Design

Land and Land Rights

Construction

Improvements to Land

New Building Cost

Building Modifications

Special Facilities

Outside Utilities

Standard Equipment

SUBTOTAL

Contingency at 308 approximate

TOTAL PROJECT IN THIRD QUARTER FY 1979 S IN THOUSANDS
Total $\$$ in Thousands Third Quarter - FY 1979

\begin{tabular}{|c|c|c|c|c|c|}
\hline Independent & Design & Integrated & Design & Colocated & Design \\
\hline \multirow{4}{*}{$\begin{array}{r}500 \\
6,050 \\
-0- \\
9,900 \\
310 \\
410\end{array}$} & $\begin{array}{c}3,030 \\
-0-\star \\
17,170\end{array}$ & & $\begin{array}{r}1,580 \\
-0- \\
8,120 \\
\end{array}$ & \multirow{4}{*}{$\begin{array}{r}510 \\
4,850 \\
140 \\
3,850 \\
440 \\
110\end{array}$} & $\begin{array}{r}2,000 \\
-0- \\
9,900 \\
\end{array}$ \\
\hline & & $\begin{array}{r}90 \\
4,190 \\
-0- \\
3,710 \\
20 \\
110\end{array}$ & & & \\
\hline & 20,200 & & 9,700 & & 11,900 \\
\hline & 6,100 & & 2,900 & & 3,600 \\
\hline & $\$ 26,300$ & & 12,600 & & $\$ 15,500$ \\
\hline
\end{tabular}

*Not included in scope of the estimate. 
in the Colocated Facility at zero because of shared use of the existing BNFP crane.

The Integrated Facility cost estimate is zero for demolition and/or relocation work in land improvements, building modifications, special facilities, and outside utilities; but in the Colocated Facility cost estimate, these categories have substantial dollar amounts. 


\subsection{CONCLUSIONS AND RECOMMENDATIONS}

(1) No facilities presently receiving, or capable of receiving, spent fuel have FSF capabilities, nor are there any "third party" facilities providing all these needed services to casks, rail cars, and/or tractortrailers. This lack of capability in the $U$. S. is of concern to GAO. Thus, a need is indicated for FSF's, or their equivalent, at the various sites to provide high quality servicing, maintenance, and requalification of transportation systems by an organization independent of owners or users.

(2) The development of independent and integrated FSF concepts is useful in establishing the anticipated maximum-to-minimum capital cost range for a facility capable of performing the functions described in Sections 2.2 and 3.2 .

(3) The estimated capital costs for independent, integrated, and colocated FSF's are approximately $\$ 26 \mathrm{mil}-$ lion, $\$ 13$ million, and $\$ 16$ million, respectively, in 1979 dollars.

(4) Since an FSF is envisioned as providing servicing, maintenance, minor repair, testing, and requalification services in or near a parent facility, a transportation system will be inspected and requalified to the extent required each time it is turned around. Present practice does not feature this coordinated approach since as many as three or four different and widely separated groups provide some minimal functions but not to the depth that would be accomplished at an FSF.

(5) Cask out-of-service (and, consequently, out-ofrevenue) time will be reduced to a minimum for an integrated or a colocated FSF for two reasons; namely, transportation time to a remotely located service site will be eliminated; in addition, services and tests at an FSF (including an independent FSF) would be performed by experienced crews performing the work as their primary function rather than as an occasional secondary job as is expected to be the case at a nondedicated remote service facility.

(6) Cask requalification compliance applies to each significant component of a cask system, not just a single cask body. As fleet sizes grow and components may increasingly be interchanged, a central control system at each FSF may provide compliance assurance more 
economically than can a number of small, decentralized, single purpose facilities. Additional studies are needed to quantify the importance of the central control system concept.

(7) An FSF colocated with the BNFP should approach very nearly the theoretical capital cost and efficiency of the integrated concept for spent fuel systems.

(8) Since the FSF concept provides a positive response to the criticism of the GAO regarding cask maintenance, it is recommended that studies continue on the FSF with greater emphasis placed on the more feasible near-term concepts. Initially, a GPSS analysis of the independent FSF concept is needed to support a complete examination of logistic and optimization studies of the three concepts. Following these studies, a detailed analysis of the operating costs of the facilities must be made. In the near term, the establishment of an FSF colocated with an existing facility may prove to be advantageous. For the longer range, an FSF integrated into an appropriate facility may prove to be the most efficient and least expensive. The above mentioned studies would be expected to strongly influence the most feasible concepts that should be carried through to a more detailed design study.

(9) Cask owners and carriers should be contacted to determine their interest and participation in FSF design, construction, and/or operations, as well as ownership and funding options.

(10) A cost analysis of potential return-on-investment for an FSF is warranted. This should include a fleet-size/cask-flow sensitivity analysis.

(11) Any further studies or design work on FSF's should provide for transport systems in addition to those for spent fuel (i.e., high-intermediate-, and low-level wastes, TRU, etc.). 


\subsection{ACKNOWLEDGMENT}

The authors wish to acknowledge and thank James $P$. Duckworth and Staff (Nuclear Fuel Services, Inc., West Valley, New York); James H. Nordahl and Staff (Exxon Nuclear Projects, Bellevue, Washington) and Eugene E. Voiland and Staff (General Electric, Morris, Illinois operations) for their informal review and comments on the Integrated FSF Concept. 


\section{BLANK PAGE}




\subsection{REFERENCES}

1. General Accounting office (GAO) report, "Federal Actions are Needed to Improve Safety and Security of Nuclear Materials Transportation," EMD-79-18 (May 1979).

2. AGNS-1040-1.5-48, September 1978, P. M. McCreery, et al, "The Conceptual Design of a spent Fuel Cask Fleet servicing Facility."

3. General Purpose simulation system, International Business Machines, New York, New York.

4. General Accounting Office (GAO) Report, "The Nations Nuclear Waste -- Proposals for Organizing and Siting," EMD-79-77 (June 21, 1979). 


\section{APPENDIX A \\ DESCRIPTION OF THE INTEGRATED \\ FLEET SERVICING FACILITY AREAS}




\subsection{DESCRIPTION OF THE INTEGRATED FACILITY AREAS}

\subsection{Washdown}

The washdown bay serves three purposes, namely:

- Road dirt and film are removed from the transportation systems allowing the effluent water to be controlled

- It serves as an air lock between the fuel unloading bay and the outside

- Since it has a capacity of 4 rail cars, it provides indoor storage for the next cars in the queue during inclement weather.

Equipment in the washdown bay includes:

- Water hose system

- Steam

- Solvent storage bins

- Grit blaster

- Hold tanks with provision for sampling liquids and solids prior to discharge

- Wet vacuum system.

\subsection{Off-Loading/Loading Bay}

This is the vehicle end of the high crane bay. In this area:

- Impact limiter and personnel barriers, if the removable type, are taken from the cask/vehicle and stored in the space provided

- Either crane system can be used in these operations

- Casks are off-loaded from and reloaded onto their vehicles

- Large spare parts, such as extra impact limiters and lifting yokes, are stored here

- Sufficient space is allowed for crossover of rubber-tired vehicles to expedite unit flow around rail cars standing in the two air locks. 


\subsection{Equipment}

- A 15-ton bridge crane serves this area exclusively.

- About 3200 square feet of storage area is provided.

- Partial use is made of the 150-ton high bay crane (30-ton auxiliary hook).

1.4 High Crane Bay

Whenever a cask is being moved between the transport vehicle and a work station, whether for unloading or maintenance, it will be handled by the high crane. Rail casks and overweight truck (OWT) casks must be lifted using the 150-ton hook, but legal weight truck (LWT) casks can be handled with either hook. Vertical travel distances have been kept to a minimum so the higher vertical speed of the 30 -ton hook is of little advantage in selecting one hook over the other for LWT handling. The primary advantage is that less time lost in changeout of lifting yokes might be realized if the 30-ton hook is used frequently for LWT's.

The crane should be radio-controlled and should have a freewheeling option on the trolley. The latter is an important safety item when rotating casks between horizontal and vertical during loading/off-loading operations. The freewheeling feature automatically centers the suspension system directly over the lifting trunnions throughout the rotation and precludes the horizontal force vectors that develop during manual positioning of the trolley.

\subsection{Vehicle Maintenance/Inspection}

In the exit air lock, the complete cask/vehicle system will undergo a thorough inspection with appropriate preventative and corrective maintenance. Each system will have had prepared for it a unique, detailed checklist of items to accomplish, and all will be performed before the system is released. Servicing may include visual checks for leaks in hydraulic lines, magnetic particle inspection of high stress areas of vehicle frames, welding of structural components, and changing wheels or bearings on rail cars. Engines which drive cooling systems can be exchanged as a part of a preventative maintenance program, with the engine just removed being serviced while the replacement is on the road. Touchup painting, lubrication, etc., would be done as well as anything else to assure first class running condition and good physical appearance when the vehicle leaves the facility. 
A manway inspection trench runs between the tracks to facilitate inspections and maintenance on the underside of the vehicles.

The inspection and maintenance area will require storage cabinets for the chemicals needed for liquid penetrant examination plus storage for clean rags. A magnetic particle testing machine will also be required.

The temperature of this area is maintained at a minimum of $40^{\circ} \mathrm{F}$ to facilitate the performance of liquid penetrant examinations. Should this facility be located in an area which experiences extremely cold winters, it may become necessary to provide an auxiliary method of raising metal temperatures to a range permitting normal liquid penetrant examination.

No requirements for eddy current or radiography of vehicle components are presently contemplated; however, if eddy current examination should be required, the test area is adequately sized to accommodate a machine of the required dimensions.

\subsection{Cask Tests and Inspections}

The tests and inspections which are anticipated for the casks fall into five basic categories:

- Pressure or leakage tests

- Thermal conductivity checks

- Radiation monitoring

- Load testing of supporting appendages

- Visual or nondestructive testing for discontinuities.

These tests would be performed in the test and repair (T\&R) stalls located in the high crane bay of the building. In the rare instance that radiography would be required, it is proposed the cask or auxiliary equipment be moved to the Cask and Insert Cleaning Area where shielding walls would most probably permit the radiography to proceed without interruption of the facility routine.

All cask testing will require a systems approach which will assure that the tests are scheduled and performed in accordance with the requirements of the latest license amendments. Additionally, the performance of visual and other nondestructive types of examinations will require the use of qualified operators performing to qualified procedures and interpreting results to preestablished standards of acceptance.

Pressure or leakage testing will require an assortment of indicating devices such as pressure gauges, combination 
vacuum and pressure gauges, thermometers, thermocouples, with associated read-out devices, pressure relief valves, and standard electrical measurement equipment. Additionally, the necessary standards and the equipment for calibrating and maintaining calibration of the test equipment will be required as well as demonstrated procedures for performing the calibrations (i.e., QA aspects of the test requirements would be addressed).

Load testing of cask appendages or cask lifting equipment necessitates development of hydraulically operated loading devices which may be calibrated to correlate pressure measurement to applied force. Test weights will be needed to provide additional weight for load testing of some cask cover lifting lugs and similar light-load handling equipment. Appropriate dimensional measurement devices will be needed for distortion measurement, and the standards for their calibration will be required.

Cask thermal tests normally require heating devices, measurement devices to monitor electrical input to the heating devices, and thermocouples and associate readouts or recorders to monitor the cask thermal conductivity at specified points. The use of pyrometers is also indicated in some instances.

Tests required for each cask will be made a part of the data base so that printouts for any given future period will list the cask to be tested and the specific test(s) to be performed within that period. The data base also will include past results of all tests.

\subsection{Internals Handling}

United States designed casks are capable of hauling either PWR or BWR fuel. To accomplish this, fuel baskets of the same OD but with different fuel cavity configurations are interchanged as needed in any given cask. After a cask has been in service for some time these baskets may become quite radioactive from "crud" which flakes off fuel assemblies. As the need arises to change internals, these hot baskets must be handled remotely in a manner that will minimize the dose to operators. The baskets will be cleaned before being stored, for obvious reasons.

The cask and insert cleaning area consists of three general sections. First, there is a cask set-down pit, accessible to the main crane. The pit is about 12 feet deep so that a typical cask will rest with its head at a convenient working level to operators standing at elevation 0 . Adjacent to the cask well is an area for temporary storage of closure heads, spacers, etc. The second section of this area is a basket 
cleaning station. Provision is made for cleaning the basket fuel cavities in the vertical position and exteriors in the horizontal position. The latter feature is necessary because some basket structures retain crud when washed in the vertical position. All cleaning is designed for remote operation for personnel protection. The third section is for basket storage. Individually covered cells of various sizes are provided to accommodate any basket now in use or contemplated for the foreseeable future.

This entire area is covered for ventilation control. A sliding door with an inflatable seal permit bringing casks into and out of the area. Material handling inside the area is by bridge crane with a trolley span the full width of the area and bridge travel the full length.

When baskets are removed from casks, the opportunity is presented for removing crud from the cask cavity bottom. Equipment is provided for brushing and water-vacuum cleaning of casks at that time.

\subsection{Provisions for Decontamination}

There are four locations within the facility for decontamination. One is in the washdown area where the manual decontamination of small areas can be accomplished. Another is the test stalls where the entire cask surface can be cleaned with the assistance of pressurized liquids and surface leaching agents. These stalls are equipped with demineralized water, steam, air, and a wet vacuum system. The open side of each stall can be closed with a plastic curtain. Separate ventilating hoods are provided. A third location is the cask insert cleaning area. The fourth location is one in which smaller parts are cleaned to unconditional release limits. This permits expensive but defective parts to be returned to their manufacturer for repairs. It also may be used to salvage tools which may have become contaminated and, in general, to reduce the quantity of material sent to burial sites for disposal. This location is provided with both ultrasonic and electrolytic cleansers and conventional decontamination equipment such as large, deep, stainless steel sinks, fume hood, stainless steellined curbed pad with floor drain, and the standard utilities.

Sinks used for the decontamination of equipment, tools, etc., will be made of noncorrosive material and should have approximate dimensions of 42 inches by 36 inches by 20 inches. Sinks will be supplied with hot and cold water and drain to a liquid radwaste system. A stainless-lined pad is provided to drain liquid radwaste also. The fume hood can be of standard chemical-handling design as is found 
in any scientific equipment supply sales catalog. Utilities include, in addition to hot and cold water, house steam, air, vacuum, and both 110- and 220-volt electrical outlets.

\subsection{Fuel Unloading Area}

The pits and unloading stations shown in Figures 2-1 and 2-2 are not considered a part of the FSF. They are shown only to provide some concept of the overall cask handling operations so that a more complete analysis General Purpose simulation system (GPSS) of the system can be made.

\section{$\underline{1.10}$ Waste Service Area}

A special area is provided for the initial treatment of the high concentration of radioactive waste in the "crud" removed from cask walls and internal adapters. The crud is filtered and prepared for shipment to a burial site while the filtrate is sent to the parent plant radwaste system.

\section{$\underline{1.11 \quad \text { HVAC }}$}

The Heating Ventilating/Air Conditioning (HVAC) are extensions of those provided by the parent facility.

\subsection{Cask Repair}

It is expected that the FSF will be capable of repairing damaged casks. However, casks damaged so severely that they cannot be opened in a normal way will be considered on a case-by-case basis. The contents of the casks; spent fuel, high level wastes, etc., will be a major consideration as to how it is opened and the kind of area needed to perform the opening or repair operations. The E-MAD Facility in Jackass Flats, Nevada, might serve as a central repair station. A facility with water-filled pits might also be used, if justified. 
APPENDIX B

GENERIC OPERATING PROCEDURE FOR THE INTEGRATED FLEET SERVICING FACILITY 


\section{INTRODUCTION}

The concept of the Fleet servicing Facility (FSF) is unique only in that the requisite cask servicing is performed under a central control system rather than by individual cask owners. A logical extension of this function in an Integrated facility is to merge cask servicing control and operations scheduling. This operating procedure is premised on that type of organization.

The maintenance and the requirements for continuing requalification of each cask are peculiar to each cask model and these are delineated in the Safety Analysis Report of that model. Each cask owner will have prepared standard testing procedures along with specific acceptance criteria for his casks. These procedures become a part of the FSF's operating procedure when servicing any given cask. Transportation vehicles shall be inspected to owner-approved (or ownersupplied) standards.

This operating procedure further assumes an automated data system which provides individually or collectively the due dates for inspection or requalification of each component of each cask, continuously updated as inspections are satisfactorily performed. This would provide an appropriate agency an independent check of all operating transportation systems which can, in turn, be used to assure various state agencies that standards have been met. (These procedures apply whether the FSF is Independent, Integrated, or Colocated.) 


\section{PROCEDURE}

\subsection{Incoming Inspection}

1.1 Verify that the Bill of Lading and the Trip Pack* information is that of the vehicle being readied for receipt.

1.2 Visually check the cask/vehicle system for damage. If safety-related damage is noted, notify FSF supervisor for instructions regarding continuing work or removal from queue awaiting concurrence of cask owner for course of action. Advise scheduler of nonsafetyrelated damage so that action may be initiated to accomplish the necessary repairs.

1.3 Perform an initial instrument survey $(\beta, \gamma, n)$ of the cask/vehicle system. Compare readings with those on the Trip Pack and notify supervisor of differences greater than two times shipper's value or in excess of DOT 1 imits.

1.4 Weather permitting, take initial contamination smears $(\alpha, \beta, \gamma)$ of cask and vehicle while the system is still outside the building. If system is wet or covered with ice, it will be brought into the washdown bay to thaw and/or dry before smears are taken. (Do not wash down the system to expedite thawing.) The system will not be washed down before smears are taken.

1.5 Remove security seals from the personnel barrier and compare with Trip Pack information.**

1.6 The scheduling group shall assign a processing sequence number and identify the cask model that this number represents. This group will then issue instructions for assembling at various locations the appropriate operating procedures, test instructions, and certification forms, check lists, and tools to be used.

*This terminology is used to identify the paperwork relating to cask and vehicle radiation physics data for a given trip.

**Throughout this procedure it is understood that when comparisons of this type result in conflicting data, the supervisor is to be consulted for instructions prior to proceeding. 


\subsection{Washdown}

NOTE: If cask/vehicle contamination exceeds DOT limits, the routine washdown operation is omitted and the cask and vehicle are decontaminated separately. See Section 11.0 .

2.1 Thoroughly wash the cask and vehicle with water, using no greater flow or pressure than is necessary to dislodge and remove road dirt. Road tar, etc., is to be removed by manual cleaning using appropriate solvents.

2.2 Remove paint from areas for which bare-metal inspection has been designated (by Scheduler) or from rusted areas in need of repainting.

2.3 Do not release contents of washdown hold tank until analyses of samples therefrom are available to determine disposition. Log volume, concentration, and disposition for each discharge from the hold tank.

2.4 When washing down a transport system, do not allow splashing onto cleaned cars still in the bay.

3.0 Off-loading from Vehicle

3.1 Attach to the appropriate lifting hook the cask 1 ifting yoke required for the cask to be off-loaded.

3.2 Verify that the assembled set of tools is the appropriate set for the cask to be off-loaded. Check tool inventory against check list.

3.3 If a sit-down area is needed for impact limiters or personnel barriers, make sure that an accessible, unimpeded space is available in an area served by the crane to be used in handling these items.

3.4 Following the cask owner's instructions, remove the detachables from the cask and lift the cask from the vehicle. Transport it without delay to the designated handling pit.

\subsection{Preparation for Unloading Fuel}

4.1 Compare head security seal identification with information given in the Trip Pack.

4.2 Verify that the assembled set of tools is the appropriate set for the cask being processed. 
4.3 As each part is handled, visually examine it for damage or excessive wear. Advise the Scheduler of deficiencies via an intercom system so that repairs or replacements can be arranged.

4.4 Secure the cask to the transport dolly.

4.5 Obtain cavity pressure readings to ascertain that damaged fuel has not resulted in higher-than-normal pressures.

4.6 Obtain samples of cavity fluids as required. Do not proceed until sample analysis results are available and instructions are given by the supervisor for the disposition of the fluids.

4.7 Remove outer head (if one is used) and place it on the appropriate head stand. Be careful not to damage the seal or the sealing surface. Assume that the underside of this head is heavily contaminated and handle it accordingly. Repeat step 4.5 for two-headed casks.

4.8 Fit the contamination barrier over the cask.

4.9 Loosen head fasteners, attach head lifting devices, install head guide pins (if required) plus any other remote handling aids.

4.10 Move the cask into position under the unloading port.

4.11 Elevate the cask to the sealing position and secure the cask to the port.

$5.0 \quad$ Fuel Unloading

NOTE: This section is not intended to be a complete guide for the dry unloading of fuel from a cask. Only those functions affecting cask integrity or routine inspections are addressed.

5.1 Remove the plug from the unloading cell and place it on its storage stand.

5.2 Attach the unloading hook to the special lifting bracket on the head and 1 ift the head so that the underside is available for inspection through the view port.

5.3 Using a telescope through the view port, examine the head for damage or excessive wear to the seal ring or 
the sealing surface, "dinged" bolt holes or guide pin slots. Advise Scheduler as in Section 4.3.

5.4 Place the cask head on the head stand.

5.5 Unload all the fuel.

5.6 Vacuum loose particulate matter from the exposed cask surfaces. Be especially certain to remove matter from the sealing surfaces.

5.7 Traverse a gamma probe the length of a centrally positioned fuel cavity. Advise the scheduler of its highest reading and the elevation at which that reading is obtained.

5.8 Replace the cask head.

5.9 Replace the unloading port plug.

6.0 Cask Removal From Pit

6.1 Release the cask from the port.

6.2 Retract cask to low position on the dolly and move dolly from beneath the cell.

6.3 Remove head lifting bracket, remove or replace head guide pins, and replace the head fasteners. All tools, brackets, etc., are to be wiped clean prior to returning to storage.

6.4 Decontaminate exposed cask surfaces as required to meet release limits.

6.5 Remove the contamination barrier from the cask.

6.6 Install the outer head (if one is used).

6.7 Fit the appropriate lifting yoke onto the crane.

6.8 Release the cask from the dolly tie-down.

6.9 Attach the yoke to the cask and lift the cask from the pit.

7.0 On-Loading Empty Cask Onto Vehicle

NOTE: During the interval in which the cask has been separated from the vehicle the latter will have been inspected and its roadworthiness assured. The vehicle maintenance procedure is delineated in 
Section 10.0. Chronologically it precedes this section.

7.1 Position the vehicle to receive the cask.

7.2 Place cask on vehicle and assemble impact limiters, personnel barrier, etc., in accordance with cask owner's instructions.

7.3 Get final smears of cask and vehicle prior to release.

7.4 Record radiation data on a new Trip Pack which has been supplied by scheduling for this specific cask.

7.5 Place security seals on personnel barrier and record seal numbers on the Trip Pack in the space provided.

\subsection{Release Authorization}

8.1 Prior to releasing a cask system, the appropriate records for each component of the cask system will have been updated and monitored for exceptions. Cask history files shall have been updated within 24 hours of the completion of the final inspection step.

8.2 The Trip Pack which was initiated by scheduling shall be signed off by a representative of the Health Physics group, certifying that contamination levels of the system are within release limits. It also shall be signed off by a representative of Quality Assurance certifying that all tests and inspections have been performed in accordance with current procedures, the results of these inspections meet or exceed the stated acceptance criteria, and that the cask meets all certification requirements and will continue to do so for a time appropriate to the maximum anticipated duration of its assigned trip.

8.3 If a cask is to be delayed in departing to its next assignment, scheduling shall review needed upcoming tests and, with the concurrence of the cask owner, use this available dead time for requalification testing.

\subsection{Cask Testing and Inspection}

9.1 When a cask system enters the receiving queue (Step 1), the scheduler will provide each operating section with the procedure to be used in processing that particular cask. Accompanying each procedure will be a checklist to be initialed by an assigned person immediately following the successful completion of a particular phase of work. Included in these 
procedures and checklists will be the maintenance checks and tests to be performed during routine handling. If the test or inspection involves the measurement of some value, then the value upon which acceptance or rejection of the test is judged will be entered on the checklist. These checklists then become a part of the permanent record of the given cask component.

9.2 Requalification tests will be performed at such intervals that certification will not expire while the cask is in normal operation.

9.3 If a cask is out-of-service for an extended period of time, test due dates will be postponed until the cask is scheduled to return to service.

9.4 Requalification tests will be performed in accordance with a procedure approved in writing by the cask owner.

9.5 The Quality Assurance program of the FSF will conform to 10 CFR 71, Appendix E.

9.6 Data and history pertaining to cask components will be available through the data system. In addition, periodic printouts of services to be performed within given time intervals will be generated routinely for use in scheduling.

9.7 Specifications for spare parts and procedures for cask repairs will be furnished by the cask owners.

9.8 If more than one FSF is in operation at any given time, provision will be made for a mutual updating of records of services performed.

10.0 Vehicle Maintenance and Repair

10.1 The same provisions for casks, as delineated in section 9.1, will apply to vehicles.

10.2 Rail car maintenance and repair is performed in accordance with AAR directives.

10.3 Maintenance of ancillary equipment (diesel-powered cooling systems, etc.) is in accordance with procedures furnished by the vehicle owner after concurrence with FSF Operators.

10.4 NDE's will be substantiated with photographic evidence unless specifically exempted. 
10.5 Vehicle maintenance and repair will be included in the quality assurance program and in the data-base system in effect for cask maintenance.

\subsection{Receipt of Excessively Contaminated Casks/Vehicles}

11.1 If contamination levels exceed the limits acceptable for routine receipt, the cask system is moved into the washdown bay without normal washdown.

11.2 If the excessive contamination is localized, spot cleaning techniques are used to decontaminate without generating free liquids.

11.3 If spot cleaning is successful, the transportation system is queued into the routine receiving operation beginning with the washdown step.

11.4 If spot cleaning cannot be used or is uneffective, the cask system is moved directly to the off-loading bay. Appropriate precautions are taken to prevent spread of contamination as the vehicle is being moved.

11.5 off-load cask and move it directly to the cask and insert cleaning area pit.

11.6 The cask is transferred into the working area for decontamination. When contamination reaches an acceptable level, the cask is queued for fuel unloading.

11.7 The vehicle is returned to the washdown area and decontaminated without the generation of free liquid. Any additional road dirt is hosed away, followed by queuing the vehicle into the vehicle inspection bay.

11.8 Once a cask or vehicle enters a routine queue, the appropriate standard procedures are followed from then on.

\subsection{Receipt of Damaged Casks}

It is expected that the FSF will be capable of repairing damaged casks. However, casks damaged so severely that they cannot be opened in a normal way will be considered on a case-by-case basis. The contents of the casks; spent fuel, high level wastes, etc., will be a major consideration as to how it is opened and the kind of area needed to perform the opening or repair operations. The E-MAD Facility in Jackass Flats, Nevada, might serve as a central repair station. A facility with water-filled pits might also be used, if justified. 
APPENDIX C

SUMMARY OF THE REFERENCED DOCUMENT 
The Integrated FSF concept tends to complement the original study (2) of a similar nature; the completely Independent FSF. In order to assist the reader of this report, the following summary of the referenced document is presented to aid in comparing the three concepts.

\section{Assumptions:}

1. Receiving capability $2000 \mathrm{MTU} /$ year; $75 \mathrm{w} / \mathrm{o} \mathrm{rail}, 20 \mathrm{w} / \mathrm{o}$ LWT, $5 \mathrm{w} / 0$ OWT.

2. The location is in the vicinity of SRP.

3. No SNM license (no loaded casks in the FSF).

4. All testing except that requiring loaded casks.

5. Complete inventory of cask-owner owned spare parts.

6. All but the most major of repairs.

7. FSF to furnish (and maintain inventory of) "special
tools."

8. Decontamination capability to include unconditional release.

9. Complete vehicle inspection.

10. Complete ancillary equipment inspection.

11. No truck tractor servicing.

12. Independent staffing.

13. Around-the-clock operation.

14. Cost estimate limited to elevation 0 and above.

Casks considered:

- NAC-1 (NFS-4), NCl-1/2, TN8 (\& 9), 1F-300, NLI 10/24

Estimates of number of casks in operation are based on:

- Average rail speed, $4 \mathrm{mph}$

- Average LWT speed, $40 \mathrm{mph}$

- Average OWT speed, $20 \mathrm{mph}$

- Rail loading time, 3 days 
- Rail unloading time, 2 days

- Truck loading time, 2 days

- Truck unloading time, 1 day

- Rail equipment scheduled in service, 335 days/year

- Truck equipment scheduled in service, 350 days/year

- Effective utilization of available casks, $75 \%$

- Ten PWR or 24 BWR average rail cask capacity

- One PWR or 2 BWR average LWT capacity

- Three PWR or 7 BWR average OWT capacity.

- Rail Casks

- Average distance 1062 miles

- Load ratio; 628 PWR, $38 \%$ BWR

- Casks required, 35.

- Truck Casks

- Average distance, 934 miles

- Load ratio; 698 PWR, $31 \%$ BWR

- LWT's required, 18

- OWT's required, 2.

Shop Capacity

- Routine Inspections

- Truck, 4.3 man-hours, 2.2 elapsed hours

- Rail, 9.7 man-hours, 4.9 elapsed hours.

- Periodic Inspections (average per trip)

- Truck, 3.6 elapsed hours

- Rail, 5.7 elapsed hours.

- Receiving Rate

- Truck; Average 3, range $0-5$

- Rail; Average 1, range 0 - 2 .

\section{Initial Concept}

The cost estimate in the referenced document is estimated at $\$ 21,720,000$ (mid-1978); however, this cost was adjusted upward when compared to the Independent FSF's full service capability, e.g.:

- Full rail car maintenance

- Full compliance testing. 


\section{Facility Makeup}

1. Washdown area for removing road dirt

2. Vehicle maintenance/inspection area

3. Cask test and inspection stalls and inspection equipment

4. An internals handling capability

5. Provision for unconditional release decontamination

6. FSF to provide special tools for all casks

7. Controlled, entirely self sufficient, effluent

8. All stores and material handling needs

9. All personnel services (lunchrooms, etc.)

10. All Health Physics needs.

Eighteen drawings are included to describe the concept.

A cost summary follows this section. 


\section{ESTIMATE SUMMARY}

PROJECT SF Cask Fleet Servicing Facility - Independent Design ACCOUNT Project Summary

ESTMATENO. UC $854-13866$ V-2

SHEET NO 1 OF 4

PREPARED BY: WK DAK

DATE: $9 / 29 / \overrightarrow{79}$

CHECKED BY:

DATE:

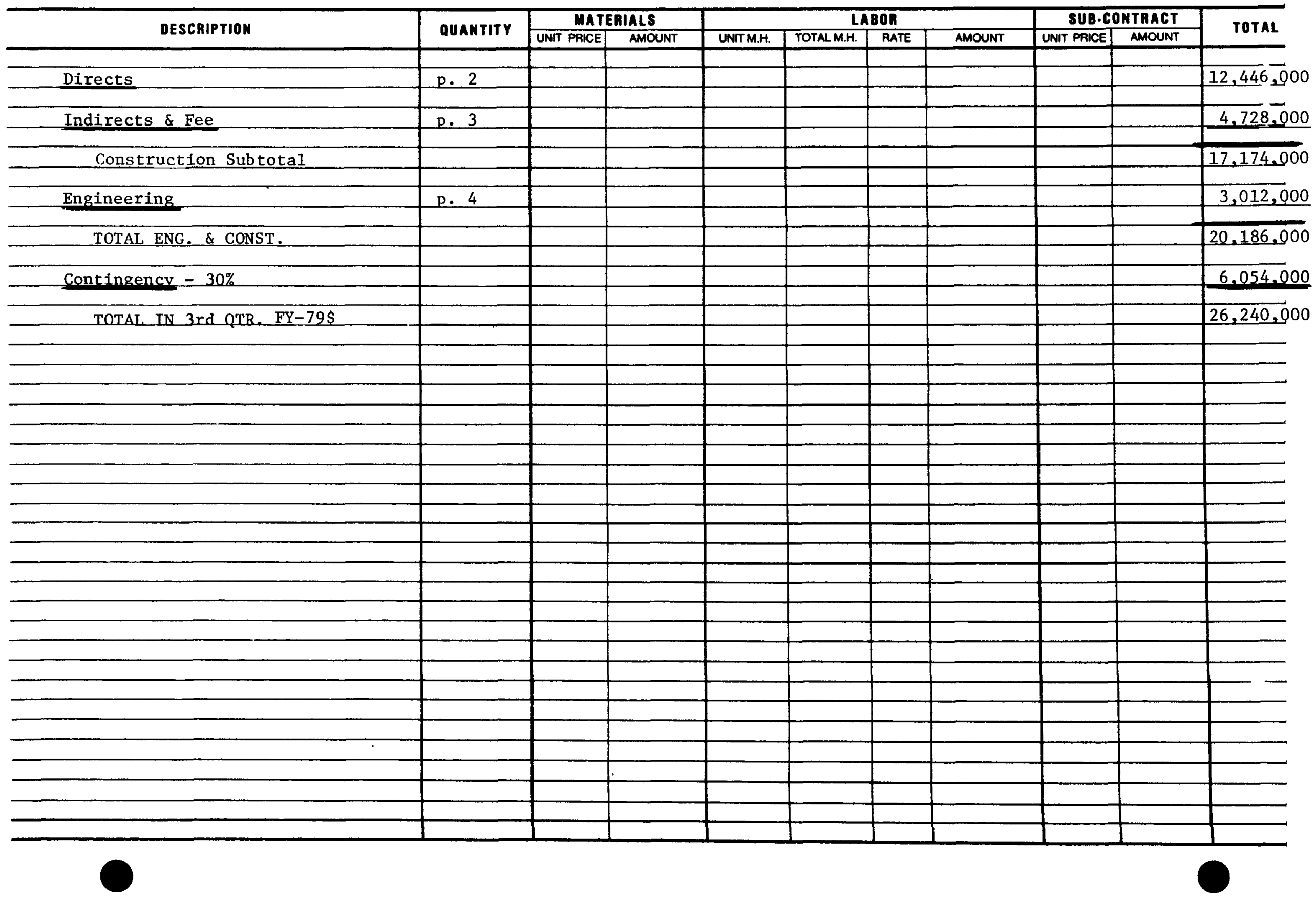




\section{ESTIMATE SUMMARY}

PROJECT

S F CASK FLEET SERVICING FACILITY INDEPENDENT DESTGN

DIRECT COST SUMMARY
ESTMATENO. UC $854-13866 \mathrm{~V}-2$

2 of 4

PREPARED BY: WK DAK

CHECKED BY:
DATE: $9 / 297 \overline{79}$

DATE

\begin{tabular}{|c|c|c|c|c|c|c|c|c|c|c|c|}
\hline \multirow{2}{*}{$\underset{\text { MCCOUNT }}{\operatorname{malN}}$} & \multirow{2}{*}{ DESCRIPTION } & \multirow{2}{*}{ QUANTITY } & \multicolumn{2}{|c|}{ MATERIALS } & \multicolumn{4}{|c|}{ LABOR } & \multicolumn{2}{|c|}{ SUB-CONTRACT } & \multirow{2}{*}{ TOTAL } \\
\hline & & & UNIT PAICE & AMOUNT & UNIT M.H & TOTAL M.H & RATE & AMOUNT & UNIT PRICE & AMOUNT & \\
\hline & IMPROVEMENTS TO LAND & & & & & & & & & & 362,000 \\
\hline & & & & & & & & & & & \\
\hline & NEW BUILDINGS & & & & & & & & & & $4,387,000$ \\
\hline & & & & & & & & & & & \\
\hline & SPECIAL FACILITIES & & & & & & & & & & $7,177,000$ \\
\hline & & & & & & & & & & & \\
\hline & OUTSIDE UTILITIES & & & & & & & & & & 224.000 \\
\hline & & & & & & & & & & & \\
\hline & STANDARD EQUIPMENT & & & & & & & & & & 295,000 \\
\hline & & & & & & & & & & & ति दर5 तर0 \\
\hline & TOTAL DIRECT COSTS & & & & & & & & & & $12,445,000$ \\
\hline & & & & & & & & & & & \\
\hline & & & & & & & & & & & \\
\hline & & & & & & & & & & & \\
\hline & & & & & & & & & & & \\
\hline & & & & & & & & & & & \\
\hline & & & & & & & & & & & \\
\hline & & & & & & & & & & & \\
\hline & & & & & & & & & & & \\
\hline & & & & & & & & & & & \\
\hline & & & & & & & & & & & \\
\hline & & & & & & & & & & & \\
\hline & & & & & & & & & & & \\
\hline & & & & & & & & & & & \\
\hline & & & & & & & & & & & \\
\hline & & & & & & & & & & & \\
\hline & & & & & & & & & & & \\
\hline & & & & & & & & & & & \\
\hline & & & & & & & & & & & \\
\hline & & & & & & & & & & & \\
\hline & & & & & & & & & & & \\
\hline & & & & & & & & & & & \\
\hline & & & & & & & & & & & \\
\hline & & & & & & & & & & & \\
\hline & & & & & & & & & & & \\
\hline & & & & & & & & & & & \\
\hline & & & & & & & & & & & \\
\hline & & & & & & & & & & & \\
\hline & & & & & & & & & & & \\
\hline
\end{tabular}




\section{ESTIMATE SUMMARY}

PROJECT

SF Cask Fleet Servicing Facility - Independent Design

Indirect Cost Summary
ESTIMATENO UC 854-13866 V-2

SHEET NO 3 of 4

PREPARED BY: WK DAK

CHECKED BY:
OATE: $2 / 29 / 79$

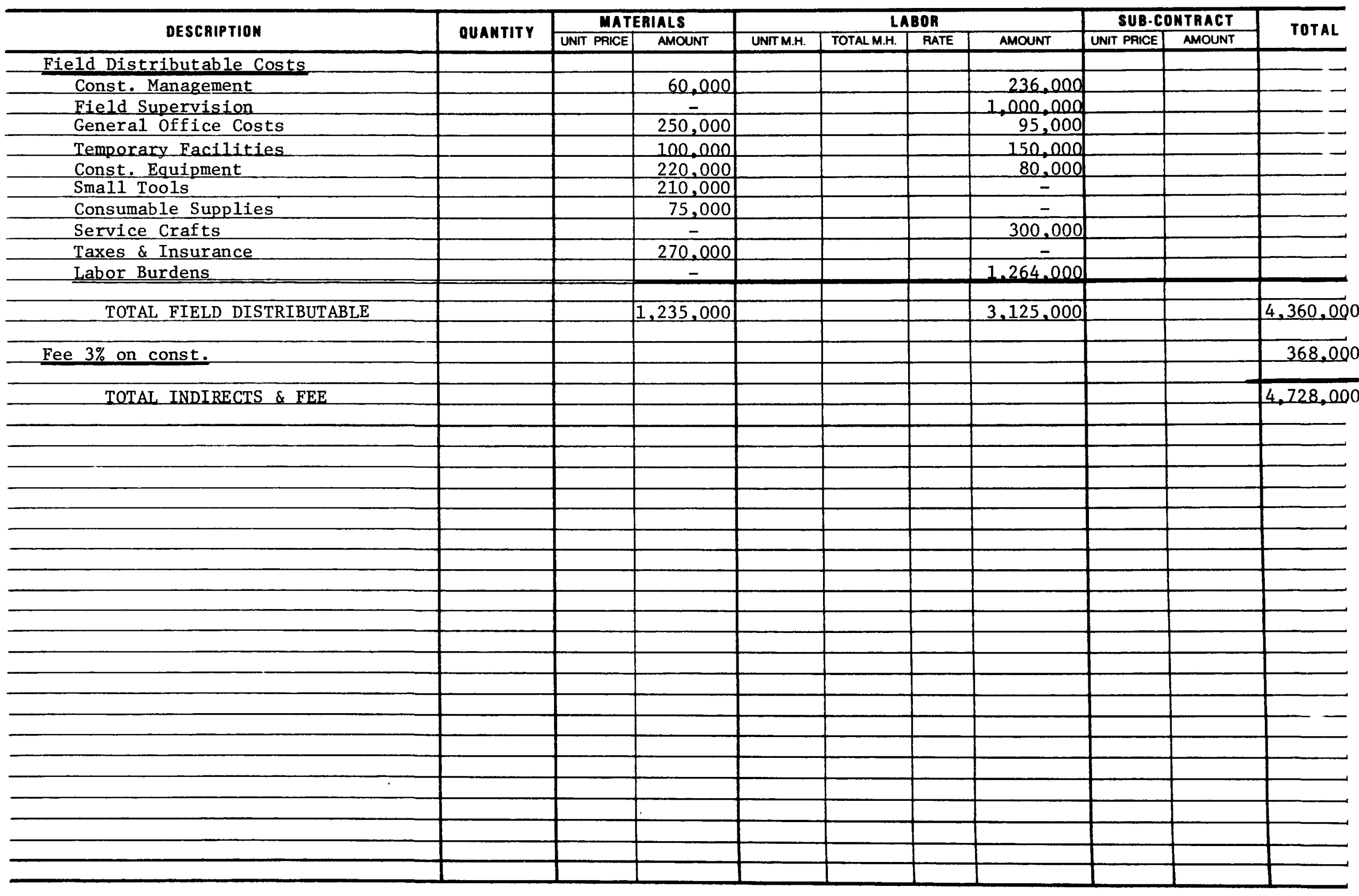




\section{ESTIMATE SUMMARY}

PROJECT

SF Cask Fleet Servicing Facility - Independent Design

ACCOUNT

Engineering

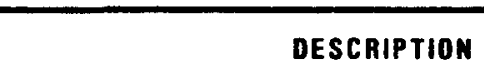

Design

Inspection

TOTAL ENGINEERING

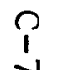

ESTIMATENO. UC 854-13866 V-2

SHEET NO 4 OF 4

PREPARED BY: WK DAK

CHECKED BY:
DATE. $9 / 29 / 79$

DATE: — — $\longrightarrow$

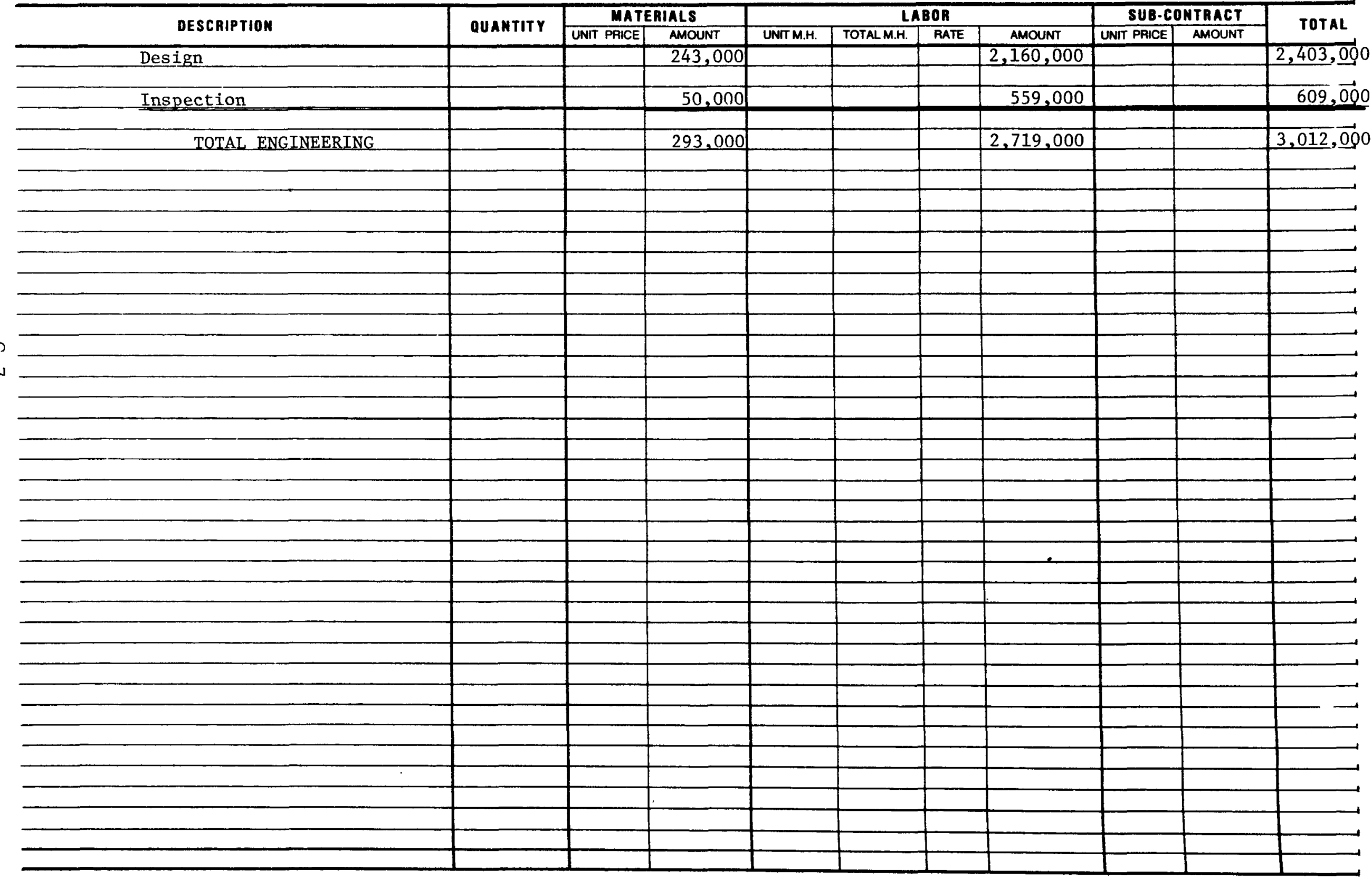


APPENDIX D

COST ESTIMATE - INTEGRATED FLEET SERVICING FACILITY

(Summary in Section 5.0) 


\section{ESTIMATE SUMMARY}

PROJECT SF Cask Fleet Servicing Facility - Integrated Design ACCOUNT Project Summary
UC $854-13866 \mathrm{~V}-1$

ESTIMATENO. 1 OF 4

PREPARED BY: WK DAK

CHECKED BY.
OATE $9 / 19 / 79$ DATE

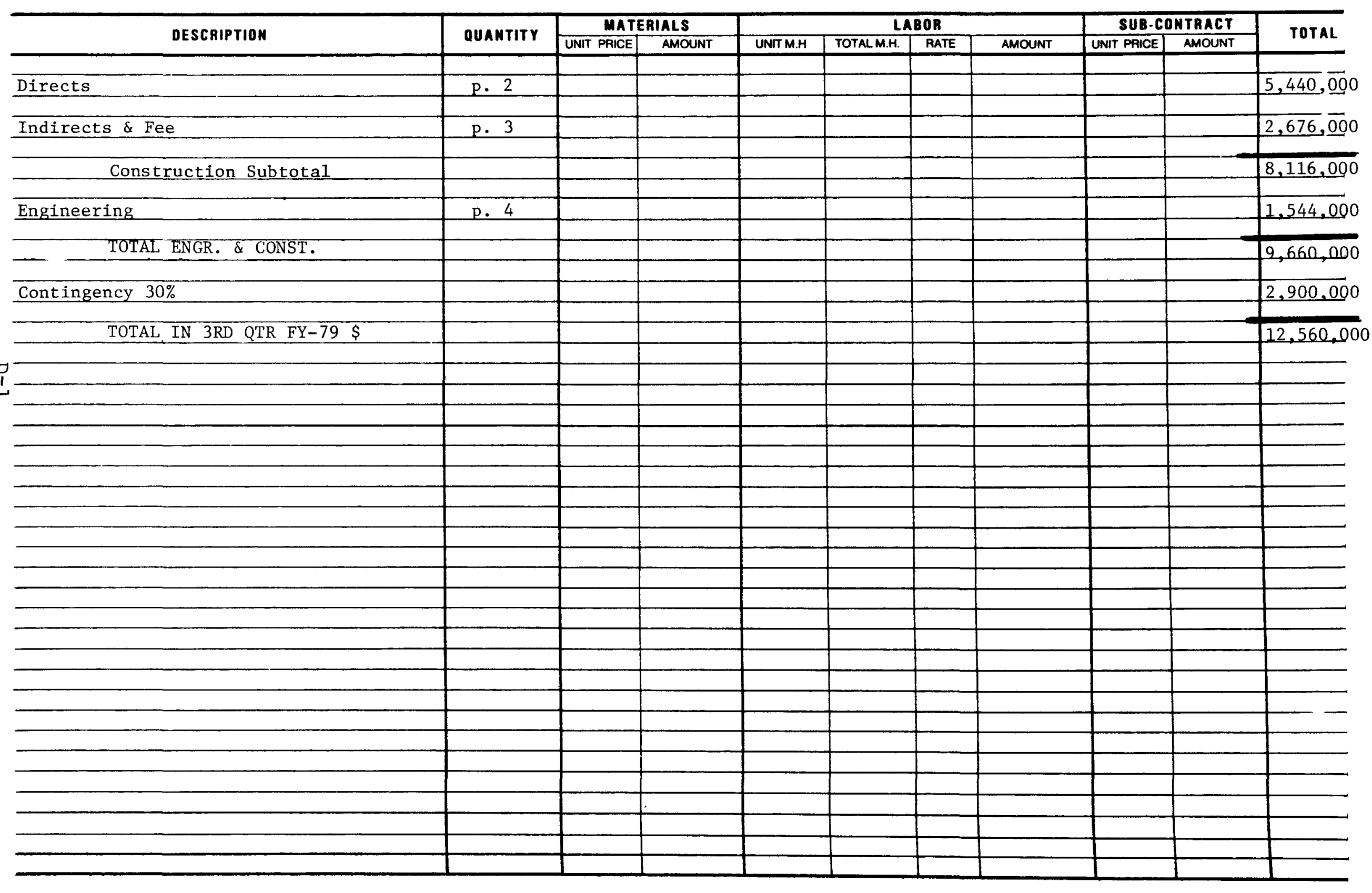


S F CASK FLEET SERVICING FACILITY-INTEGRATED DESIGN

DIRECT COST SUMMARY
ESTMATENO UC $854-13866 \mathrm{~V}-1$

SHEET NO 2 of 4

PREPARED $Q Y$ WK DAK

CHECKED BY:
DATE: $9 / 19 / 79$ DATE

\begin{tabular}{|c|c|c|c|c|c|c|c|c|c|c|c|}
\hline \multirow{2}{*}{$\underset{\text { Account }}{\operatorname{Maln}}$} & \multirow{2}{*}{ DESCRIPTION } & \multirow{2}{*}{ QUANTITY } & \multicolumn{2}{|c|}{ MATERIALS } & \multicolumn{4}{|c|}{ LABOR } & \multicolumn{2}{|c|}{ SUB-CONTRACT } & \multirow{2}{*}{ TOTAL } \\
\hline & & & UNIT PRICE & AMOUNT & UNTIM.H. & TOTALM.H. & RATE & MMOUNT & UNIT PAICE & AMOUNT & \\
\hline & IMPROVEMENTS TO LAND & & & & & & & & & & 59,000 \\
\hline & & & & & & & & & & & \\
\hline & NEW BUILDINGS & & & & & & & & & & $2,816,000$ \\
\hline & & & & & & & & & & & 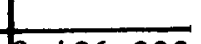 \\
\hline & SPECIAL FACILITIES & & & & & & & & & & $2,486,000$ \\
\hline & OUTSIDE UTILITIES & & & & & & & & & & $\begin{array}{r}9.000 \\
\end{array}$ \\
\hline & & & & & & & & & & & \\
\hline & STANDARD EQUIPMENT & & & & & & & & & & 70,000 \\
\hline & & & & & & & & & & & + \\
\hline & & & & & & & & & & & + \\
\hline & TOTAL DIRECT COSTS & & & & & & & & & & $5,440,000$ \\
\hline & & & & & & & & & & & \\
\hline & & & & & & & & & & & \\
\hline & & & & & & & & & & & 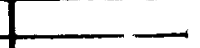 \\
\hline & & & & & & & & & & & \\
\hline & & & & & & & & & & & - \\
\hline & & & 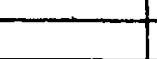 & & & 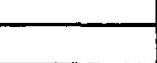 & 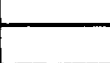 & & & & 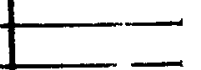 \\
\hline & & & & & & & & & & & 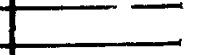 \\
\hline & & & & & & & & & & & \\
\hline & & & & & & & & & & & \\
\hline & & & & & & & & & & & - \\
\hline & & & & & & & & & & & 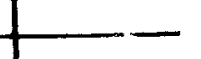 \\
\hline & & & & & & & & & & & - \\
\hline & & & & & & & & & & & \\
\hline & & & & & & & & & & & \\
\hline & & & & & & & & & & & \\
\hline & & & & & & & & & & & \\
\hline & & & & & & & & & & & \\
\hline & & & & & & & & & & & \\
\hline & & & & & & & & & & & \\
\hline & & & & & & & & & & & \\
\hline & & & & & & & & & & & \\
\hline & & & & & & & & & & & \\
\hline & & & & & & & & & & & \\
\hline
\end{tabular}


ESTIMATE SUMMARY

PROJECT SF Cask Fleet Servicing Facility - Integrated Design ACCOUNT_ Indirect Cost Summary

ESTIMATENO UC $854-13866 \mathrm{~V}-1$

SHEET NO 3 OF 4

PREPARED BY WK DAK

DATE $9 / 19 / 79$

CHECKEDBY

DATE _ - -

\begin{tabular}{|c|c|c|c|c|c|c|c|c|c|c|}
\hline \multirow{2}{*}{ DESCAIPTION } & \multirow{2}{*}{ QUANTITY } & \multicolumn{2}{|c|}{ MATERIALS } & \multicolumn{4}{|c|}{ LABOR } & \multicolumn{2}{|c|}{ SUB-CONTRACT } & \multirow{2}{*}{ TOTAL } \\
\hline & & UNIT PRICE & AMOUNT & UNITMH & TOTALMH & RATE & AMOUNT & UNIT PRICE & AMOUNT & \\
\hline \multicolumn{11}{|l|}{ Field Distributable Costs } \\
\hline & & & & & & & & & & \\
\hline Construction Management & & & 35,000 & & & & 135,000 & & & \\
\hline & & & & & & & & & & \\
\hline Field Supervision & & & - & & & & 530,000 & & & \\
\hline & & & & & & & & & & \\
\hline General Office Costs & & & 145,000 & & & & 45,000 & & & \\
\hline Temporary Facilities & & & 65,000 & & & & 80,000 & & & \\
\hline & & & & & & & & & & \\
\hline Construction Equipment & & & 130,000 & & & & 45,000 & & & \\
\hline & & & & & & & & & & \\
\hline Small Tools & & & 120,000 & & & & - & & & \\
\hline Consumable Supplies & & & 45,000 & & & & - & & & \\
\hline & & & & & & & & & & \\
\hline Service Crafts & & & $=$ & & & & 175,000 & & & \\
\hline & & & & & & & & & & \\
\hline Taxes \& Insurance & & & 140,000 & & & & - & & & \\
\hline Labor Burdens & & & - & & & & 750,000 & & & \\
\hline & & & & & & & & & & \\
\hline$-2-2-2$ & & & & & & & & & & \\
\hline TOTAL DISTRIBUTABLE & & & 680,000 & & & & $1,760,000$ & & & $2,440,000$ \\
\hline & & & & & & & & & & \\
\hline Fee (on Const) 3\%+ & & & & & & & & & & 236,000 \\
\hline TOTAL INDIRECT COSTS & & & & & & & & & & $2,676,000$ \\
\hline & & & & & & & & & & - 20 \\
\hline & & & & & & & & & & \\
\hline & & & & & & & & & & \\
\hline & & & & & & & & & & \\
\hline & & & & & & & & & & \\
\hline & & & & & & & & & & \\
\hline & & & & & & & & & & \\
\hline & & & & & & & & & & \\
\hline & & & & & & & & & & \\
\hline
\end{tabular}




\section{ESTIMATE SUMMARY}

ACCOUNT:- Engineering ntegrated Design

\begin{tabular}{|c|c|c|c|c|c|c|c|c|c|c|}
\hline \multirow{2}{*}{ DESCRIPTION } & \multirow{2}{*}{ QUANTITY } & \multicolumn{2}{|c|}{ MATERIALS } & \multicolumn{4}{|c|}{ LABOA } & \multicolumn{2}{|c|}{ SUD-CONTRACT } & \multirow{2}{*}{ TOTAL } \\
\hline & & UNIT PRICE & AMOUNT & UNTT M.H. & TOTAL M.H. & RATE & AMOUNT & UNIT PRICE & AMOUNT & \\
\hline Design & & & 130,000 & & & & $1,154,000$ & & & $1,284,000$ \\
\hline & & & & & & & & & & \\
\hline Inspection & & & 25,000 & & & & 235,000 & & & 260,000 \\
\hline & & & & & & & & & & 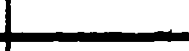 \\
\hline TOTAL & & & 155,000 & & & & 1.389 .000 & & & 7.544 .000 \\
\hline & & & & & & & & & & \\
\hline & & & & & & & & & & \\
\hline & & & & & & & & & & \\
\hline & & & & & & & & & & \\
\hline & & & & & & & & & & \\
\hline & & & & & & & & & & \\
\hline & & & & & & & & & & \\
\hline & & & & & & & & & & \\
\hline & & & & & & & & & & \\
\hline & & & & & & & & & & \\
\hline & & & & & & & & & & \\
\hline & & & & & & & & & & \\
\hline & & & & & & & & & & \\
\hline & & & & & & & & & & \\
\hline & & & & & & & & & & \\
\hline & & & & & & & & & & \\
\hline & & & & & & & & & & \\
\hline & & & & & & & & & & \\
\hline & & & & & & & & & & \\
\hline & & & & & & & & & & \\
\hline & & & & & & & & & & \\
\hline & & & & & & & & & & \\
\hline & & & & & & & & & & \\
\hline & & & & & & & & & & \\
\hline & & & & & & & & & & \\
\hline & & & & & & & & & & \\
\hline & & & & & & & & & & \\
\hline & & & & & & & & & & \\
\hline & & & & & & & & & & \\
\hline & & & & & & & & & & \\
\hline & & & & & & & & & & \\
\hline & & & & & & & & & & \\
\hline & & & & & & & & & & \\
\hline - & & & & & & & & & & \\
\hline
\end{tabular}

ESTMATENO. UC $854-13866 \mathrm{~V}-1$

SHEET NO 4 Of 4

PREPARED BY: WK DAK

CHECKED BY:
Dare $9 / 19 / 79$
OATE $9 / 19 / 79$

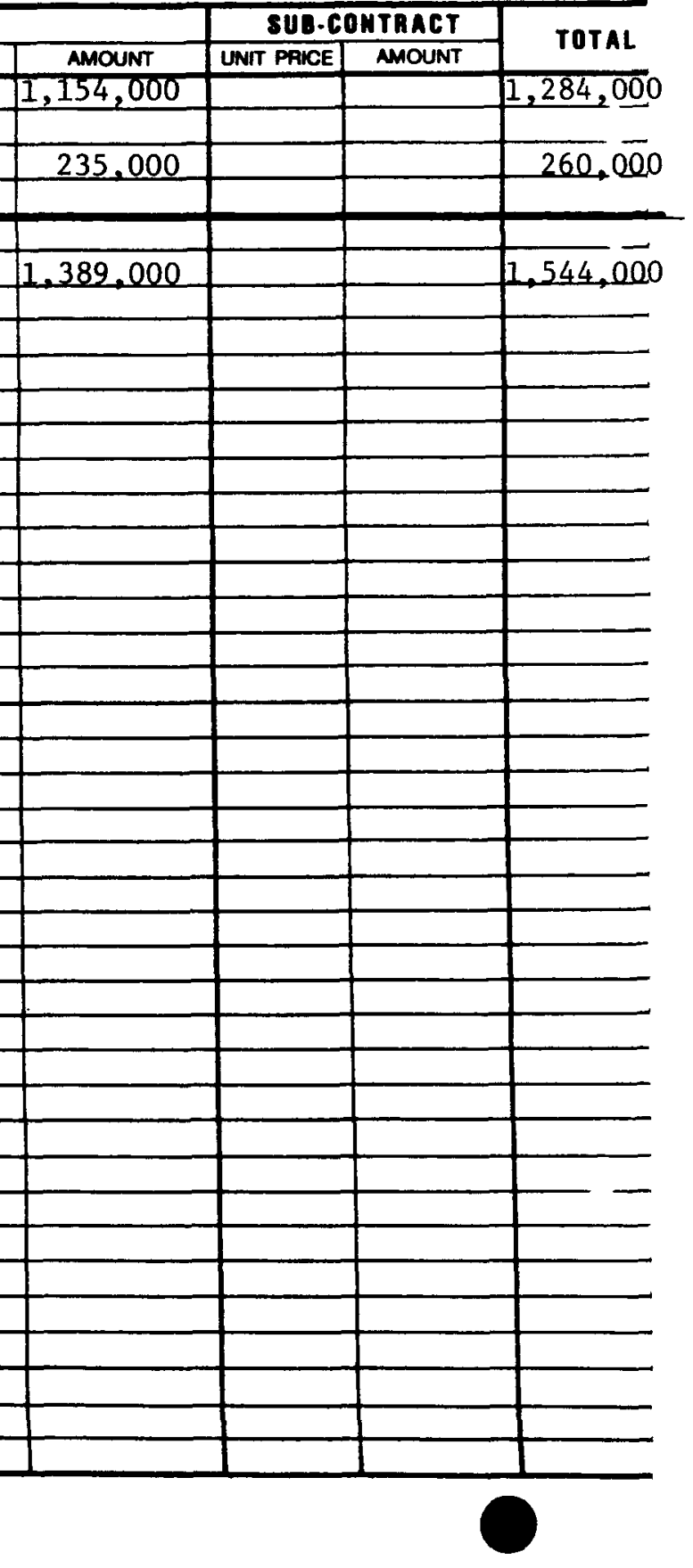




\section{ESTIMATE DETAILS}

PROJECT SF Cask Fleet Servicing Facility - Integrated Design ACCOUNT Improvements to Land
ESTMAATE NO. UC $854-13866 \mathrm{~V}-1$

SHEETNO 1 of 8

PPEPARED BY: W. KnOX

REV BY : DAK
DATE $8 / 24 / 79$ DATE: $9 / 19 / 79$

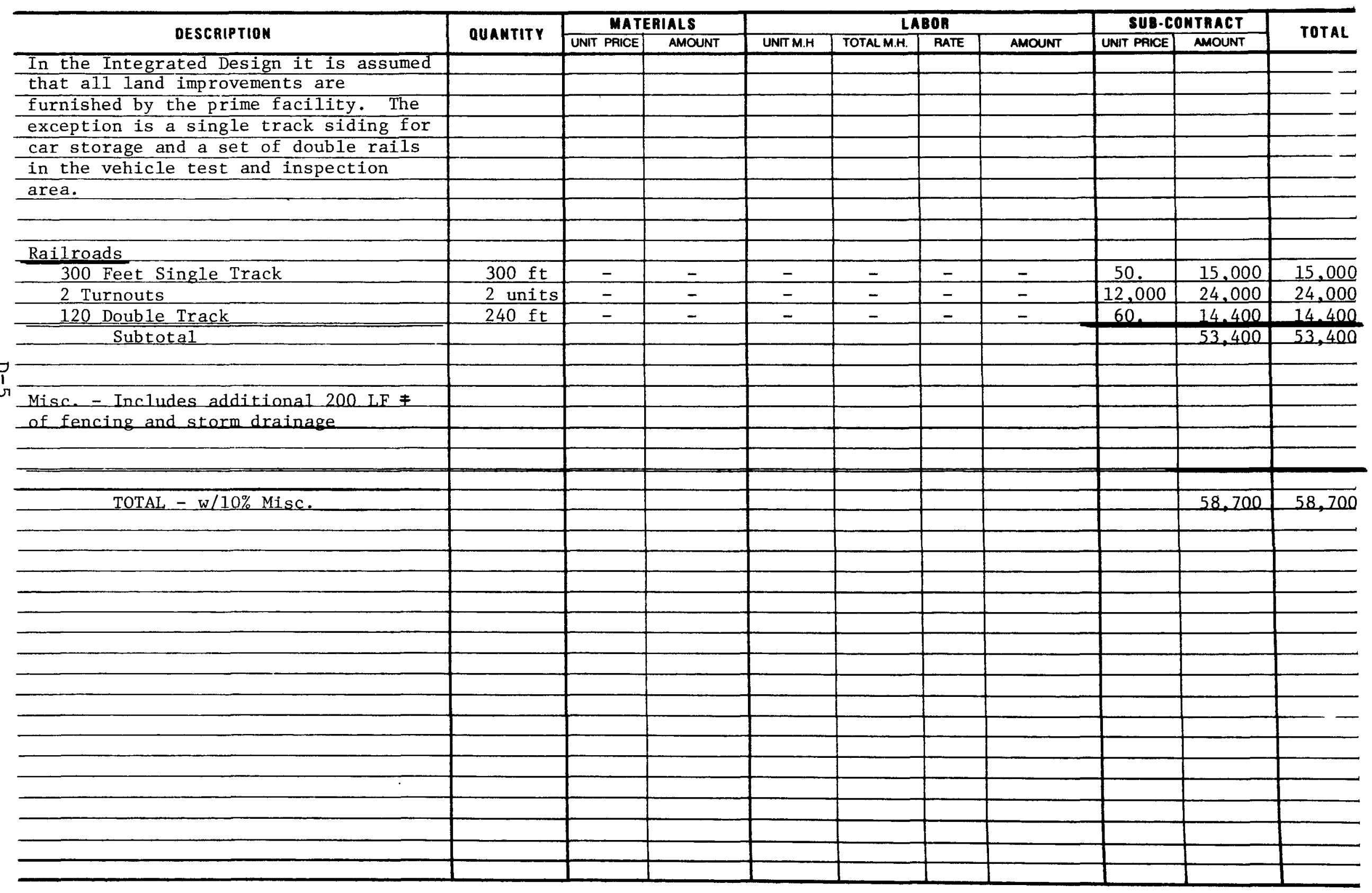




\section{ESTIMATE DETAILS}

PROJECT SF Cask Fleet Servicing Facility - Integrated Design

ESTMATENO. UC $854-13866 \mathrm{~V}-1$

ACCOUNT New Buildings

SHEET NO 2 of 8

PREPARED BY: DAK

DATE: $9 / 19 / \overline{79}$

CHECKED BY:

DATE:

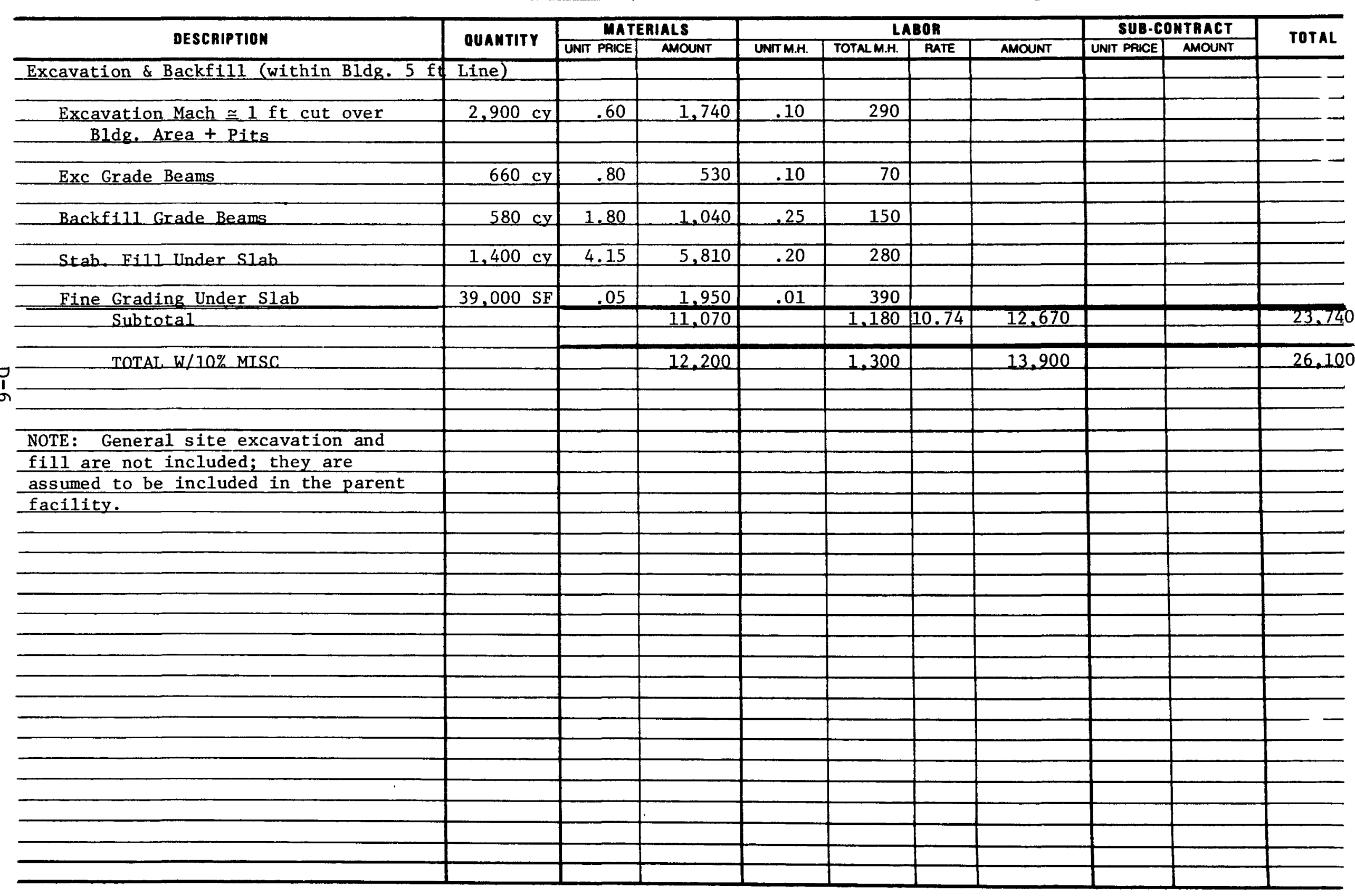

NOTE: General site excavation and

assumed to be included in the parent

facility. 


\section{ESTIMATE DETAILS}

PROJECT. SF Cask Fleet Servicing Facility - Integrated Design

ESTIMATENO. UC $854-13866 \mathrm{~V}-1$

SHEET NO 3 OF 8

PREPARED BY: W. KnOX

REV BY : DAK
DATE: $8 / 24 / 79$ DATE: $9 / 19 / 79$

\begin{tabular}{|c|c|c|c|c|c|c|c|c|c|c|}
\hline \multirow{2}{*}{ DESCAIPTION } & \multirow{2}{*}{ QUANTITY } & \multicolumn{2}{|c|}{ MATERIALS } & \multicolumn{4}{|c|}{ LABOR } & \multicolumn{2}{|c|}{ SUB-CONTRACT } & \multirow{2}{*}{ TOTAL } \\
\hline & & UNIT PRICE & AMOUNT & UNIT M.H. & TOTAL M.H. & RATE & AMOUNT & UNIT PAICE & AMOUNT & \\
\hline \multicolumn{11}{|l|}{ Concrete } \\
\hline Structural Foundations & $82 \mathrm{cy}$ & 80 & 6,560 & 20 & 1,640 & 8.77 & 14,380 & - & - & 20,940 \\
\hline Floor Slabs & 1,740 cy & 140 & 243,600 & 28 & 48,720 & 8.77 & 427,270 & - & - & 670,870 \\
\hline Elevated Slabs & $77 \mathrm{cy}$ & 150 & 11,550 & 36 & 2,770 & 8.77 & 24,290 & - & $=$ & 35,840 \\
\hline Wa11s & $620 \mathrm{cy}$ & 150 & 93,000 & 45 & 27,900 & 8.77 & 244,680 & - & 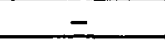 & 337,680 \\
\hline Test \& Inspection Pits & $75 \mathrm{cy}$ & 150 & 11,250 & 45 & 3,380 & 8.77 & 29,650 & - & - & 40,900 \\
\hline Cask Pit & $22 \mathrm{cy}$ & 150 & 3,300 & 45 & 990 & 8.77 & 8,680 & - & $=$ & 11,980 \\
\hline Cask Inert Pits & $94 \mathrm{cy}$ & 150 & 14,100 & 45 & 4,230 & 8.77 & 37,120 & - & $=$ & 51,220 \\
\hline Precast Pit Covers & 20 units & 200 & 4,000 & 10 & 200 & 8.77 & 1,750 & - & - & 5,750 \\
\hline Misc. Concrete & $60 \mathrm{cy}$ & 140 & 8.400 & 35 & 2.100 & 8.77 & 18.420 & - & - & 26.820 \\
\hline Subtotal - Concrete & $2,770 \mathrm{cy}$ & & 395,760 & & 91,930 & & 806,240 & & & $1,202,000$ \\
\hline TOTAL W/10\% MISC & & & 435,300 & & 101,120 & & 886,900 & & & $1,322,200$ \\
\hline \multicolumn{11}{|l|}{ Other Building Components } \\
\hline Structural Steel & $470 \mathrm{~T}$ & 1,000 & 470,000 & 45 & 21,150 & 11.77 & 248,940 & - & - & 718,940 \\
\hline Insulated Siding & $366 \mathrm{sq}$ & - & - & - & - & - & - & 660 & 241.560 & 241,560 \\
\hline Insulated Roofing & $350 \mathrm{sq}$ & $=$ & $=$ & - & - & - & - & 170 & 59.500 & 59,500 \\
\hline Built-up Roof & $68 \mathrm{sq}$ & - & - & - & - & - & - & 170 & 11,560 & 11,560 \\
\hline Overhead Doors $-16^{\prime} \times 22^{\prime}$ & 4 ea & - & - & - & $=$ & - & - & 4.000 & 16.000 & 16.000 \\
\hline $10^{\prime} \times 14^{\prime}$ & 1 ea & - & - & - & - & - & - & 2,400 & 2.400 & 2.400 \\
\hline $8^{\prime} \times 10^{\prime}$ & 1 ea. & - & - & - & - & - & - & 1,300 & 1,300 & 1,300 \\
\hline Windows & 10 ea & 150 & 1,500 & 6 & 70 & 8.00 & 560 & - & - & 2,060 \\
\hline Doors \& Hardware & 45 ea & 200 & 9,000 & 8 & 360 & 8.00 & 2,880 & - & - & 11.880 \\
\hline SPL Hardware & 10 ea & 500 & 5,000 & 8 & 80 & 8.00 & 640 & - & $=$ & 5.640 \\
\hline Suspended Ceilings & $5000 \mathrm{SF}$ & - & - & $=$ & - & - & - & 1.65 & 8.250 & 8.250 \\
\hline Floor Tile. & $5000 \mathrm{SF}$ & $=$ & - & $=$ & - & - & - & 1.40 & 7, & 7, \\
\hline Masonry-Exterior & $2300 \mathrm{SF}$ & 1.65 & 3,800 & 16 & 370 & 9.00 & 3,330 & - & - & 7,130 \\
\hline Masonry-Interior & $7200 \mathrm{SF}$ & .90 & 6,480 & .13 & 940 & 9.00 & 8,460 & - & $=$ & 14,940 \\
\hline Plumbing and Drain Piping & 20 Fix & 500 & 10,000 & 15 & 300 & 2.00 & 3.600 & $=$ & $=$ & 13,600 \\
\hline Sprinklers office \& Unloading A & $60 \mathrm{Hds}$ & - & - & - & - & - & - & 160 & 9.600 & 9,600 \\
\hline Floor Hardner & $39,000 \mathrm{SF}$ & .75 & 29,250 & - & - & - & - & - & - & 29,250 \\
\hline Office Partitions & $2,000 \mathrm{SF}$ & - & - & - & - & - & - & 4.00 & 8,000 & $8, \overline{000}$ \\
\hline Subtota1-0ther B1dg. Components & - & - & 535,030 & & 23,270 & var & 268,410 & & 365,170 & $1,168,610$ \\
\hline TOTAL W/10\% MISC & - & - & 588,500 & & 25,600 & & 295,300 & & 401,700 & $1,285,500$ \\
\hline & & & & & & & & & & \\
\hline & & & & & & & & & & \\
\hline & & & & & & & & & & \\
\hline
\end{tabular}




\section{ESTIMATE DETAILS}

SF Cask Fleet Servicing Facilities - Integrated Design

ACCOUNT:- New Buildings - Continued

ESTIMATENO. UC $854-13866 \mathrm{~V}-1$

SHEET NO 4 OF 8

PREPARED BY: W. KnOX

DATE: $8 / 24 / 79$

REV BY: DAK DATE $9 / 19 / 79$

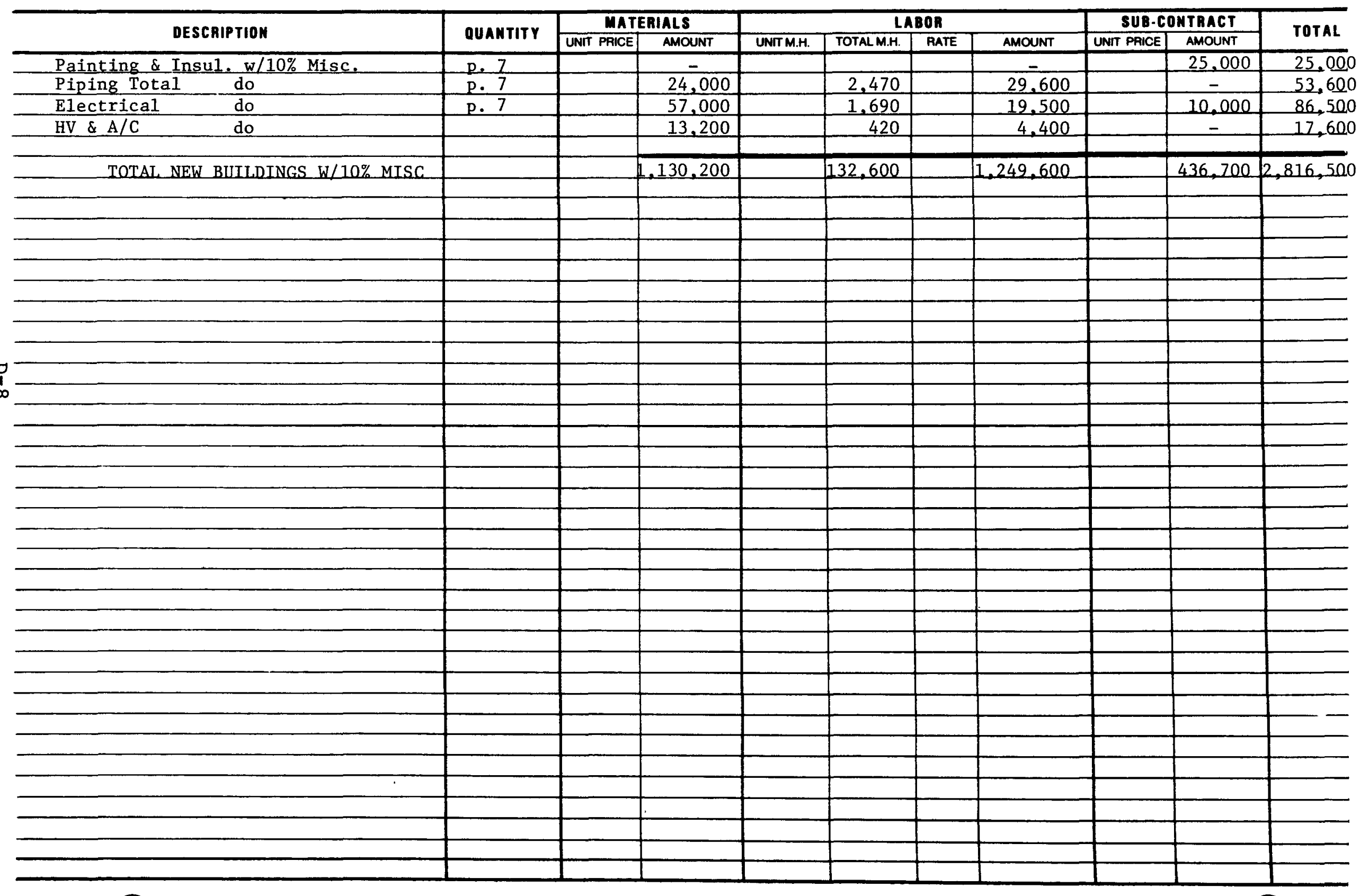




\section{ESTIMATE DETAILS}

PROJECT

SF Cask Fleet Servicing Facility - Integrated Design

Special Facilities
ESTMATENO UC $854-13866 \mathrm{~V}-1$

SHEET NO 5 of 8

PREPARED BY: W. KnOX

CHECKED BY:
DATE: $8 / 2 4 \longdiv { 7 9 }$ DATE: -

\begin{tabular}{|c|c|c|c|c|c|c|c|c|c|c|}
\hline \multirow{2}{*}{ DESCAIPTIDN } & \multirow{2}{*}{ QUANTITY } & \multicolumn{2}{|c|}{ MATERIALS } & \multicolumn{4}{|c|}{ LABOR } & \multicolumn{2}{|c|}{ SUB-CONTRACT } & \multirow{2}{*}{ TOTAL } \\
\hline & & UNIT PRICE & AMOUNT & UNIT M.H. & TOTAL M.H. & RATE & AMOUNT & UNIT PAICE & AMOUNT & \\
\hline \multicolumn{11}{|l|}{ Process Equipment } \\
\hline & & & & & & & & & & \\
\hline \multicolumn{11}{|l|}{ Tanks } \\
\hline Deionized Water Storage Tank & 1 & - & 9,300 & - & 50 & 10.34 & 520 & - & - & 9,820 \\
\hline Filter Regeneration Tank & 1 & - & 2,200 & - & 35 & 10.34 & 360 & - & - & 2,560 \\
\hline Wash Down Area Sump Tank & 1 & - & 11,000 & - & 100 & 10.34 & 1,030 & - & - & 12,030 \\
\hline Subtotal - Tanks & 3 & - & 22,500 & - & 185 & & 1,910 & $=$ & - & 24,410 \\
\hline TOTAL W/10\% MISC & & & 24,800 & & 200 & & 2,100 & & & 26.900 \\
\hline \multicolumn{11}{|l|}{ Pumps } \\
\hline High Pressure Cleaning Pump & 1 & - & 38,500 & - & 110 & 10.34 & 1,140 & - & - & 39,640 \\
\hline Cask Jet Pump & 1 & - & 4,400 & - & 40 & & 410 & - & - & 4.810 \\
\hline Deionizer Supply Pump & 1 & - & 2,200 & - & 40 & & 410 & - & - & 2,610 \\
\hline Filter Waste Pump & 1 & - & 2,200 & - & 40 & & 410 & - & - & 2,610 \\
\hline Slurry Pump & 1 & - & 4,400 & - & 40 & I. & 410 & - & - & 4.810 \\
\hline Sump Pumps & 4 & 5,500 & 22,000 & 60 & 240 & 10.34 & 2,480 & - & $=$ & 24,480 \\
\hline Spare Parts \& Vendor Reps. & & & 7.400 & & & & & & & 7400 \\
\hline Subtotal - Pumps & 9 & - & 81,100 & - & 510 & & 5,260 & - & - & 86,360 \\
\hline & & & & & & & & & & \\
\hline TOTAL W/10\% MISC & & & 89,200 & & 560 & & 5,800 & & & 95,000 \\
\hline \multicolumn{11}{|l|}{ Vacuum Equipment } \\
\hline Sump Ejector & 1 & - & 640 & - & 40 & 10.34 & 410 & - & - & 1,050 \\
\hline Vacuum Cleaning Jet & 1 & - & 2,200 & - & 40 & 10.34 & 410 & - & - & 2,610 \\
\hline Subtotal - Vacuum Equipment & 2 & - & 2,840 & - & 80 & & 820 & - & - & 3,660 \\
\hline TOTAL W/10\% MISC & & & 3,100 & & 90 & & 900 & & & 4,000 \\
\hline & & & & & & & & & & \\
\hline \multicolumn{11}{|l|}{ Compressors \& Blowers } \\
\hline Filter Blowdown Compr \& Tank & 1 unit & - & 660 & - & 50 & 10.34 & 520 & - & - & 1,180 \\
\hline HVAC Blower & 1 & - & 3,960 & - & 75 & 10.34 & 780 & - & - & 4,740 \\
\hline Spare Parts \& Vendor Reps. & & - & 460 & - & $=$ & 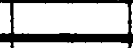 & & - & & -460 \\
\hline Subtotal - Compr \& Blowers & 2 & - & 5,080 & $=$ & 125 & & 1,300 & - & - & 6,380 \\
\hline TOTAL W/10\% MISC & & & 5,600 & & 140 & & 1,400 & & & 7,000 \\
\hline & & & & & & & & & & \\
\hline & & & & & & & & & & \\
\hline & & & & & & & & & & \\
\hline & & & & & & & & & & \\
\hline
\end{tabular}




\section{ESTIMATE DETAILS}

PROJECT SF Cask Fleet Servicing Facility - Integrated Design ACCOUNT

$$
\text { Special Facilities - Continued }
$$

ESTIMATE NO. UC 854- $\frac{13866 \mathrm{~V}-1}{6 \text { of } 8}$
SHEET NO

PHEET NOPARE BY: W. KnOX

CHECKED BY:
DATE $8 / 24 / 79$

DATE: — _ - -

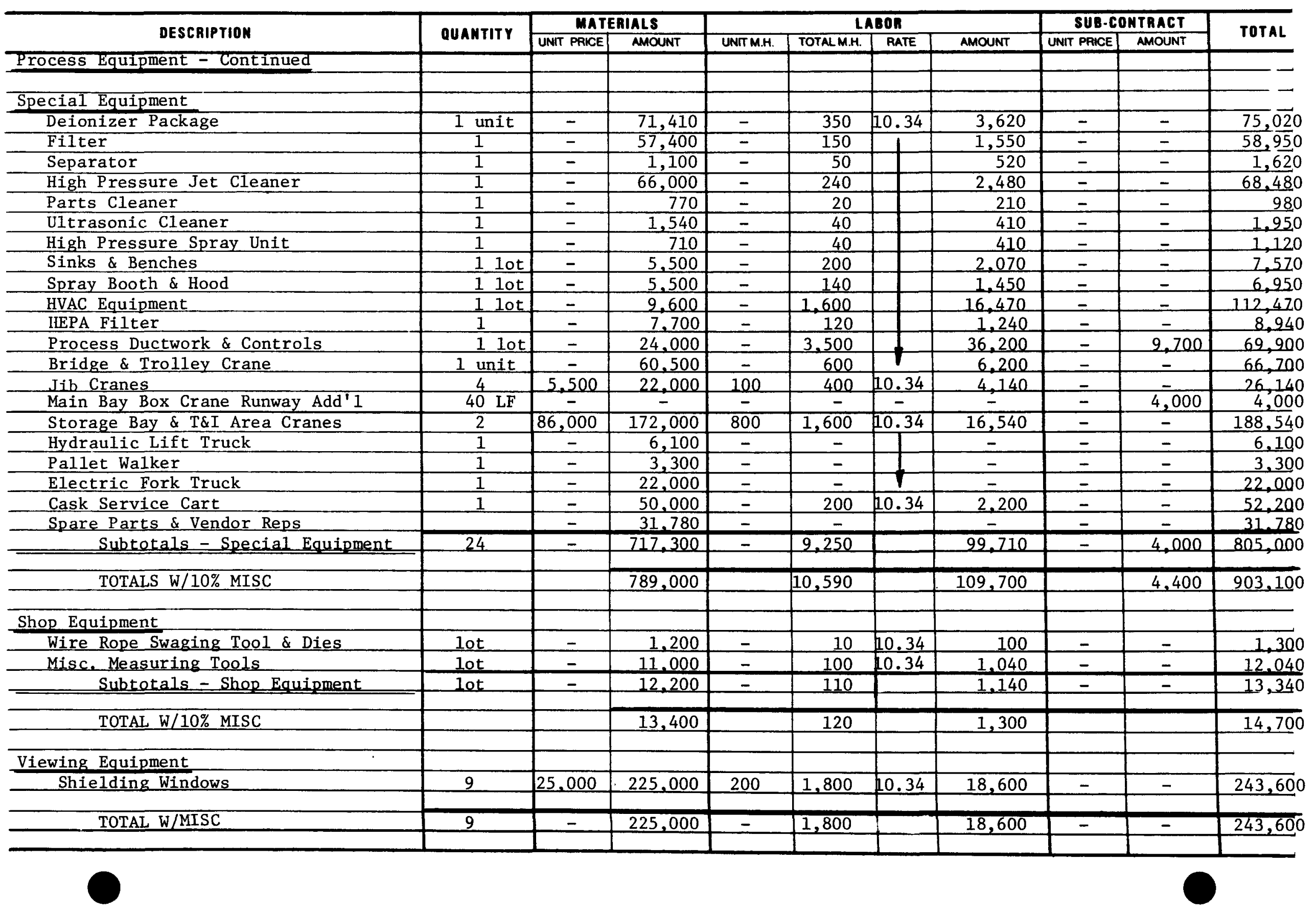




\section{ESTIMATE DETAILS}

PROJECT

SF Cask Fleet Servicing Facility - Integrated Design ACCOUNT

\section{Special Facilities - Continued}

ESTIMATENO. UC $854-13866 \mathrm{~V}-1$

SHEET NO 7 OF 8

PREPARED BY: W. KnOX

DATE: $8 / 24 / 79$

CHECKED BY: DATE

\begin{tabular}{|c|c|c|c|c|c|c|c|c|c|c|}
\hline \multirow{2}{*}{ DESCRIPTION } & \multirow{2}{*}{ QUANTITY } & \multicolumn{2}{|c|}{ MATERIALS } & \multicolumn{4}{|c|}{ LABOR } & \multicolumn{2}{|c|}{ SUB.CONTRACT } & \multirow{2}{*}{ TOTAL } \\
\hline & & UNIT PRICE & AMOUNT & UNIT M.H. & TOTALM.H. & RATE & AMOUNT & UNIT PAICE & AMOUNT & \\
\hline \multicolumn{11}{|l|}{ Process Equipment - Continued } \\
\hline TOTAL - PROCESS EQUIPMENT & - & - & $1,150.100$ & $=$ & & 10.34 & 139,800 & - & 4.400 & $1,294,300$ \\
\hline \multicolumn{11}{|l|}{ Instrumentation } \\
\hline \multicolumn{11}{|l|}{ Allow $15 \%$ of Process Equipment } \\
\hline \multicolumn{11}{|l|}{ material costs excluding cranes, } \\
\hline \multicolumn{11}{|l|}{ shop equip., and viewing equip $=$} \\
\hline$\$ 671,000=\$ 100,000$ & 11 ot & - & 75,000 & - & 2,060 & 12.14 & 25.000 & - & $=$ & 100, \\
\hline TOTAL - INSTRUMENTATION W/MISC & & - & 75,000 & - & 2,060 & 12.14 & 25,000 & - & $=$ & 100,000 \\
\hline \multicolumn{11}{|l|}{ Piping } \\
\hline Allow $40 \%$ of above value & 1 lot & - & 120,000 & $=$ & 12,330 & 720 & 148,000 & - & $=$ & 268,000 \\
\hline TOTAL - PIPING W/MISC $80 \%$ & & - & 120,000 & - & 12,330 & 12.00 & 148,000 & - & - & 268,000 \\
\hline \multicolumn{11}{|l|}{ Misc. Structural Steel \& Liners } \\
\hline Crane Rails & 46 tons & 2,800 & 128,800 & 300 & 13,800 & 11.77 & 162,430 & $=$ & - & 291,230 \\
\hline Equipment Supports & 9 tons & 3,800 & 34,200 & 200 & 1,800 & 1 & 21,190 & - & - & 55,390 \\
\hline Platforms \& Handrail & 27 tons & 1,900 & 51,300 & 200 & 5,400 & & 63,560 & - & - & 114,860 \\
\hline Pipe Racks & 5 tons & 1,500 & 7,500 & 100 & 500 & & 5,890 & - & - & 13,390 \\
\hline Pit Liners & 34 tons & 5,000 & 170,000 & 150 & 5,100 & 11.77 & 60,030 & - & - & 230,030 \\
\hline Subtotal - Misc. Stru. Steel & 121 tons & - & 391,800 & - & 26,600 & & 313,100 & - & - & 704,900 \\
\hline TOTAL W/10\% MISC & & & 431,000 & & 29,260 & & 344,400 & & & 775,400 \\
\hline \multirow{2}{*}{\multicolumn{11}{|c|}{ 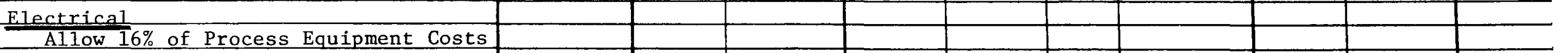 }} \\
\hline & & & & & & & & & & \\
\hline \multicolumn{11}{|l|}{ excluding Shop Equip \& Viewing } \\
\hline Equip. $=\$ 1,018,400=\$ 163,000$ & & - & 114,000 & - & 3,390 & 11.50 & 39,000 & - & 10,000 & 163,000 \\
\hline TOTAL - ELECTRICAL W/MISC $/ 50 \%$ & & - & 114.000 & - & 3,390 & & 39,000 & - & 10,000 & 163,000 \\
\hline Painting \& Inswlation - W/Misc/50\% & & - & - & - & - & - & 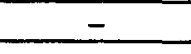 & - & 50,000 & 50,000 \\
\hline TOTAL - SPECTAL FACTITTIES INCL & & & & & & & & & & \\
\hline ONLY $\%$ OF ITEMS NOTED & & $=$ & $1,795,900$ & - & & & 642,700 & - & 34,400 & $2,473,000$ \\
\hline & & & & & & & & & & \\
\hline & & & & & & & & & & \\
\hline
\end{tabular}




\section{ESTIMATE DETAILS}

PROJECT: SF Cask Fleet Servicing Facility - Intergrated Design

ESTMAATE NO. UC $854-13866$ V-1

ACCOUNT:- Standard Equipment

SHEETNO 8 Of 8

PREPARED BY: WK DAK

DATE: $9 / 19 / 79$

CHECKED BY

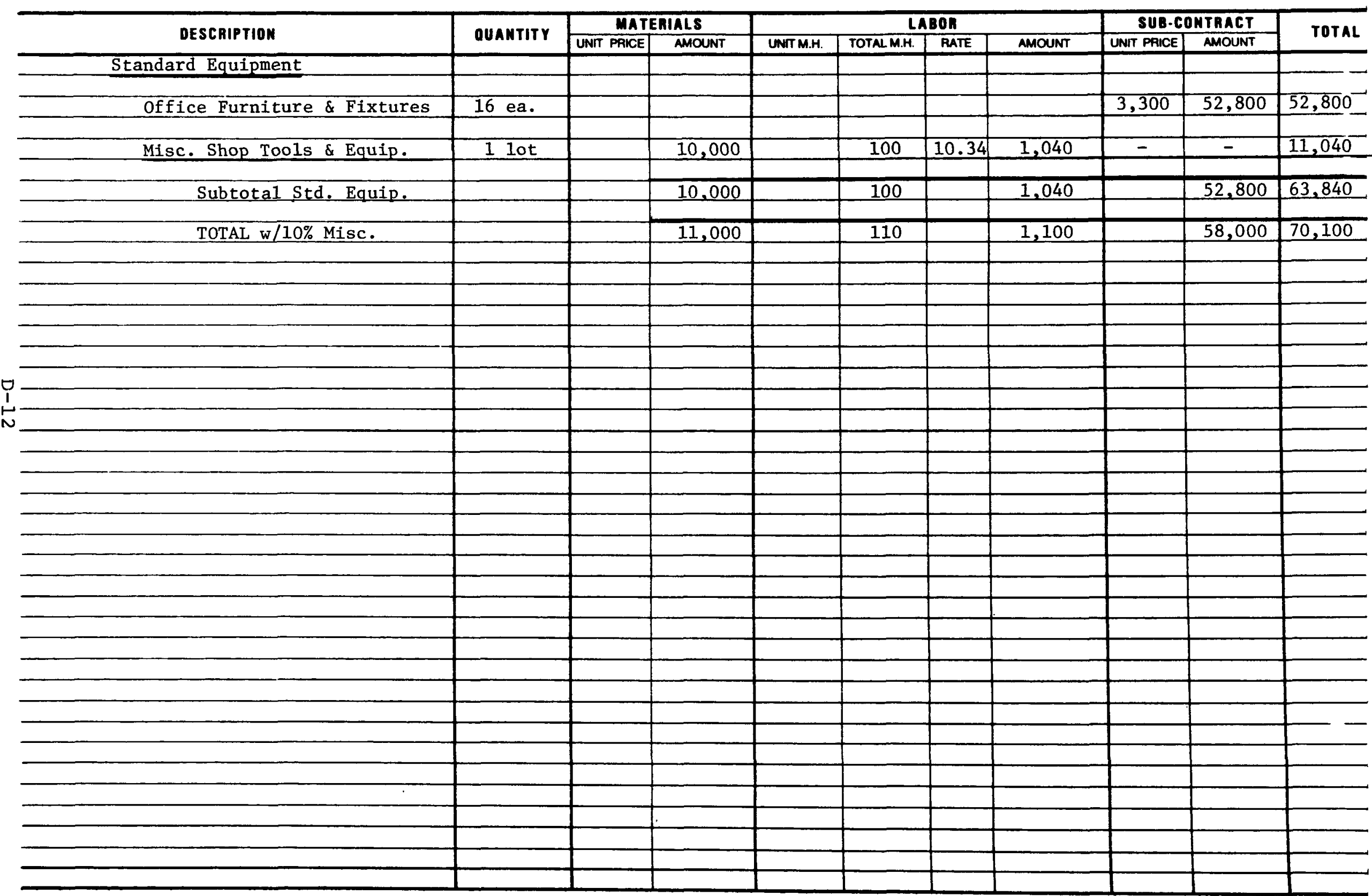




\section{APPENDIX E \\ COST ESTIMATE - COLOCATED FLEET SERVICING FACILITY \\ (Summary in Section 5.0)}




\section{ESTIMATE SUMMARY}

PROJECT SPENT FUEL CASK FSE -- COLOCATED (BNFP) PROJECT SUMMARY

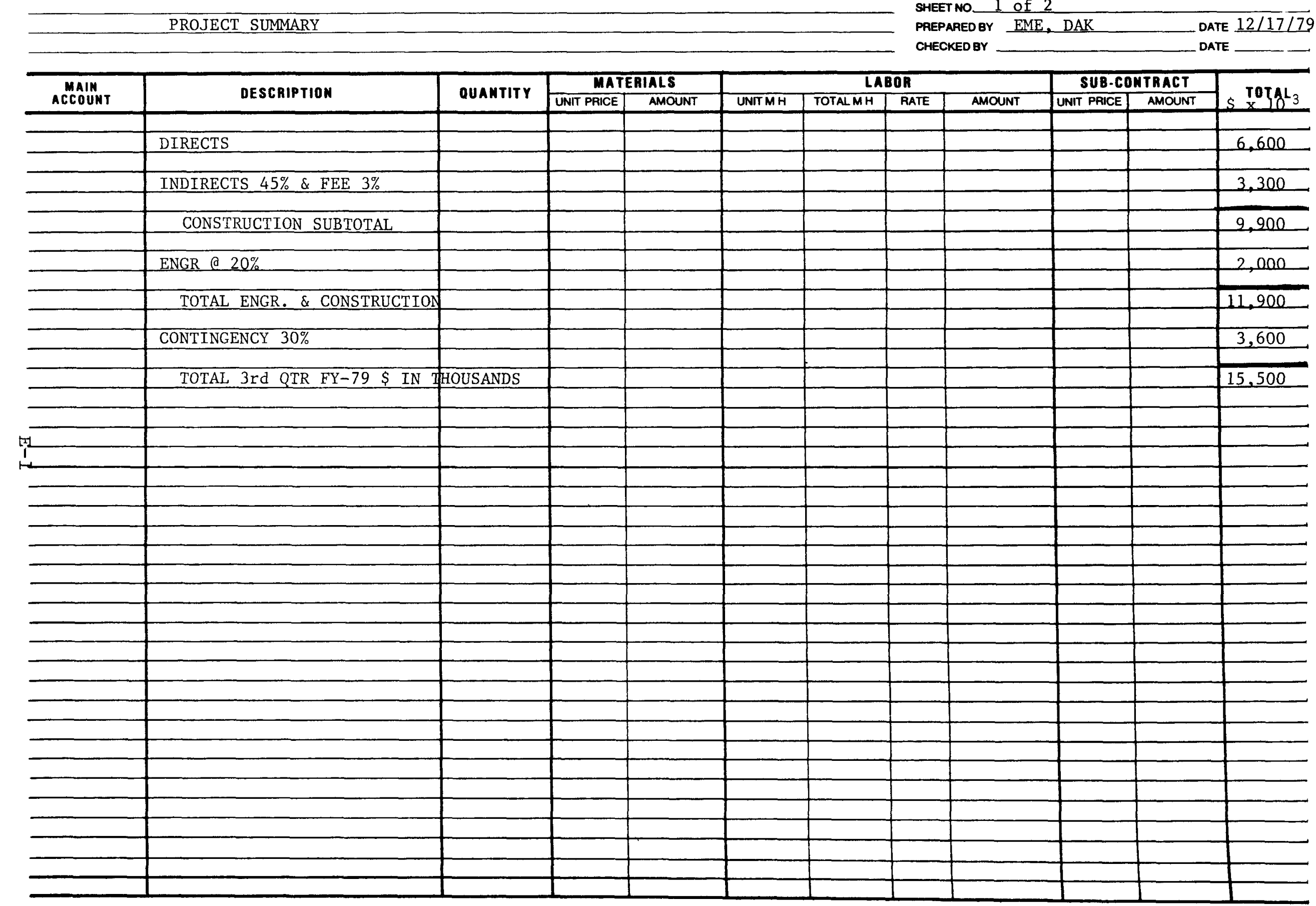

ESTMMATE NO

SHEET NO 1 of 2

PREPARED BY EME, DAK

DATE $12 / 17 \overline{179}$

DATE 
ESTIMATE SUMMARY

PROJECT SPENT FUEL CASK FSF -- COLOCATED (BNFP) DIRECT COST SUMMARY
ESTMMATE NO.
SHEET NO 2 of 2

PREPARED BY: EME, DAK

CHECKEDBY:
OATE: $12 / 17 / 79$

DATE

\begin{tabular}{|c|c|c|c|c|c|c|c|c|c|c|c|}
\hline \multirow{2}{*}{$\begin{array}{c}\text { MAIN } \\
\text { ACCOUNT }\end{array}$} & \multirow{2}{*}{ DESCRIPTION } & \multirow{2}{*}{ QUANTITY } & \multicolumn{2}{|c|}{ MATERIALS } & \multicolumn{4}{|c|}{ LABOA } & \multicolumn{2}{|c|}{ SUB-CONTRACT } & \multirow{2}{*}{ s cotyets } \\
\hline & & & UNIT PRICE & AMOUNT & UNITMH & TOTALMH & RATE & AMOUNT & \begin{tabular}{|l|} 
UNIT PAICE \\
\end{tabular} & AMOUNT & \\
\hline & IMPROVEMENTS TO LAND & p. 1 & & 100 & & & & 153 & & 82 & 335 \\
\hline & & & & & & & & & & & \\
\hline & NEW BULLDING & p. 4 & & 1,376 & & & & 1,252 & & 558 & 3,186 \\
\hline & & & & & & & & & & & \\
\hline & BLDG. MODIFICATIONS & p. 5 & & 28 & & & & 65 & & & 93 \\
\hline & SPECIAL FACILITIES & p. 9 & & 1,810 & & & & 624 & & 100 & 2.534 \\
\hline & & & & & & & & & & & \\
\hline & OUTSIDE UTIUTTIES & p. 11 & & 98 & & & & 68 & & 124 & 290 \\
\hline & & & & & & & & & & & \\
\hline & STANDARD EQUIP & p. 12 & & 11 & & & & 1 & & 58 & 70 \\
\hline & & & & - & & & & & $\ldots$ & & 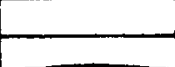 \\
\hline & TOTAL DIRECTS & & & 3,423 & & & & 2,163 & & 922 & 6,508 \\
\hline & & & & & & & & & & & \\
\hline & & & & & & & & & & & \\
\hline & & & & & & & & & & SAY & 6,600 \\
\hline & & & & & & & & & & 4 & \\
\hline & & & & & & & & & \begin{tabular}{|l} 
\\
\end{tabular} & $\ldots$ & \begin{tabular}{|l} 
\\
\end{tabular} \\
\hline & & & & & & & & & & & \\
\hline & & & & & & & & & & & \\
\hline & & & & & & & & & & & \\
\hline & & & & & & & & & & & \\
\hline & & & & & & & & & & & \\
\hline & & & & & & & & & & & \\
\hline & & & & & & & & & & & \\
\hline & & & & & & & & & & & \\
\hline & & & & & & & & & & & \\
\hline & & & & & & & & & & & \\
\hline & & & & & & & & & & & \\
\hline & & & & & & & & & & & \\
\hline & & & & & & & & & & & \\
\hline & & & & & & & & & & & \\
\hline & & & & & & & & & & & \\
\hline & & & & & & & & & & & \\
\hline & & & & $-\quad--$ & & & & & & & \\
\hline
\end{tabular}




\section{ESTIMATE DETAILS}

PROJECT SPENT FUEL CASK FSF -- COLOCATED (BNFP)

ACCOUNT IMPROVEMENTS TO LAND

ESTIMATE NO

SHEETNO 1 of 12

PREPARED BY EME, DAK

DATE $12 / 17 / 79$

CHECKED BY DATE

\begin{tabular}{|c|c|c|c|c|c|c|c|c|c|c|}
\hline \multirow{2}{*}{ DESCRIPTION } & \multirow{2}{*}{ QUANTITY } & \multicolumn{2}{|c|}{ MATERIALS } & \multicolumn{4}{|c|}{ LABOR } & \multicolumn{2}{|c|}{ SUB-CONTRACT } & \multirow{2}{*}{ TOTAL } \\
\hline & & UNIT PRICE & AMOUNT & UNT MH & TOTALMH & RATE & AMOUNT & UNIT PRICE & AMOUNT & \\
\hline \multicolumn{11}{|l|}{ Demolition Exterior of Existing Buildind } \\
\hline Earth Berm Removal & 7, 800 C. . . & .74 & 5,800 & 10 & 780 & 10.74 & 8.400 & & $=$ & 14,200 \\
\hline \multicolumn{11}{|l|}{ Storm Drainage Removal } \\
\hline $8^{\prime \prime} \phi$ Pipe $\& 12^{\prime \prime} \phi$ Pipe & 280 L.F. & .60 & 170 & & 40 & & & & & \\
\hline Catch Basin & 3 units & 10.00 & 30 & & 20 & & & & & \\
\hline Roof Drains \& Downspouts & 2 each & 100.00 & 200 & & 40 & & & & & \\
\hline Reinforced Concrete Retaining Walls & 900 C.Y. & 15.00 & 13.500 & 2.67 & 2.400 & 7.78 & 18,700 & & $=-$ & 32,200 \\
\hline Asphalt Pavement & 26,400 S.F. & .07 & 1,900 & & 200 & 10.74 & 2,100 & & -- & 4,000 \\
\hline Replace Earth Berm & 3,900 C.Y. & 1.20 & 4,700 & & 1,000 & 10.74 & 10,700 & & $=$ & 15,400 \\
\hline \multicolumn{11}{|l|}{ New Storm Drainage } \\
\hline 8" $\$$ Pipe & 340 L.F. & 2.00 & 680 & & 60 & & & & & \\
\hline Catch Basin & 3 each & 300.00 & 900 & & 64 & & & & & \\
\hline Trenching & 500 L.F. & 1.60 & 800 & & 40 & & & & & \\
\hline SUBTOTALS & & & 2,800 & & 200 & 12.00 & 2,400 & & - & 5,200 \\
\hline Rework West Drainage Ditch & 500 L.E. & 10.00 & 5,000 & & 1,400 & 8.77 & 12,300 & & $=$ & 17,300 \\
\hline New Conc. Retaining Wall & 475 C.Y. & 120.00 & 57,000 & 20 & 9.500 & 8.77 & 83,300 & 9.90 & 4,700 & 145,000 \\
\hline Repair Asphalt Paving & 9,000 S.F. & & $=$ & & $\overline{--}$ & & -- & .75 & 6,000 & 6,000 \\
\hline Miscellaneous & & & 9.100 & & 1,560 & & 13,900 & & 7,500 & 30,500 \\
\hline TOTAL IMPROVEMENTS TO LAND & & & 100,200 & & 17.140 & & 153,000 & & 82,0 & 335,200 \\
\hline & & & & & & & & & & \\
\hline & & & & & & & & & & \\
\hline & & & & & & & & & & \\
\hline & & & & & & & & & & \\
\hline & & & & & & & & & & \\
\hline & & & & & & & & & & \\
\hline & & & & & & & & & & \\
\hline
\end{tabular}


ESTIMATE DETAILS

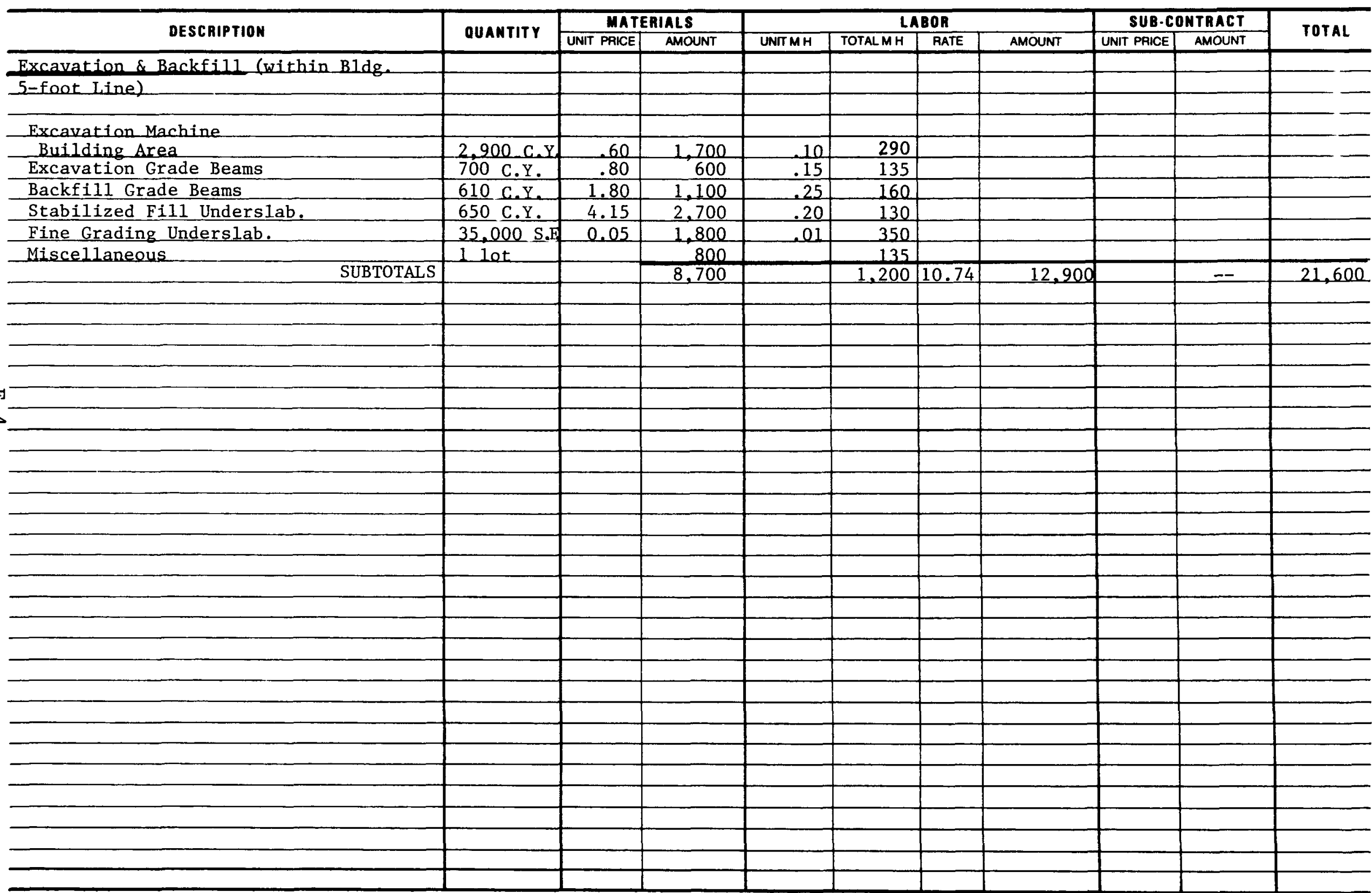




\section{ESTIMATE DETAILS}

PROJECT

ACCOUNT

NEW BUILDINC
ESTMATE NO

SHEET NO 3 of 12

PREPARED BY: EME,DAK

CHECKED BY:
DATE: $12 / 17 / 79$ DATE:

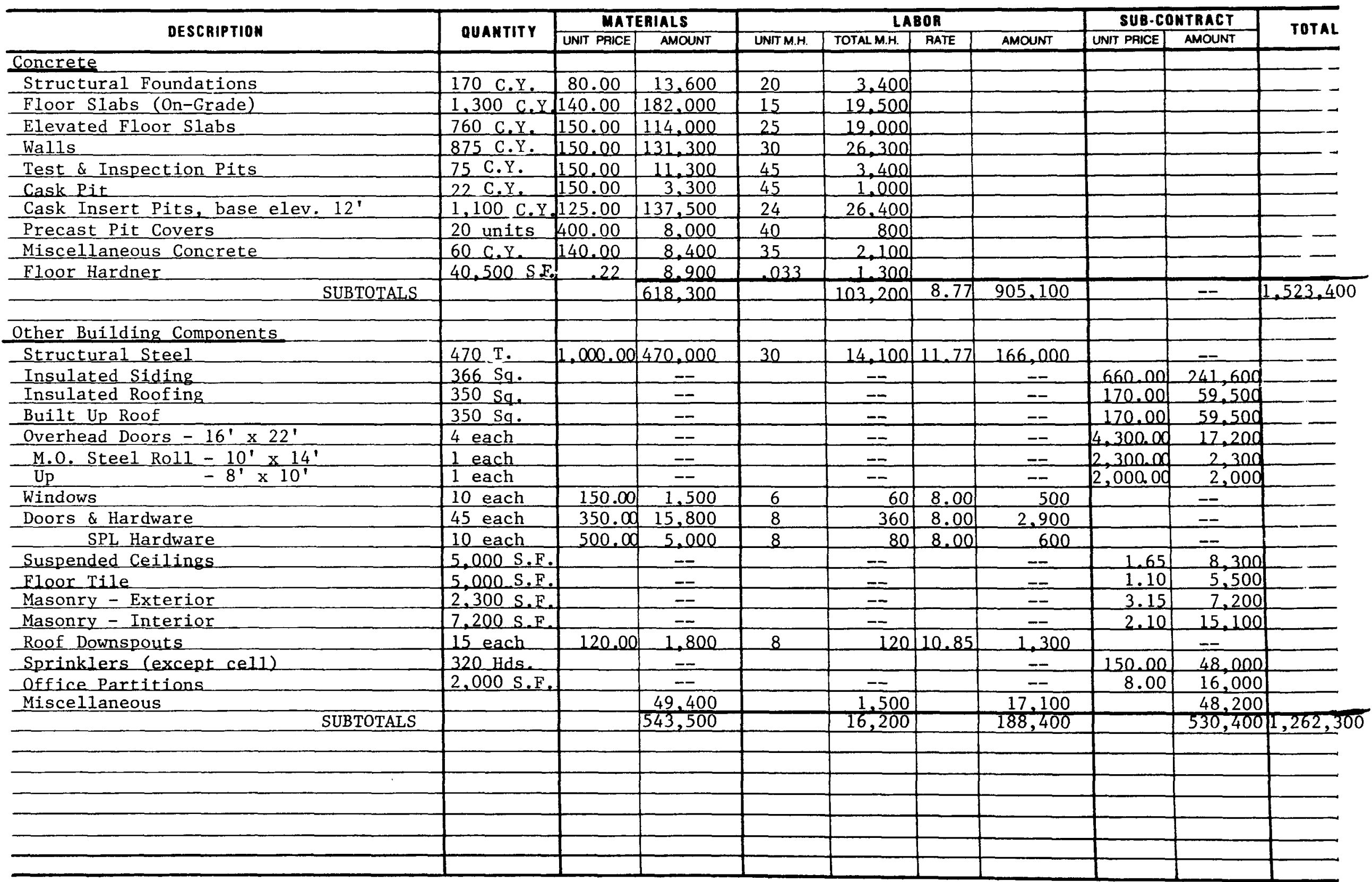




\section{ESTIMATE DETAILS}

PROJECT

ACCOUNT

NEW BUILDINC
ESTMATENO

SHEET NO 4 of 12

PREPARED BY EME, DAK

CHECKED BY
DATE $12 / 17 / 79$

DATE

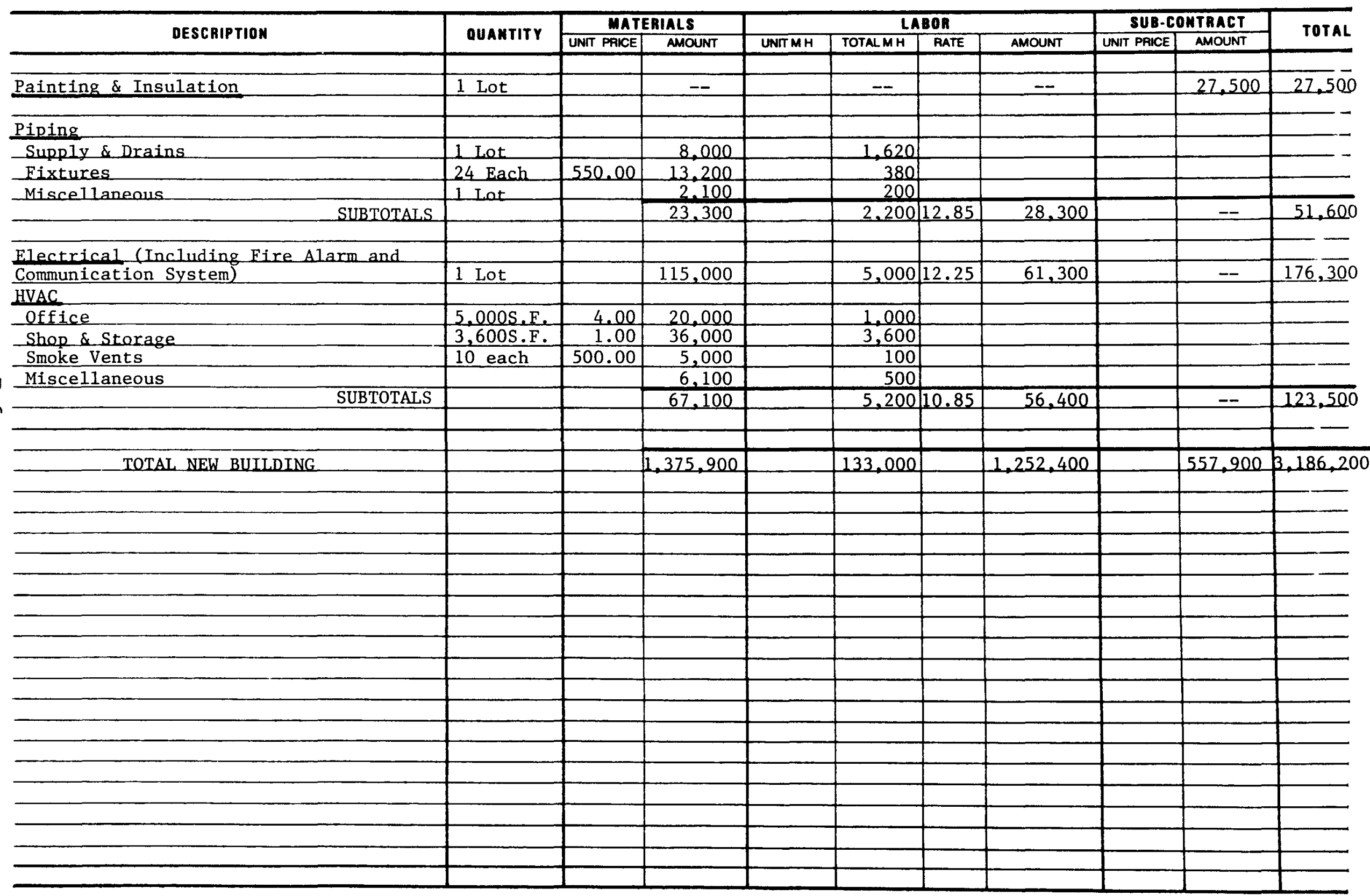




\section{ESTIMATE DETAILS}

PROJECT

ACCOUNT

MODIFICATIONS TO (EXISTING) BUILDING
ESTMATENO

SHEET NO 5 Of 12

PREPARED BY EME,DAK

CHECKED BY
DATE $12 / 17 / 79$ OATE

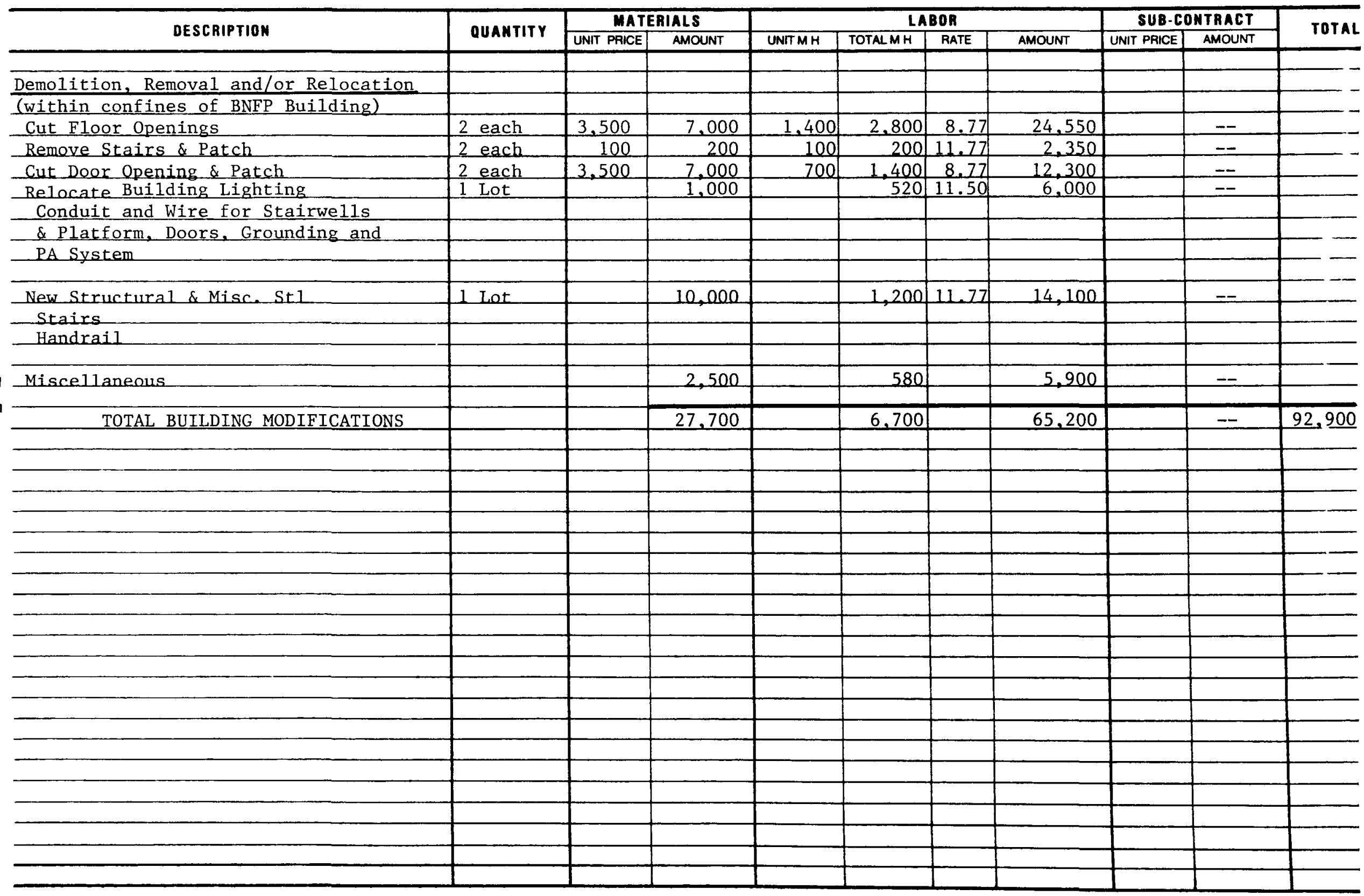




\section{ESTIMATE DETAILS}

\begin{tabular}{|c|c|c|c|c|c|c|c|c|c|c|}
\hline \multirow{2}{*}{ DESCRIPTION } & \multirow{2}{*}{ QUANTITY } & \multicolumn{2}{|c|}{ MATERIALS } & \multicolumn{4}{|c|}{ LABOR } & \multicolumn{2}{|c|}{ SUB-CONTRACT } & \multirow{2}{*}{ TOTAL } \\
\hline & & UNIT PRICE & AMOUNT & UNIT M H & TOTALMH & RATE & AMOUNT & UNIT PRICE & AMOUNT & \\
\hline \multicolumn{11}{|l|}{ Process Equipment } \\
\hline \multicolumn{11}{|l|}{ Tanks } \\
\hline Deionized Water Storage Tank & $1 \mathrm{Ea}$. & & 9,300 & & 50 & & & & & \\
\hline Filter Regeneration Tank & $1 \mathrm{Ea}$. & & 2,200 & & 35 & & & & & \\
\hline Washdown Area Sump Tank & $1 \mathrm{Ea}$. & & 11,000 & & 100 & & & & & \\
\hline Misc. & 1 Lot & & 2,300 & & 15 & & & & & \\
\hline & & & & & & & & & & \\
\hline SUBTOTALS & & & 24,800 & & 200 & 10.34 & 2,100 & & $=$ & 26,900 \\
\hline \multicolumn{11}{|l|}{ Pumps } \\
\hline High Pressure Cleaning Pump & $1 \mathrm{Ea}$. & & 38,500 & & 110 & & & & & \\
\hline Cask Jet Pump & $1 \mathrm{Ea}$. & & 4.400 & & 40 & & & & & \\
\hline Deionizer Supply Pump & 1 Ea. & & 2,200 & & 40 & & & & & \\
\hline Eilter Waste Pump & $1 \mathrm{Ea}$. & & 2,200 & & 40 & & & & & \\
\hline Slurry Pump & $1 \mathrm{Ea}$. & & 4,400 & & 40 & & & & & \\
\hline Sump Pumps & $4 \mathrm{Ea}$. & 5,500 & 22,0 & 60 & 240 & & & & & \\
\hline Misc. & 1 Lot & & 8,100 & & 50 & & & & & \\
\hline SUBTOTALS & & & 89,200 & & 560 & 10.34 & 5,800 & & - & 95,000 \\
\hline \multicolumn{11}{|l|}{ Vacuum Equipment } \\
\hline Sump Ejector & 1 Ea. & & 640 & & 40 & & & & & \\
\hline Vacuum Cleaning Jet & 1 Ea. & & 2,200 & & 40 & & & & & \\
\hline Misc. & 1 Lot & & 260 & & 10 & & & & & \\
\hline SUBTOTALS & & & 3,100 & & 90 & 10.34 & 900 & & - & 4,000 \\
\hline \multicolumn{11}{|l|}{ Compressors \& Blowers } \\
\hline Filter Blowdown Compr.\& Tank & 1 Unit & & 660 & & 50 & & & & & \\
\hline Blower & 1 Ea. & & 3,960 & & 75 & & & & & \\
\hline Spare Parts \& Vendor Reps. & 1 Lot & & 460 & & - & & & & & \\
\hline Misc. & & & 520 & & 15 & & & & & \\
\hline SUBTOTALS & & & 5,600 & & 140 & 10.34 & 1,400 & & - & 7,000 \\
\hline & & & & & & & & & & \\
\hline & & & & & & & & & & \\
\hline & & & & & & & & & & \\
\hline & & & & & & & & & & \\
\hline
\end{tabular}


ESTIMATE DETAILS

PROJECT

ACCOUNT SPECIAL FACILITIES
ESTIMATENO

SHEET NO 7 of 12

PREPARED BY EME, DAK

CHECKED BY
DATE $12 / 17 / 79$

\begin{tabular}{|c|c|c|c|c|c|c|c|c|c|c|}
\hline \multirow{2}{*}{ DESCRIPTION } & \multirow{2}{*}{ QUANTITY } & \multicolumn{2}{|c|}{ MATERIALS } & \multicolumn{4}{|c|}{ LABOR } & \multicolumn{2}{|c|}{ SUB-CONTRACT } & \multirow{2}{*}{ TOTAL } \\
\hline & & UNIT PRICE & AMOUNT & UNIT MH & TOTALMH & RATE & AMOUNT & UNIT PRICE & AMOUNT & \\
\hline \multicolumn{11}{|l|}{ Process Equipment (Continued) } \\
\hline \multicolumn{11}{|l|}{ Special Equipment } \\
\hline Filter & $1 \mathrm{Ea}$. & & 57,400 & & 150 & & & & & \\
\hline Separator & $1 \mathrm{Ea}$. & & 1,100 & & 50 & & & & & \\
\hline High Pressure Jet Cleaner & $1 \mathrm{Ea}$. & & 66,000 & & 240 & & & & & \\
\hline Parts Cleaner & 1 Ea. & & 770 & & 20 & & & & & \\
\hline U1trasonic Cleaner & 1 Ea. & & 1,540 & & 40 & & & & & \\
\hline High Pressure Spray Unit & $1 \mathrm{Ea}$ & & 710 & & 40 & & & & & \\
\hline Sinks \& Benches & 1 Lot & & 5,500 & & 200 & & & & & \\
\hline Spray Booth \& Hood & 1 Lot & & 5,500 & & 140 & & & & & \\
\hline Bridge \& Trolley Crane (Cask \& Insert) & 1 Unit & & 60,500 & & 600 & & & & & \\
\hline \multicolumn{11}{|l|}{$10 \mathrm{~T}$} \\
\hline Jib Cranes & $4 \mathrm{Ea}$. & 5,500 & 22,000 & 100 & 400 & & & & & \\
\hline Air Pallets & $5 \mathrm{Ea}$. & 13,000 & 65,000 & 40 & 200 & & & & & \\
\hline Storage Bay and T\&I Area Crane $15 \mathrm{~T}$ & 2 Ea. & 86,000 & 172,000 & 800 & 1.600 & & & & & \\
\hline Pallet Walker & 1 Ea. & & 5,500 & & - & & & & & \\
\hline Electric Fork Truck & $1 \mathrm{Ea}$. & & 22,000 & & - & & & & & \\
\hline Cask Service Cart & $1 \mathrm{Ea}$. & & 50,000 & & 200 & & & & & \\
\hline Spare Parts \& Vendor Reps. & 1 Lot & & 30,600 & & - & & & & & \\
\hline \multirow[t]{3}{*}{ Misc. } & 1 Lot & & 64,400 & & 420 & & & & & \\
\hline & & & 708,000 & & 4,650 & 10.34 & 48,100 & & - & 756,100 \\
\hline & & & & & & & & & & \\
\hline \multicolumn{11}{|l|}{ Shop Equipment } \\
\hline Wire Rope Swaging Tool \& Dies & 1 Lot & & 1,200 & & 100 & & & & & \\
\hline Misc. Measuring Tools & 1 Lot & & 11,000 & & 100 & & & & & \\
\hline \multirow[t]{3}{*}{ Misc. } & I Lot & & 1,200 & & 20 & & & & & \\
\hline & & & 13,400 & & 220 & 10.34 & 2,300 & & - & 15,700 \\
\hline & & & & & & & & & & \\
\hline \multicolumn{11}{|l|}{ Viewing Equipment } \\
\hline Shielding Windows & $9 \mathrm{Ea}$. & 25,000 & 225,000 & 200 & 1,800 & 10.34 & 18,600 & & - & 243,600 \\
\hline & & & & & & & & & & \\
\hline Subtotal Process Equipment & & & $1,069,100$ & & 7,440 & & 79,200 & & - & $1,148,300$ \\
\hline Less Cranes, Shop \& Viewing Equipment & & & $(636,700)$ & * & & & & & & \\
\hline & & & & & & & & & & \\
\hline
\end{tabular}




\section{ESTIMATE DETAILS}

PROJECT

ACCOUNT

SPECIAL FACILITIES

ESTIMATE NO

SHEET NO 8 of 12

PREPARED BY EME, DAK

CHECKED BY

DATE $1 2 / 1 7 \longdiv { 7 9 }$

DATE

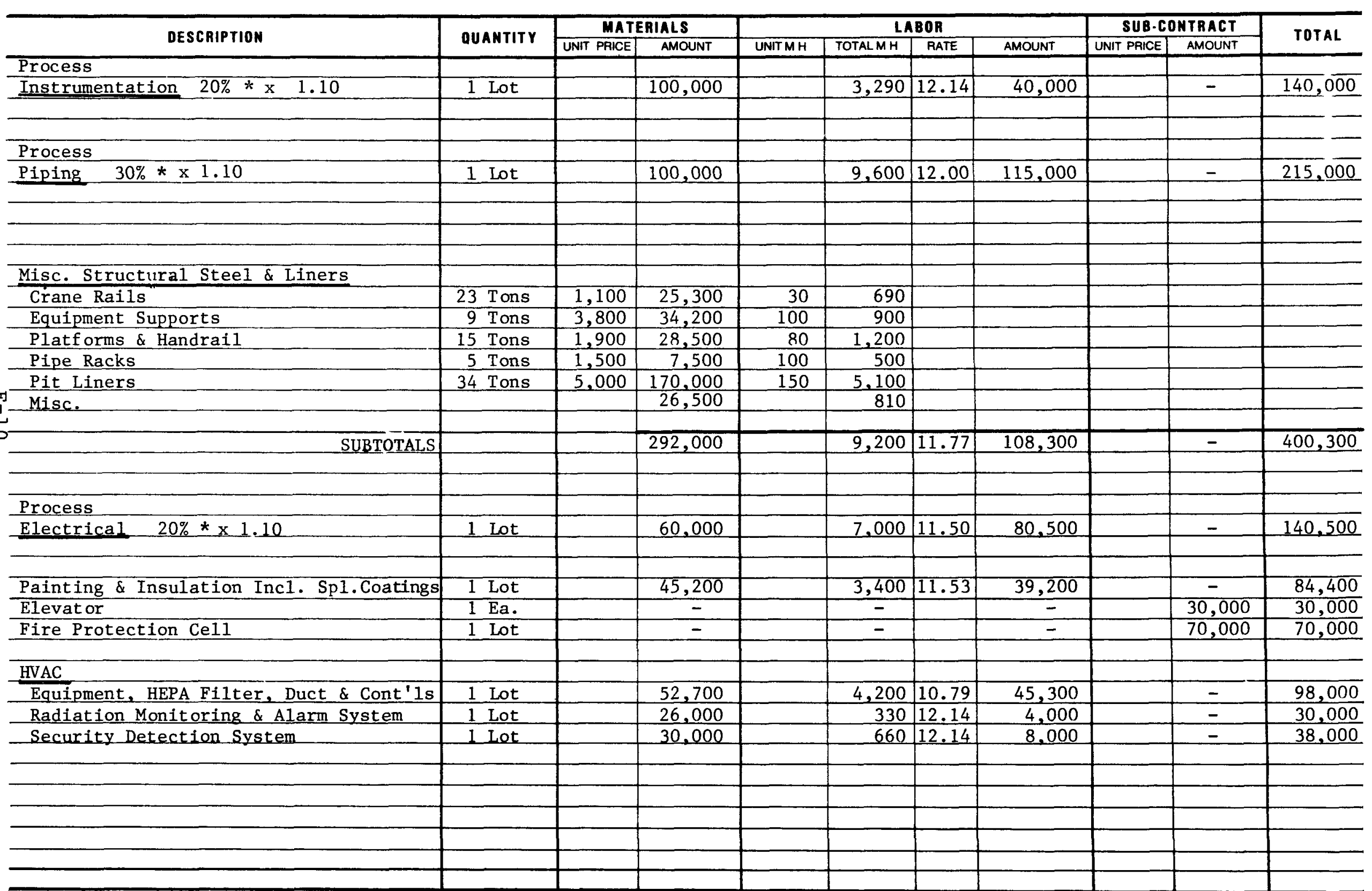




\section{ESTIMATE DETAILS}

PROJEC

ACCOUNT: SPECIAL FACILITIES
ESTIMATE NO._- 9 of 12
SHEET NO

SHEET NO EME, DAK

CREPARE

\begin{tabular}{|c|c|c|c|c|c|c|c|c|c|c|}
\hline \multirow{2}{*}{ DESCRIPTION } & \multirow{2}{*}{ QUANTITY } & \multicolumn{2}{|c|}{ MATERIALS } & \multicolumn{4}{|c|}{ LABOR } & \multicolumn{2}{|c|}{ SUB-CONTAACT } & \multirow{2}{*}{ TOTAL } \\
\hline & & UNIT PRICE & AMOUNT & UNIT M.H. & TOTAL M.H. & RATE & AMOUNT & UNIT PRICE & AMOUNT & \\
\hline \multicolumn{11}{|l|}{ Remove \& Relocate Existing Process } \\
\hline \multicolumn{11}{|l|}{ Equipment and Services: } \\
\hline \multicolumn{11}{|l|}{ Remove: } \\
\hline Tanks & 1 Lot & & 100 & & 40 & 12.00 & 500 & & - & 600 \\
\hline Pumps & 1 Lot & & - & & 10 & 12.00 & 100 & & $=$ & 100 \\
\hline Piping & I Lot & & 1,000 & & 480 & 12.00 & 5,800 & & - & 6.800 \\
\hline Platform & 1 Lot & & 400 & & 200 & 11.77 & 2,400 & & - & 2,800 \\
\hline Duct & 1 Lot & & 100 & & 280 & 10.85 & 3,000 & & $=$ & 3,100 \\
\hline Electrical & 1 Lot & & 1,000 & & 400 & 11.50 & 4,600 & & $=$ & 5.600 \\
\hline \multicolumn{11}{|l|}{ Mtr. Cont 1 Pane1 } \\
\hline \multicolumn{11}{|l|}{ Motors 4} \\
\hline \multicolumn{11}{|l|}{ Controllers \& Sw } \\
\hline \multirow{2}{*}{\multicolumn{11}{|c|}{$\begin{array}{l}\text { MCC, Conduit \& Wire } \\
\text { Control Panels, Conduit \& Wire }\end{array}$}} \\
\hline & & & & & & & & & & \\
\hline \multirow{2}{*}{\multicolumn{11}{|c|}{ Relocate and Instald Above Equip. and }} \\
\hline & & & & & & & & & & \\
\hline Platform & 1 Lot & & 2000 & & 600 & 11.77 & 7,100 & & - & Services: \\
\hline Tanks & 1 Lot & & 200 & & 40 & 12.00 & 500 & & - & 700 \\
\hline Pumps & 1 Lot & & 100 & & 20 & 12.00 & 200 & & & 300 \\
\hline Piping & 1 Lot & & 6,000 & & 2,000 & 12.00 & 24,000 & & - & 30.000 \\
\hline Duct & 1 Lot & & 4,000 & & 400 & 10.85 & 4.300 & & - & 8.300 \\
\hline Electrical & 1 Lot & & 12.600 & & 1600 & 1150 & 18 / & & 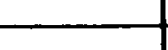 & $21 \cap \cap 0$ \\
\hline \multicolumn{11}{|l|}{ Mtr. Cont 1 Panel } \\
\hline \multicolumn{11}{|l|}{ Motors } \\
\hline \multicolumn{11}{|l|}{ Leve1 Sw Temp Cont 1} \\
\hline \multicolumn{11}{|l|}{ MCC, Conduit \& Wire } \\
\hline \multicolumn{11}{|l|}{ Control Panels, Conduit \& Wire } \\
\hline Instrumentation & $1 \mathrm{Lot}$ & & 7.000 & & 2.400 & 12.14 & 29.100 & & - & 36,100 \\
\hline Misc. Cutting \& Patching. & 1 Lot & & 2,000 & & 400 & 11.50 & 4,600 & & - & 6,600 \\
\hline SUBTOTALS & & & 36.500 & & 7,460 & & 104,600 & & - & 141,100 \\
\hline TOTAL SPECIAL FACILITIES & & & $, 809,500$ & & 52,530 & & 624,100 & & 100,000 & $2,533,60$ \\
\hline & & & & & & & & & & \\
\hline & & & & & & & & & & \\
\hline & & & & & & & & & & \\
\hline
\end{tabular}




\section{ESTIMATE DETAILS}

\begin{tabular}{|c|c|c|c|c|c|c|c|c|c|c|}
\hline \multirow{2}{*}{ DESCRIPTION } & \multirow{2}{*}{ QUANTITY } & \multicolumn{2}{|c|}{ MATERIALS } & \multicolumn{4}{|c|}{ LABOR } & \multicolumn{2}{|c|}{ SUB-CONTRACT } & \multirow{2}{*}{ TOTAL } \\
\hline & & UNIT PRICE & AMOUNT & UNIT M.H. & TOTAL M.H. & RATE & AMOUNT & UNIT PRICE & AMOUNT & \\
\hline \multicolumn{11}{|l|}{ Demolition $\&$ Relocation Extr. of } \\
\hline \multicolumn{11}{|l|}{ Building } \\
\hline & & & & & & & & & & \\
\hline & & & & & & & & & & \\
\hline \multicolumn{11}{|l|}{ Fire Protection Removal } \\
\hline $8^{\prime \prime} \emptyset$ \& 6" $\emptyset$ Pipe (AFZU) Welded (C\&W) & 324 L.F. & .40 & 100 & & 40 & 12.00 & 500 & & - & 600 \\
\hline & & & & & & & & & & \\
\hline \multicolumn{11}{|l|}{ and Valve Boxes } \\
\hline \multicolumn{11}{|l|}{ Railroad Track Removal } \\
\hline In Conc. & 130 L.F. & 2.00 & 250 & & 160 & & & & & \\
\hline In Asphalt & 150 I.F. & 1.00 & 150 & & 80 & & & & & \\
\hline SUBTOTALS & & & 400 & & 240 & 7.78 & 1,100 & & - & 1,500 \\
\hline & & & & & & & & & & \\
\hline \multicolumn{11}{|l|}{ Electrical Removal } \\
\hline $30^{\prime}$ Light Pole & $4 \mathrm{Ea}$. & & - & & 16 & & & & & \\
\hline Roof Mounted Lights & 2 Ea. & & $=$ & & 4 & & & & & \\
\hline Receptacles & $1 \mathrm{Ea}$. & & $=$ & & 2 & & & & & \\
\hline $1^{\prime \prime \emptyset}$ Conduit in Concrete ( $3^{\prime}$ deep) & 700 L.F. & & 1.500 & & 240 & & & & & \\
\hline $1 " \emptyset$ Conduit Above Ground & 30 L.F. & & - & & 4 & & & & & \\
\hline Concrete Duct bank, 3-1" $\emptyset$ Conduits & & & & & & & & & & \\
\hline$\& 2-2 " \emptyset$ Conduits & 150 L.F. & & 300 & & 54 & & & & & \\
\hline SUBTOTALS & & & 1,800 & & 320 & 11.50 & 3,700 & & - & 5,500 \\
\hline & & & & & & & & & & \\
\hline \multicolumn{11}{|l|}{ Relocation Outside Confines of New B1dg. } \\
\hline New Fire Protection Trenching Cut \& Patch & 1,150 L.F. & 5.00 & 5.800 & & 600 & & & & & \\
\hline $10^{\prime \prime} \emptyset$ Sch 40 Pipe (Welded $C \& W$ ) & 210 L.F. & 35.00 & 7.400 & & 200 & & & & & \\
\hline $8 " \emptyset \quad " 1 \quad 1 " \quad n \quad " 1$ & 565 L.F. & 25.00 & 14,100 & & 320 & & & & & \\
\hline $6 " \emptyset \quad " 1$ & 375 I.E. & 20.00 & 7,500 & & 160 & & & & & \\
\hline $10^{\prime \prime} \emptyset \mathrm{PIV}$ & 1 Ea. & 1000.00 & 1,000 & 10 & 10 & & & & & \\
\hline 8"Ø PIV & $2 \mathrm{Ea}$. & 600.00 & 1,200 & 7 & 14 & & & & & \\
\hline 6"Ø PIV & 5 Ea. & 380.00 & 1,900 & 6 & 30 & & & & & \\
\hline SUBTOTALS & & & 38,900 & & 1,334 & 12.00 & 16,000 & & - & 54,900 \\
\hline \multicolumn{11}{|l|}{ New Electrical Instrument Lines } \\
\hline Concrete Duct bank,3-1" $\emptyset$ Cond. $\&$ & & & & & & & & & & \\
\hline $2-2 " \emptyset$ Conduits +1 MH & 200 L.F. & 20.00 & 4,000 & & 400 & 11.77 & 4,700 & & - & 8,700 \\
\hline
\end{tabular}


ESTIMATE DETAILS

PROJECT

ACCOUNT OUTSIDE UTILITIES
ESTIMATE NO.

SHEET NO 11 of 12

PREPARED BY: EME. DAK

CHECKED BY:
DATE12/17/79

DATE.

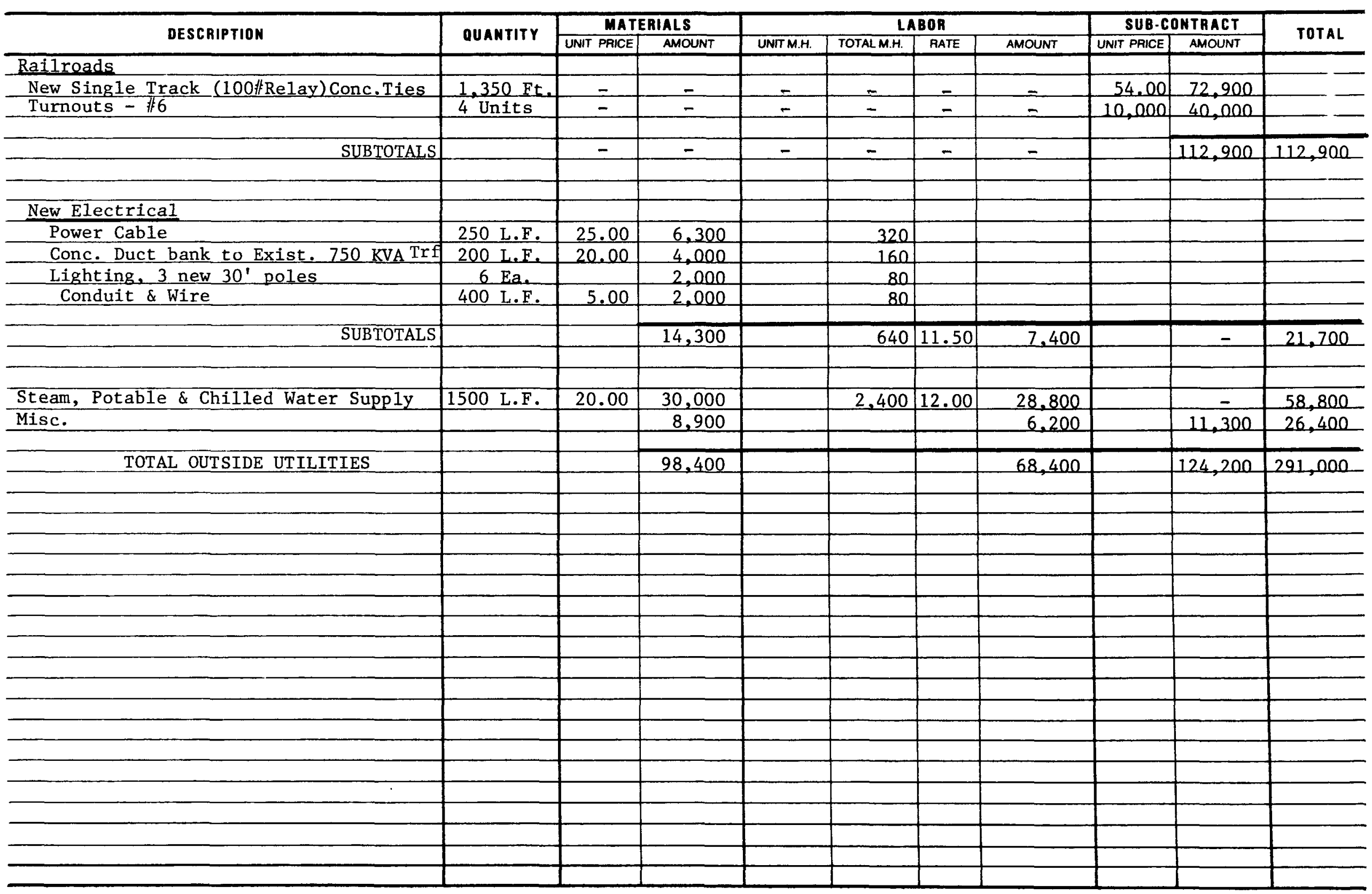


ESTIMATE DETAILS

\begin{tabular}{|c|c|c|c|c|c|c|c|c|c|c|}
\hline \multirow{2}{*}{ DESCRIPTION } & \multirow{2}{*}{ QUANTITY } & \multicolumn{2}{|c|}{ MATERIALS } & \multicolumn{4}{|c|}{ LABOA } & \multicolumn{2}{|c|}{ SUB-CONTRACT } & \multirow{2}{*}{ TOTAL } \\
\hline & & UNIT PRICE & AMOUNT & UNT MH & TOTALMH & RATE & AMOUNT & UNIT PAICE & AMOUNT & \\
\hline \multicolumn{11}{|l|}{ Standard Equipment } \\
\hline Office Furniture \& Fixtures & $16 \mathrm{Ea}$. & & - & & $=$ & & $=$ & 3,300 & 52800 & + \\
\hline Std. Shop Tools \& Equipment & 1 Lot & & 10,000 & & 100 & & & & & \\
\hline Misc. & 1 I ot & & 10 & & 10 & & & & & \\
\hline & & & 1,000 & & & & & & 5,200 & \\
\hline TOTAL STANDARD EQUIPMENT & & & 11,000 & & 110 & 10.34 & 1,100 & & 58.000 & 70.100 \\
\hline & & & & & & & & & & \\
\hline & & & & & & & & & & \\
\hline & & & & & & & & & & \\
\hline & & & & & & & & & & \\
\hline & & & & & & & & & & \\
\hline & & & & & & & & & & \\
\hline & & & & & & & & & & \\
\hline & & & & & & & & & & \\
\hline & & & & & & & & & & \\
\hline & & & & & & & & & & \\
\hline & & & & & & & & & & \\
\hline & & & & & & & & & & \\
\hline & & & & & & & & & & \\
\hline & & & & & & & & & & \\
\hline & & & & & & & & & & \\
\hline & & & & & & & & & & \\
\hline & & & & & & & & & & \\
\hline & & & & & & & & & & \\
\hline & & & & & & & & & & \\
\hline & & & & & & & & & & \\
\hline & & & & & & & & & & \\
\hline & & & & & & & & & & \\
\hline & & & & & & & & & & \\
\hline & & & & & & & & & & \\
\hline & & & & & & & & & & \\
\hline & & & & & & & & & & \\
\hline & & & & & & & & & & \\
\hline & & & & & & & & & & \\
\hline & & & & & & & & & & \\
\hline & & & & & & & & & & \\
\hline & & & & & & & & & & \\
\hline & & & & & & & & & & \\
\hline
\end{tabular}




\section{DISTRIBUTION}

ORNL Internal

1. C. W. Alexander

2. M. Bender

3. J. O. Blomeke

4. B. T. Bottenfield

5. R. E. Brooksbank

6. W. D. Burch

7. D. J. Crouse

8. D. E. Ferguson

9. B. C. Finney

10. B. J. Hudson

11. D. A. Keith

12. T. F. Lomenick

13. A. L. Lotts

14. K. J. Notz

15. T. W. Pickel
16. H. Postma

17. M. K. Preston (14)

18. C. D. Scott

19. R. D. Seagren

20. L. B. Shappert (3)

21. M. J. Skinner

22. M. G. Stewart

23. W. P. Stockdale

24. D. B. Trauger

25. W. E. Unger

26. J. E. Van Cleve

27. C. D. Watson (12)

28. R. G. Wymer

29. Laboratory Records (2)

30. Central Research Library (2)

31. Y-12 Technical Library, Document Reference Section

ORNL External

1. W. A. Pryor

Total ORNL - 59

\section{AGNS Internal}

1. K. J. Bambas

10. P. N. McCreery

2. J. A. Buckham

3. J. W. Cantwell

4. R. J. Cholister

5. E. M. Easterling

6. J. V. Halvorsen

7. P. F. Highberger

8. W. Knox

9. A. S. Lamprey

11. R. C. ravasz

12. R. R. Reust

13. J. C. Smith

14. G. T. Stribling

15. G. Wiedemann

16. A. K. Williams

17. M. Young

18. C. Files $(50)$

Total AGNS - 76 


\section{DISTRIBUTION (continued)}

External Distribution

1. George C. Allen (5)

Sandia Laboratories

Transportation System Development

Division \#4552

P. O. Box 5800

Albuquerque, NM 87185

2. Mr. Frank Arsenault, Director

Division of Safeguards, Fuel Cycle, and Environmental Research

Office of Nuclear Regulatory Commission

Washington, DC 20555

3. Mr. Robert M. Burgoyne

General Atomic Company

Radioactive Materials Shipping

P. O. Box 81608

San Diego, CA 92138

4. Mr. R. B. Chitwood (2)

Department of Energy

Transportation Branch, NEW

Mail Stop B-107

Germantown, MD 20545

5. Mr. James P. Duckworth, Manager

Nuclear Fuel Services

P. O. Box 124

West Valley, NY 14171

6. Mr. D. Durrel

Westinghouse Electric Corporation

Advanced Energy Systems Division

Nevada Operations

P. O. Box 708

Mercury, NV 89023

7. Mr. George Evans

Rockwell Hanford Operations

Energy Systems Group

Basalt Waste Isolation Program

P. O. Box 800

Richland, WA 99352 
8. Mr. E. C. Hardin (3)

Transportation Program Manager

Albuquerque Operations Office

Department of Energy

P. O. Box 5400

Albuquerque, NM 87115

9. Mr. D. L. Hill

NUS Corporation

Four Research Place

Rockville, MD 20850

10. Mr. T. B. Hindman, Jr. (6)

Savannah River Plant

E. I. du Pont de Nemours and Company

Aiken, SC 29801

11. Mr. R. M. Jefferson, Manager (1)

Sandia Laboratories

Nuclear Materials Transportation

Technology Department \#4550

P. O. Box 5800

Albuquerque, NM 87185

12. Mr. M. C. Kirkland (5)

Spent Fuel Project office

Department of Energy

Savannah River Operations office

P. O. Box A

Aiken, SC 29801

13. Mr. R. W. Lambert

General Electric

175 Curtner Avenue

Mail Code 858

San Jose, CA 95125

14. Mr. D. E. Large (2)

Department of Energy

Oak Ridge Operations office

P. O. Box E

Oak Ridge, TN 37830

15. Mr. M. J. Lawrence (1)

Acting Director

Fuel Storage and Transfer

Department of Energy

Germantown, MD 20545 
16. Mr. Robert E. Luna (1)

Sandia Laboratories

Transportation Analysis and

Information Division \#4551

P. O. Box 5800

Albuquerque, NM 87185

17. Mr. R. A. McFeely (1)

Savannah River Plant

E. I. du Pont de Nemours and Company

Aiken, SC 29801

18. Mr. M. P. McGahee (15)

Savannah River Plant

E. I. du Pont de Nemours and Company

Aiken, Sc 29801

19. Mr. L. W. Meyer (5)

Savannah River Plant

E. I. du Pont de Nemours and Company

Aiken, SC 29801

20. Mr. L. C. O'Malley

Exxon Nuclear Company

777 106th Avenue, NE, C-00777

Bellevue, WA 98009

21. Mr. S. W. O'Rear, TIS (2)

Savannah River Plant

E. I. du Pont de Nemours and Company

Aiken, SC 29801

22. Mr. R. G. Page

Special Assistant to the Director for Licensing

Division of Safeguards

Office of Nuclear Material Safety and

Safeguards

Nuclear Regulatory Commission

Washington, DC 20545

23. Mr. R. W. Peterson (6)

Battelle, Columbus Laboratories

Office of Nuclear Waste Isolation

505 King Avenue

Columbus, Ohio 43201 
24. Mr. Ronald B. Pope (1)

Sandia Laboratories

Transportation System Development

Division \# 4552

P. O. Box 5800

Albuquerque, NM 87185

25. Mr. C. J. Roberts

Argonne National Laboratory

Division of Environmental Statements

900 South Cass Avenue

Argonne, IL 60439

26. Mr. R. L. Shoup

NUS Corporation

Suite 207

320 Cedar Bluff Road

Knoxville, TN 37919

27. Mr. G. L. Stukenbroker

Manager, Operations

NL Industries, Inc.

Nuclear Division

1130 Central Avenue

Albany, NY 12205

28. Mr. William R. Teer

Vice-President

Transnuclear, Inc.

One North Broadway

White Plains, NY 10601

29. Mr. J. M. Viebrock, Manager

Operations and Engineering

Nuclear Assurance Corporation

24 Executive Park West

Atlanta, GA 30329

30. Mr. E. E. Voiland, Manager

Morris Operations

General Electric Company

7555 E. Collins Road

Morris, IL 60450

31. Mr. D. E. Wisenbaker

Department of Energy

Savannah River Operations

Aiken, SC 29801 